\title{
What do Astronomers Do: A Survey of U.S. Astronomers' Attitudes, Tools and Techniques, and Social Interactions Engaged in through their Practice of Science
}

Timothy S. Spuck

Follow this and additional works at: https://researchrepository.wvu.edu/etd

\section{Recommended Citation}

Spuck, Timothy S., "What do Astronomers Do: A Survey of U.S. Astronomers' Attitudes, Tools and Techniques, and Social Interactions Engaged in through their Practice of Science" (2017). Graduate Theses, Dissertations, and Problem Reports. 6707.

https://researchrepository.wvu.edu/etd/6707

This Dissertation is protected by copyright and/or related rights. It has been brought to you by the The Research Repository @ WVU with permission from the rights-holder(s). You are free to use this Dissertation in any way that is permitted by the copyright and related rights legislation that applies to your use. For other uses you must obtain permission from the rights-holder(s) directly, unless additional rights are indicated by a Creative Commons license in the record and/ or on the work itself. This Dissertation has been accepted for inclusion in WVU Graduate Theses, Dissertations, and Problem Reports collection by an authorized administrator of The Research Repository @ WVU.

For more information, please contact researchrepository@mail.wvu.edu. 
What do Astronomers Do: A Survey of U.S. Astronomers' Attitudes, Tools and Techniques, and Social Interactions Engaged in through their Practice of Science

Timothy S. Spuck

Dissertation submitted

To the College of Education and Human Services

At West Virginia University

Education Doctorate

In Curriculum \& Instruction

\author{
Jim Rye, Ph.D., Chair \\ Ron Iannone, Ed.D. \\ D.J. Pisano, Ph.D. \\ Bruce Smith, Ph.D.
}

Department of Curriculum \& Instruction

Morgantown, West Virginia

2017

Keywords: Astronomy, Astronomers, Authentic Learning, Practice of Science, Science Attitudes, Science Social Interactions

Copyright 2017 Timothy S. Spuck 


\section{ABSTRACT \\ What do Astronomers Do: A Survey of U.S. Astronomers' Attitudes, Tools and Techniques, and Social Interactions Engaged in through their Practice of Science}

Timothy S. Spuck

Astronomy is one of the oldest STEM enterprises today. It is a discipline through which technology has been advanced, as well as our understanding of the universe. Further, astronomy is a gateway science that inspires the imagination of young learners, and can be used to promote STEM careers. In order to advance the astronomy enterprise, we must maintain an informed citizenry. The practice of astronomy has changed over time; astronomy today is much different than it was 50 years ago. In an effort to identify the current practice of astronomy, or what it is that today's astronomers do, 478 U.S. astronomers participated in the study focusing on their engagement in three areas of scientific practice; science attitudes, tools and techniques, and social interactions. In addition, astronomers' perceptions about career choice, work-related activities they engage in, motivations for doing astronomy, and changes needed in education were also explored. Data were collected over a 3-month time period via an online survey and telephone interviews. Data provided by survey participants provides a solid foundation from which findings and conclusions are drawn. Today's population of astronomers is largely white, male, and older, however moving toward gender balance. The population as a whole places great importance on the practice of attitudes such as thinking critically, respecting the evidence, honesty, and objectivity. Unlike many might think, astronomers spend little time at the telescope collecting data, but rather the vast majority of their time is spent working at a computer. Further, engaging in administrative duties, writing, use of mathematics, searching for funding, mentoring others, and collaborating with colleagues are all critical tools/techniques and social skills in the practice of astronomy today. Finally, pop culture and personal experience plays a significant role in attracting individuals to a career in astronomy, and exploration and uncovering that which is unknown, the thrill of discovery, is what keeps them motivated. This study identified and quantified the activities in which professional astronomers engage, and the findings can be used to design formal and informal learning experiences $\mathrm{K}$ through adult to more closely reflect the science of astronomy and the people who engage in the practice. 


\section{DEDICATION}

This dissertation is dedicated to my father Charles W. Spuck, and mother Melda R. Spuck. My father grew up in a time when few people finished high school, he made it to the $8^{\text {th }}$ grade. However, he was the true example of a life-long learner, always pushing to educate himself. It was rare that I did not see him in the evening at the kitchen table without a book in his hand. In his mid 50's he walked across the stage to receive his GED. That was one of his proudest moments in life. My mother too had a passion for learning, she was the first in her family to graduate high school. They both have been, and continue to be, inspirations in my life.

Then there is Dr. Patricia Obenauf, Pat. What an amazing person. We first met at the National Radio Astronomy Observatory in Green Bank, WV. She inspired me to pursue my doctoral program and she served as my advisor and my Committee Chair until her sudden passing earlier this year. She never gave up on me, always providing that gentle tap on my shoulder and words of encouragement.

While these three individuals no longer share my space and time in their physical form, they continue to guide me in my decisions and daily activities, and to have a profound impact in my life. Without them this dissertation, this accomplishment, would not be possible. Mom, Dad, Pat ... this accomplishment is dedicated to you. 


\section{ACKNOWLEDGEMENTS}

There are many people that have contributed to make this research project a success, and it is not possible to adequately recognize each person and to give them the credit they truly deserve. However, a number of people rise to the top of the list. First, I'd like to thank my Advisor and Committee Chair, Dr. Jim Rye and Dr. Pat Obenauf, for their guidance and patience throughout this process. I could not have asked for two better mentors. In addition, I would like to thank my Doctoral Committee including Dr. Ron Iannone, Dr. D.J. Pisano, and Dr. Bruce Smith. Their guidance and input greatly enriched the study and my dissertation.

A number of astronomers provided input in the development and testing of the online survey instrument, including Dr. Rick Fisher, Dr. Varoujan Gorjian, Dr. Steve Howell, Dr. Ron Maddalena, Dr. Stephen Pompea, Dr. Luisa Rebull, and Dr. Kartik Sheth; thank you. In addition, thank you to the nearly 500 astronomers who took time out of their busy schedules to completed the survey. Your time and effort made this study possible. I would also like to recognize the Statistical Consulting Services at West Virginia University for the assistance they provided with data analysis.

In addition, thank you to my students and professional colleagues. Throughout my career in education, I've had the privilege to work with many students and professional scientists and engineers to engage in astronomy and earth science related research. I will not attempt to name each of you here; you know who you are. The insight and inspiration you provided me throughout my journey not only fueled the initial idea for the study, but it helped me to mature as a professional and a human being. I am grateful to each of you.

Last but certainly not least, I would like to thank my family and friends for their patience, encouragement and support. When my busy schedule prevented me from caring for my mom as much as I would have liked in that last year, my sisters and brother were there to step in. My sons Jordan and Jacob also inspired me to complete the long trek to a dissertation, and were supportive throughout. Then there is my wife Karen; few could have been as patient and supportive over the years. She has been a constant source of advice and encouragement. I'm not sure I would have finished without her. I am very appreciative of you. Thank you.

I'll close with a quote by Reinhold Niebuhr, "Nothing we do, however virtuous, can be accomplished alone; therefore we are saved by love." Thank you all for your love. 


\section{TABLE OF CONTENTS}

$\begin{array}{ll}\text { ABSTRACT } & \text { ii }\end{array}$

$\begin{array}{ll}\text { DEDICATION } & \text { iii }\end{array}$

ACKNOWLEDGEMENT $\quad$ iv

LIST OF TABLES Vii

LIST OF FIGURES $\quad$ ix

$\begin{array}{ll}\text { CHAPTER } 1 & \text { INTRODUCTION } \\ & \text { Astronomy and Society }\end{array}$

Background 2

Statement of the Problem $\quad 7$

$\begin{array}{ll}\text { Research Question } & 7\end{array}$

Research Sub-questions $\quad 7$

$\begin{array}{lr}\text { Rational for the Study } & 8\end{array}$

$\begin{array}{lr}\text { Definitions of Terms } & 10\end{array}$

Limitations of the Study $\quad 12$

$\begin{array}{ll}\text { Document Format } & 13\end{array}$

CHAPTER 2 REVIEW OF THE LITERATURE

$\begin{array}{ll}\text { Overview } & 14\end{array}$

Astronomy and the Evolution of Science 14

Astronomers: Who are They? 18

Where can we Find Astronomers Today? 22

What do Astronomers Do? 24

Attitudes Practiced by Scientists $\quad 25$

Tools and Techniques of Astronomers 26

Astronomers and their Social Interactions 33

Summary $\quad 36$

CHAPTER 3 METHODOLOGY

$\begin{array}{ll}\text { Overview } & 38\end{array}$

Research Questions $\quad 38$

$\begin{array}{ll}\text { Research Design } & 39\end{array}$

The Survey Instrument $\quad 39$

Measuring Survey Validity $\quad 39$

Research Participants $\quad 40$

Data Collection $\quad 41$

Data Analysis Plan $\quad 42$

IRB Requirements $\quad 44$

CHAPTER 4 FINDINGS AND DISCUSSIONS 
Review of Research Questions and Design 45

Recruitment of Participants $\quad 47$

Data Analysis Overview $\quad 48$

Statistical Analysis $\quad 51$

Overview of Major Findings $\quad 55$

Demographics of Astronomer Participants $\quad 57$

Employment Status, Gender and Ethnicity 57

Degree(s) Earned $\quad 59$

Research and Associated Astronomy Sub-disciplines $\quad 60$

Time as a Practicing Astronomer $\quad 62$

Employment Change and Time at Institution 64

Attitudes Practiced by U.S. Astronomers 69

Tools and Techniques Used by U.S. Astronomers $\quad 74$

Social Interactions Engaged in by U.S. Astronomers 92

$\begin{array}{lr}\text { Perceptions of U.S. Astronomers } & 102\end{array}$

Astronomer Career Influences 103

Perceptions About Work-related Activities $\quad 105$

What Makes Astronomy Meaningful? 107

Changes Needed Pre-K through College 108

Summary

CHAPTER 5 SUMMARY AND CONCLUSIONS

$\begin{array}{ll}\text { Summary } & 114\end{array}$

$\begin{array}{ll}\text { Conclusions } & 116\end{array}$

Implications for Policy and Practice 116

Recommendations for Future Research 127

$\begin{array}{ll}\text { Final Concluding Thoughts } & 128\end{array}$

$\begin{array}{lr}\text { REFERENCES } & 129\end{array}$

APPENDICES $\quad$ A. Invite to Participate Letter 139

B. IRB Letter of Exemption - Initial Protocol Review 141

C. Participant Online Survey 142

D. Additional Tables - Women/Men, and

Academic/Non-academic Institutions 158

E. Sample Astronomer Interview Transcripts 164 


\section{LIST OF TABLES}

$\begin{array}{lll}\text { Table 2.1 } & \text { Major contributors to early astronomy } & 19\end{array}$

Table 2.2 Astronomer gender and ethnicity distribution 22

Table 2.3 Distribution of astronomers across employment sectors 23

Table 2.4 Distribution of scientists and engineers across employment sectors 23

Table 2.5 Mapping the Framework for K-12 science 24

Table 2.6 Major telescopes of today and tomorrow 28

Table 2.7 Astronomy journal publications 33

Table 4.1 Employment status and gender of U.S. astronomer participants 58

$\begin{array}{lll}\text { Table } 4.2 & \text { Ethnicity of U.S. astronomer participants } & 59\end{array}$

$\begin{array}{lll}\text { Table } 4.3 & \text { Degree(s) earned by U.S. astronomer participants } & 60\end{array}$

Table 4.4 Current area(s) of research for U.S. astronomer participants 61

$\begin{array}{lll}\text { Table } 4.5 & \text { Other current area(s) of research } & 61\end{array}$

Table 4.6 Time as a practicing astronomer 63

$\begin{array}{lll}\text { Table } 4.7 & \text { Ethnicity versus time as an astronomer } & 64\end{array}$

$\begin{array}{lll}\text { Table } 4.8 & \text { Time at current place of employment } & 65\end{array}$

Table $4.9 \quad$ U.S. astronomers' number of institutions employed 66

Table 4.10 Hours worked by U.S. astronomers 67

$\begin{array}{lll}\text { Table } 4.11 & \text { Attitudes in the practice of astronomy } & 70\end{array}$

Table 4.12 Bias, opinion, and societal impact in astronomy 73

Table 4.13 Time spent at the instrument/telescope $\quad 75$

$\begin{array}{lll}\text { Table } 4.14 & \text { Time spent at a computer } & 76\end{array}$

Table 4.15 Number of investigations engaged in by U.S. Astronomers 78

$\begin{array}{lll}\text { Table 4.16 Research project time to completion } & 79\end{array}$

$\begin{array}{lll}\text { Table } 4.17 & \text { U.S. Astronomer research related activities } & 80\end{array}$

$\begin{array}{lll}\text { Table } 4.18 & \text { Type of data used in astronomy research } & 83\end{array}$

$\begin{array}{lll}\text { Table } 4.19 & \text { Other data typically used in astronomy research } & 84\end{array}$

$\begin{array}{lll}\text { Table 4.20 Data format used in astronomy research } & 84\end{array}$

$\begin{array}{lll}\text { Table } 4.21 & \text { Other data formats used in astronomy research } & 85\end{array}$

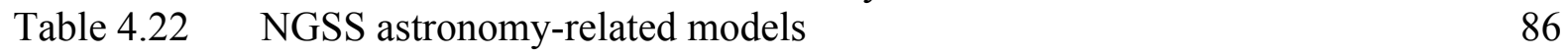

$\begin{array}{lll}\text { Table } 4.23 & \text { Use of models in astronomy } & 87\end{array}$

Table 4.24 Use of math in astronomy $\quad 89$

Table 4.25 Use of imagination and intuition in astronomy 91

$\begin{array}{lll}\text { Table } 4.26 & \text { Social interactions in astronomy } & 93\end{array}$

Table 4.27 U.S. astronomer publications $\quad 95$

Table 4.28 Professional meetings/conferences attended 96

Table 4.29 Formal presentations made $\quad 97$

$\begin{array}{lll}\text { Table } 4.30 & \text { Number of collaborators } & 98\end{array}$

Table 4.31 Number of international collaborators $\quad 99$

$\begin{array}{lll}\text { Table } 4.32 & \text { Number of collaborators outside astronomy } & 100\end{array}$

$\begin{array}{lll}\text { Table } 4.33 & \text { Collaborations in disciplines outside astronomy } & 100\end{array}$

$\begin{array}{lll}\text { Table } 4.34 & \text { Collaborators: other discipline categories } & 102\end{array}$

$\begin{array}{lll}\text { Table } 4.35 & \text { Career influences } & 104\end{array}$

$\begin{array}{lll}\text { Table } 4.36 & \text { Other career influences } & 104\end{array}$

Table 4.37 Astronomers proposed changes to activities they engage in 106

Table 4.38 What makes astronomy meaningful to U.S. astronomers 108 
Table 4.39 U.S. astronomers' recommendations and science education reform $\quad 110$ Table 4.40 Perceived changes needed in astronomy education 111

Table A.1 Disaggregated data for attitudes in the practice of astronomy 158

Table A.2 Disaggregated data for bias, opinion, and societal impact in astronomy 159

Table A.3 Disaggregated data for astronomer research related activities 159

Table A.4 Disaggregated data for use of models in astronomy 160

Table A.5 Disaggregated data for use of imagination and intuition in astronomy 161

Table A.6 Disaggregated data for use of math in astronomy 161

Table A.7 Disaggregated data for social interactions in astronomy 162 


\section{LIST OF FIGURES}

Figure 2.1 Distribution of Astronomers and Position Type 21

Figure 4.1 Relative Frequency Tables Explained 54

Figure 4.2 Time as a Practicing Astronomer 63

Figure 4.3 Time at Current Place of Employment 65

Figure 4.4 U.S. Astronomers and Number of Institutions Employed 67

Figure 4.5. Hours Worked by U.S. Astronomers 69

Figure 4.6 Attitudes in the Practice of Astronomy 72

Figure 4.7 Bias, Opinion, and Societal Impact in Astronomy 73

Figure 4.8 Time Spent at the Instrument/Telescope 76

$\begin{array}{lll}\text { Figure } 4.9 & \text { Time Spent at a Computer } & 77\end{array}$

$\begin{array}{lll}\text { Figure 4.10 Number of Investigations Engaged In } & 79\end{array}$

$\begin{array}{lll}\text { Figure 4.11 Research Project Time to Completion } & 80\end{array}$

Figure 4.12 U.S. Astronomer Research Related Activities 82

Figure 4.13 Type of Data used in Astronomy Research 83

Figure 4.14 Data Formats Used in Astronomy Research 85

$\begin{array}{lll}\text { Figure 4.15 Use of Models in Astronomy } & 88\end{array}$

$\begin{array}{lll}\text { Figure 4.16 Use of Math in Astronomy } & 90\end{array}$

Figure 4.17 Use of Imagination and Intuition in Astronomy 92

Figure 4.18 Social Interactions in Astronomy 94

Figure 4.19 Astronomer Publications 96 


\section{CHAPTER 1}

\section{INTRODUCTION}

\section{Astronomy and Society}

"All human beings share the desire and fascination to understand the Universe, asking ourselves similar questions about our cosmic origins: Where do we come from? Where are we going?" (Banados, 2010, p. 4). These are profound questions being explored by astronomers at universities, national observatories, and other institutions across the United States (U.S.), and a significant financial investment is being made. In 2014 the National Aeronautics and Space Administration (NASA) spent $\$ 12.5$ billion on astronomy and other space exploration activities

(NASA, 2014). The National Science Foundation (NSF) also invests about \$240 million annually in astronomy research, and that does not include the $\$ 500$ million it recently spent on the construction of the Atacama Large Millimeter/submillimeter Array (ALMA) telescope in Chile (Eisenstein et al., 2012). In addition, the private sector and universities themselves invest heavily into the astronomical sciences as well. With such a large investment being made, some wonder why we spend so much money trying to learn about what's in space when we have significant problems here on Earth.

Over the years astronomy has demonstrated its relevance and importance to society. Astronomy has helped advance science, technology, engineering, and mathematics (STEM), and through a wide variety of spin-off technologies and practices has produced a significant return on investment (Fabian, 2010; Fernandes, Pessoa, \& Silva, 2014). There are many examples of technology transfer from astronomy to industry: specialized film used by solar astronomers to monitor the Sun's temperature is now used extensively in industry and medicine; the charged coupled device (CCD) was first used in astronomy for imaging in 1976 and today CCDs can be 
found in virtually every camera including smart phones; a programming language invented by astronomers is now used by General Motors to analyze data from car crashes; and radio astronomers developed a technique called aperture synthesis that is the basis for computerized tomography (CAT scans) and magnetic resonance imaging (MRI), which are used extensively in the practice of modern medicine (Fabian, 2010; Rosenberg, Russo, Bladon, \& Christensen, 2015). These are but a few examples from a very extensive list of ways astronomy and those who practice the science have benefited society.

Perhaps the greatest benefit is that astronomy advances our way of thinking about science itself. The discovery of gravity revolutionized how we thought about systems within the universe. The discovery of radio waves from space changed our fundamental understanding of the make up of the universe. The recent discovery that the expansion of the universe is accelerating has led to the prediction of "dark energy" which has fundamentally impacted the way we think about space, and the properties of matter and energy. Further, the recent discovery of many new planets around distant stars, has forced us to rethink our models of how the Earth itself may have formed. Through the study of astronomy, we continually expand and improve our understanding of basic science and the universe of which we are so very much a part.

Recently, astronomy and astrophysics have also "come to play a central role in the natural sciences, with many direct links to other sciences (e.g. many aspects of physics, mathematics, chemistry, and the geosciences)" (European Association for Astronomy Education, 1994, p. 1). Because astronomy is such a "connecting" science, it is also used in integrative and interdisciplinary approaches to learning, and these approaches are becoming more important in modern curriculum development (Huang et al., 2014; Percy, 2006). Considering the many areas of study in astronomy today, including astrobiology, astrochemistry, astroengineering, 
archeoastronomy, astrotourism, space law, etc., it is easy to understand how learning can take place across disciplines using astronomy as the foundation. Clearly, through astronomy other sciences can be incorporated and enriched.

Beyond its interdisciplinary nature, astronomy is also seen as a science that inspires and interests young learners. A study of middle school students found the three most interesting topics in physics are a) how it feels to be weightless in space, b) how meteors, comets, or asteroids may cause disasters on earth, and c) black holes, supernovas, and other spectacular objects in space (Trumper, 2006). This interest in astronomy in the formative years can be used to motivate students to learn a variety of STEM topics and consider careers in STEM fields.

Because of the motivator astronomy can be to young learners, its interdisciplinary nature, and the positive economic role it plays, a deeper understanding of the current practice of astronomy, and the incorporation of this understanding into a variety of learning experiences, is a worthy pursuit.

\section{Background}

The focus of this study emerged out of years of personal and professional experience. Between 1988 and 2010 I taught earth \& space science courses at Oil City Area High School. In addition, I was employed by two local universities in Northwestern Pennsylvania as an astronomy and earth science instructor. It was not until several years into my own teaching career, and after completing a Masters Degree in science education, that I had my first formal experience doing "real" science. It took place in the summer of 1992 at the National Radio Astronomy Observatory (NRAO). While there I was placed on an astronomy research team along with three other teachers, a mentor teacher, and a scientist. Together we completed a 
research project using the facility's forty-foot radio telescope. The focus of our research was to push the instrument to its limits and determine the faintest detectible object we could observe in space. My team beat the previous record, and more than 20 years later the memory of that experience remains vivid in my mind.

The NRAO experience introduced me not only to science and astronomy but the people who do astronomy for a living: the astronomers. As an educator I began looking for opportunities to engage both myself, and my students, in real-world science practices, and to interact with other scientists. I began an astronomy research team at Oil City High School, and for many years we designed and conducted research projects using the 40 Foot Radio Telescope in Green Bank. In the summer of 1995 I spent eight weeks working with Hands-On Universe (HOU) as a Department of Energy - Teacher Resource Associate at Lawrence Berkeley National Labs. Each step of the way, I tried to find ways to engage my students in the research process. In 1994, using an HOU telescope, two of my students provided professional astronomers with some of the earliest supernovae light curve data in history by capturing first light of SN1994I in the Whirlpool Galaxy (Pennypacker, Deustua, Perlmutter, Goldhaber, \& Arsem, 1994; Richmond et al., 1996). Following the SN1994I discovery I worked on the design and development team for the HOU Asteroid Search project. Through the Search, my students discovered a number of new asteroids, and assisted in the discovery of others, including one of the first 100 Trans-Neptunian objects (Morelli, 2006; Pack, 2000).

Over the years I continued to build on this network of scientists and educators I had developed. In the year 2000, I spent the summer at NRAO working with radio astronomer Dr. J. Richard Fisher using galaxy data from the Arecibo Radio Telescope in Puerto Rico to calculate the expansion rate of the universe (Spuck, 2004). In the years that followed I found myself 
partnering with scientists from Kitt Peak National Observatory and the Spitzer Science Center. Each opportunity gave me the chance to work with astronomers doing science, and to engage my students in that process. Our research spanned the spectrum of opportunities in astronomy leading to the discovery of young sun-like stars in their early stages of development (Guieu et al., 2010), as well as exploring the relationship between infrared and UV emissions in active galactic nuclei (Gorjian et al., 2011).

Beginning in the year 2010, through the Albert Einstein Distinguished Educator Fellowship program, I spent two years working with the NSF Graduate STEM Fellows in K-12 Education (GK-12) Program. Throughout my fellowship experience I had a great deal of interaction with a variety of scientists and engineers at NSF and at numerous research institutions across the United States. These experiences provided me with a unique opportunity to gain both depth of understanding of research being done within individual science disciplines, as well as science being done across disciplines.

Then in years 2011 and 2012, I joined research teams in Greenland and Antarctica where I worked with scientists and engineers studying changes in ice thickness, penguin population dynamics, and space weather. Flying with the NASA IceBridge team in Greenland I had an opportunity to spend significant time with engineers and scientists charged with operating and maintaining sensitive ice penetrating radar equipment. While in Antarctica working with the Automatic Geophysical Observatories project, the vast majority of my time was spent working with engineers to upgrade power and communication systems at a remote site on the East Antarctic Plateau.

Today, I serve as a STEM Education Development Officer working with a variety of professionals at Associated Universities Inc. and the National Radio Astronomy Observatory. 
Through my experiences in the science research community, I've noticed something: not all science is practiced the same, nor do all scientists engage in the same types of day-to-day activities at the same frequency. The "objects" they studied, the way data were collected and analyzed, the amount of time spent collecting data vs. analyzing it, the nature of collaborations, and other day-to-day practices, could be quite different. I began to ask questions. How authentic (representative of the real world) are the science courses we teach? In particular, how well do astronomy learning experiences, in and out of school, reflect what astronomers do? From what I have seen there is a disconnect between what learners in astronomy are doing and what astronomers in the real world do. That is problematic.

While there may be some common practices among scientists, there are also obvious differences. For example, consider the study of biology, geology, and astronomy. The majority of biologists study a subject that is tangible. The subject is present with them and variables can be manipulated and responses can be observed over time. However, for geologists, while the subject being studied is often present, the subject is of such a massive scale that it may be impossible for conditions to be manipulated. They must wait for "mother nature" to bring about the conditions they wish to observe, and that can sometimes take years. Astronomers are different yet. Their subject is not present but rather light years away in many cases. There is nothing tangible for them to work with. They typically can not manipulate variables, and they generally do not interact with their subject outside the visible and invisible light that is emitted or reflected. Where biologists can take action, astronomers can not. How do these and other basic differences impact, for example, the length of time spent on a research project, the nature of collaborations, or time spent collecting data vs. analyzing it? 
My experiences bring me to ask the question, "How might astronomy learning experience and courses be improved if they were based on a framework that is grounded in, and more authentically reflective of, what astronomers do?" If we want the learner to authentically understand astronomy, learning experiences need to be framed within the real world. Accurately characterizing what astronomers do is an essential first step.

\section{Statement of the Problem}

Astronomers are scientists and science is what scientists do (Chinn and Malhotra 2002;

Mathews 2003; Rahm, Miller et al. 2003). According to Edelson (2003), key features of scientific practice fall into three categories, (1) attitudes, (2) tools and techniques, and (3) social interactions. A deeper understanding of the attitudes, tools and techniques, and social interactions astronomers engage in can be beneficial to the field of astronomy, and more broadly, astronomy educators. A comprehensive study of astronomers and their current practice of science does not exist.

\section{Research Question}

What do U.S. astronomers do?

\section{Research Sub-questions}

1) What science related attitudes are most important to U.S. astronomers in their practice of astronomy?

2) What tools and techniques are most frequently used by U.S. astronomers in their practice of astronomy? 
3) What social interactions are most frequently engaged in by U.S. astronomers in their practice of astronomy?

4) What are astronomers' perceptions about career influences, work related activities, personal motivations for doing astronomy, and how to make astronomy education more reflective of the practice of astronomy?

\section{Rational for the Study}

Fewer than $40 \%$ of students who enter college majoring in a STEM field complete a STEM degree (Drew, 2011; Presidents Council of Advisors on Science and Technology, 2012). Further, recent figures also show the share of undergraduate students graduating with STEM degrees has declined from $24 \%$ in 1985 to $18 \%$ in 2009 (Casey, 2012), and more than $50 \%$ of high school students say they may be discouraged from pursuing a STEM career because of a "lack of understanding of the subjects or what people in these fields do" (Lemelson-MIT Program, 2010, p. 1). A recent study by the Pew Research Center also indicates that while $70 \%$ of Americans believe scientists contribute "a lot" to society's well-being, $85 \%$ of scientists view the public's lack of scientific knowledge as a major problem, and nearly $50 \%$ believe the public has unrealistic expectations of scientists (The Pew Research Center, 2009).

There is evidence that students who have experiences that engage them in the real-world practice of science while in high school are more likely to both enter and maintain a career in science compared to students who do not have these experiences (Markowitz, 2004; Roberts \& Wassersug, 2009). In addition, students who participate in authentic science experiences show significant increases in conceptual knowledge, question and hypothesis development, modeling, 
and logical argumentation (Charney et al., 2007). The question is, "How do we get science learners to have more real-world science experiences?"

Addressing thousands of STEM professionals at the National Academy of Sciences President Obama (2009) stated: "So I want to persuade you [STEM Professionals] to spend time in the classroom, talking and showing young people what it is that your work can mean, and what it means to you" (Obama, 2009, p. 1). A recent Scientific America initiative, "1,000 Scientists in 1,000 Days" encouraged scientists to volunteer at schools across the U.S.; suggesting scientists might help by, "spending an hour in a local classroom or school auditorium talking about a typical day in the lab - thereby helping to demystify the world of science for children" (Nature, 2011, p. 123). Can we expect an astronomer to come into a classroom for an hour and have students walk away with an understanding of what it has taken the astronomer years to achieve themselves?

In order to attract and more effectively teach today's learners, it's crucial that we modernize science curricula (Moreno \& Mayer, 2007). If we are to modernize astronomy curricula to make it more reflective of what astronomers do, we must first understand the activities modern astronomers engage in on a day-to-day basis. A student taking a course in astronomy should leave with a realistic understanding of what an astronomer does, and the same is true for other science disciplines.

In addition to science curricula, virtual environments promoting science learning are beginning to play a more prominent role in science education. In 2010 Americans spent between \$15.4 and \$15.6 billion on video games (DeCarlo, 2011). According to NPD Group, 64 million children, or $91 \%$ of kids between age 2 and 17 in America, are playing video games (Reisinger, 2011). Research shows that games are more engaging than traditional instruction, and potentially 
lead to better, more sustained learning (Adams, Mayer, MacNamara, Koenig, \& Wainess, 2012; Barab, Pettyjohn, Gresalfi, Volk, \& Solomou, 2012). As such, we are seeing greater investments being made in the development of science games and their use in learning environments.

However, when it comes to gaming or virtual environments, better data on what scientists do is needed. The director of the Educational Environments Group at TERC, Jodi Asbell-Clarke, stated in a personal interview that having "better data on activities scientists engage in would significantly benefit the educational game development community" (Asbell-Clarke, 2012, p. 1). Regardless of whether it's new curricula or virtual environments, if we want learners to gain a true understanding of astronomy and what astronomers do, we must engage them in experiences that reflect astronomy in authentic ways.

How often should students in an astronomy course engage in the collection of new data vs. using archival data? How important is it to build opportunities into the curriculum for international collaboration? How much time should be devoted to collection of data vs. analysis and reporting results? Should educators design experiences that lead the learners to think about social and political implications of their research in astronomy? The Federal Science,

Technology, Engineering, and Mathematics (STEM) 5-Year Strategic Plan calls for a "50 percent increase in the number of U.S. youth who have an effective, authentic STEM experience each year prior to completing high school" (Committee on STEM Education, 2013, p. 9). Shouldn't we first have a clear understanding of what scientists do in their disciplines?

\section{Definitions of Terms}

Astronomer - an individual who is a practicing scientist in the field of astronomy or astronomy sub-discipline. 
Astronomy Sub-Disciplines - The following are sub-disciplines, or areas of specialization, in the field of astronomy.

- Archaeoastronomy

- Astrobiology

- Astrochemistry

- Astroengineering

- Astrometry

- Astronomy Education

- Astrophysics

- Celestial mechanics

- Computational astronomy

- Physical cosmology

- Extragalactic astronomy

- Galactic astronomy

- Gamma-ray astronomy

- Gravitational-wave astronomy

- Neutrino astronomy

- Observational astronomy

- Planetary science

- Radio astronomy

- Solar Astronomy

- Stellar astronomy

- X-ray astronomy

Authentic Science - the processes scientists exercise throughout their daily lives, or simply what scientists do (Chinn \& Malhotra, 2002; Mathews, 2003; Rahm, Miller, Hartley, \& Moore, 2003).

Practice of science - What scientists do. This includes all activities scientists engage in through or related to their work as a scientist.

Practicing Astronomer - An individual with one or more science or science related degrees, with at least one at the Masters Degree level or higher, who works primarily in one or more of the astronomy sub-disciplines (see definition of Astronomy sub-disciplines above), and is currently engaged in, or has engaged in at least one astronomy related research project within the past two years. 
Real-world science - Science as it is currently practiced by scientists within the context of their place of work and today's society.

Research Project - A science, technology, engineering, or mathematics investigation that could potentially lead to a journal article, book, or report, and that would have the potential of successfully going through a peer review process, and making it to publication.

Science Related Attitudes - attitudes identified as often practiced by scientists (e.g. uncertainty, commitment, patience, respect for evidence, willingness to change your mind, thinking critically, honestly, objectivity, no rush to judgment, and consideration of societal impact) (R. D. Anderson, 2002; Bencze, 2000; Chinn \& Malhotra, 2002; Edelson, 2003; Kozlow \& Nay, 1976; Rahm et al., 2003; Robinson, 2004; Zion et al., 2004).

Social Interaction - ways in which scientists interact with each other through their work-related activities.

Work-related activities - activities that are (1) required by your employer or manager, (2) are necessary or beneficial for the successful completion of assigned duties, or (3) contribute to the advancement of science.

\section{Limitations of the Study}

1) Nonrandom sampling will be used, and as a result all participants will be self-selecting. It may be that those astronomers who are more likely to engage in Education and Public Outreach (EPO) will complete the survey at a greater frequency than those who are less interested in EPO. As a result, sampling bias may exist. 
2) The survey will be offered in English only. Some astronomers at U.S. facilities may have limitations in their language skills. Respondents who do not possess strong skills in the English language may not fully understand the nature of the questions being asked.

3) The study is limited to astronomers at U.S. institutions and facilities. As such, the findings may not be applicable to astronomers in other countries.

4) Like many people in society, astronomers change their place of employment throughout their career. This study will be a snapshot of astronomers in their current place and time. Roles and responsibilities may have changed over time and with employment location.

5) This study clusters astronomers from academic institutions together with astronomers at non-academic institutions. There would likely be differences in activities between the two. In the event sufficient data is collected, de-clustering could be used to explore differences between the two populations.

6) This study looks narrowly at a single discipline, astronomy. The results may not be applicable to other science disciplines.

\section{Document Format}

Chapter 1 provides an introduction to the research study. Chapter 2 provides a review of the relevant literature. Chapter 3 presents the research design and methodologies. Chapter 4 presents the data along with a discussion of the results. In conclusion, Chapter 5 provides a summary and addresses conclusions, implications of the study and potential areas for further research. 


\section{CHAPTER 2}

\section{REVIEW OF THE LITERATURE}

\section{Overview}

Chapter 2 begins with a review of how astronomy has evolved over time from the precisly positioned rocks at Stonehenge, to the discovery of quantum physics, and the use of some of the most sophisticated instruments on and off the planet. With this foundation in place Chapter 2 explores the who, where, and what of astronomers. Who are these astronomers and how have the changed throughout history? Where can we find individuals engaged in the practice of astronomy? What attitudes do they practice? And, what tools and techniques do they use, and what is the nature of their social interactions? Chapter 2 lays the foundation from which the content and framework of the study itself has emerged.

\section{Astronomy and the Evolution of Science}

The practice of astronomy and the types of activities astronomers engage in has evolved over time. For example, astronomy and astrology were seen as one and the same until the late 1600 's when Newton discovered the force of gravity influenced objects in our universe (Temming, 2014). Since that time astronomy has evolved into a separate field of its own. Over the years astronomy has very much paralleled and been influenced by changes in how science has been practiced in general. As a result, it is beneficial to spend a little time discussing this historical evolutionary path of science more broadly.

While it's true that knowledge about the universe had been pursued for thousands of years by the Egyptians, Chinese, and other cultures around the globe, the first recorded efforts in Western civilization to describe what it means to know are provided for us by the Greek 
philosopher Plato in 400 B.C.E. (Bybee, 2002). In the Meno, Plato looks to the methods of his teacher Socrates for greater understanding of the learning process. Socrates believed souls waiting to be born had to first drink from the River of Forgetfulness. Some souls would drink a lot and others would drink a little. The less a soul drank, the easier they would find it to learn in this world. Thus according to both Plato and Socrates, someone born into this world already possessed knowledge, and it was the teacher's job to simply help the learner rediscover this knowledge (Ozmon and Craver, 2003). Plato himself did not trust the observations he could make with his physical senses, but rather retreated to thought when a question arose (Hakim, 2004).

Although Aristotle studied under Plato, he developed a different perspective. Rather than retreating to thought alone to answer a question, Aristotle moved beyond thought to examine objects and to eventual experimentation (Hakim, 2004). However, Aristotle still considered religious questions of the human soul and God to be more relevant than investigations of the material world (Capra, 1991; Hakim, 2004). Thanks primarily to the Church, the Aristotelian philosophy remained the primary influence on western science for nearly 2000 years until Galileo entered the scene in the late 1500's. Although Ptolemy and Copernicus made some initial attempts to use mathematics in science, Galileo is recognized as the individual who formally brought quantitative analysis into science by combining mathematics with experimentation (Capra, 1991; Hakim, 2004), and this practice was fundamental to advancements in astronomy. Prior to this point science was primarily based on qualitative analysis. Galileo believed that through the use of measurement and mathematics, science could become precise. Galileo also provided structure to the practice of science in the development of the scientific method, and is often given credit for the birth of modern science (Capra, 1991; Hakim, 2005; Hawking, 2009). 
In 1596, thirty-two years after the birth of Galileo, Rene Descartes was born in France. Descartes is considered by some to be the Father of Modern Philosophy. He proposed that in order to understand how something works that its parts should be studied individually, and that by understanding how each part worked by itself you could understand the whole (Capra, 1991; Hakim, 2004). Descartes' philosophy was a departure from previous thinking in science, and a clear break from Eastern philosophy which to this date considers an understanding of fragmented parts to be a "disturbance" that must be overcome. However, Descartes' view of the world has dominated Western science since the mid 1600's (Capra, 1991; Hakim, 2005).

While the scientific philosophy itself changed little over 400 years, the practice did see periods of refinement. For example, in the mid 1800's Darwin proposed a radically new idea; we were living in an evolving world. Due to the overwhelming evidence he provided, the theory became quickly accepted among the majority of scientists and philosophers throughout Europe (Mayr, 2001). Darwin's science however required a different type of science, the historical narrative. In his work he could not observe the creatures of the past. This new method required him to observe the current state of affairs and create an imaginary story as to how things came to be (Mayr, 2001). Astronomers too paint a picture of how the universe changed over time using the "skeletal remains" of stars and population surveys of celestial objects.

While scientific discovery has come a long way, and significant refinement has taken place since the 1600 's, the underlying philosophy in science remains largely unchanged in most disciplines. For example, scientists in the hard sciences (e.g. biology, chemistry, physics, astronomy, etc.), for the most part, still look at things in pieces and continue to incorporate the scientific method. However, postmodernism has become a pillar in the social sciences and is making its way into the hard sciences as well. As its name implies, postmodernism is the period 
of time following modernism or the Enlightenment period of modern science. Postmodernism first enters society around 1870 as a revolution in the arts, moving beyond French Impressionism to postmodern style of painting (Hassan \& Hassan, 1987). Although the context in which it is being used impacts how postmodernism is defined, a fundamental precept is that no absolute truth (Truth) can be implied. Truth is something that is constructed by the observer and therefore any conclusion is biased in some way by the observer (Bereiter, 1994; Patton, 2002).

Over the past 100 years, postmodernism has played a significant role in literature, theology, architecture, and social sciences, and has made in-roads into the hard sciences. We can see evidence of the impact of postmodernism in the current practice of physics and astronomy. For example, the view that the universe is a "machine" made of pieces is being replaced with the idea that the parts of the universe are so interconnected that the parts can only be understood through the whole (Capra, 1991). We've come to understand that what we believe to be true of the part is dependent on the perspective of the observer. Heisenberg is credited with bringing the role of the observer into quantum physics. "Natural science, says Heisenberg, does not simply describe and explain nature; it is part of the interplay between nature and ourselves." (Capra, 1991, p. 140) Galileo and Descartes isolated the individual from the experiment and declared them the objective observer, but what Heisenberg appears to be saying is that the observer is part of the experiment. In order to fully understand what is being studied science must take into consideration the observers understanding of the process of knowledge, or their epistemology.

Ken Wilber (2007) in the development of Integral Theory and All Lines All Quadrants (AQAL) model moves beyond postmodernism, and integrates the qualities of the observer(s), the levels of development along these lines (qualities), and the environment in which discourse takes place. Although Integral Theory is not yet part of mainstream practice in the physical sciences, it 
is playing an increasing role in in scholarly research in some disciplines including psychology, ecology, education, and health and medicine (Esbjörn-Hargens, 2010).

While it may first appear postmodernism and integral theory throw modern science, or modern astronomy, out the window, that is not the case. As a matter of principle, science builds on the "truths" of the past as it evolves into the future. Experience is built on previous experience. We see evidence of postmodernism and integral theory when astronomers apply principles of quantum physics. In addition, today's astronomers find themselves engaging more and more in interdisciplinary research and collaborations. This practice recognizes and values diversity in perspectives of different researchers, a key quality of postmodern science and integral theory. When one considers the practice of science and how it has evolved throughout history, the foundation of the practice is embedded in authentic discourse and how one comes to know (Bereiter, 1994; Freire, 2000; Wilber, 2007; Yore, Florence, Pearson, \& Weaver, 2006).

\section{Astronomers: Who are They?}

There is much evidence (e.g. cave drawings, Stonhenge, etc.) indicating that people have gazed at the heavens since the dawn of man. Early myths for example were attempts by primitive people to explain the world around them and gain understanding of their environment (Herzberg, 1952). Ancient Greeks worshiped many gods, but in reality these gods were a way for them to classify and understand their universe. The stars, constellations, and planets themselves were named after the gods as a way to bring meaning to observations. The planet that moved quickly across the sky was named after the god Mercury who himself was swift messenger. The planet the glowed red was named after the god of war, Mars. 
The shaman too is often thought of as a religious figure, but he was much more, he was a direct link to the cosmic power and understanding; "Behind the myths and ceremonies lay the core belief in a cosmic force that permeated all things." (Reader's Digest Association, 1995, p 11). At the core, how different is this "cosmic force" than our modern day understanding of gravity, atomic structure, and quantum physics? An argument could be made that the ancient Greeks and the shaman were scientists on a quest for Truth, but with limited resources, understanding, and instrumentation.

Astronomy transitioned from what is often referred to as ancient astronomy to the period of modern astronomy around 1600 CE (Seeds, 1992). As indicated in Table 2.1, ancient astronomers were men who focused predominantly on recording the precise positions of objects in the night sky over time and theorized about the origins and nature of the universe. It was Galileo's use of the telescope, coinciding with society's transition out of the Dark Ages that catapulted astronomers into a new era of discovery. However, the modern era of astronomy was dominated by men, with the exception of figures like Caroline Herschel (1750-1848) and Henrietta Leavitt (1868-1921) who were known for the production of the Herschel star catalogs and discovering the relationship between the luminosity and the period of variable stars (Seeds, 1992). Other "giants" of the modern era of astronomy include Newton for his laws of gravity, and William Herschel for his advancements in telescope design and production of extensive star catalogs.

Table 2.1

Major contributors to early astronomy.

\begin{tabular}{|c|c|l|}
\hline Name & Time Period & \multicolumn{1}{c|}{ Major Contribution } \\
\hline Anaxagoras & $500-428$ BCE & $\begin{array}{l}\text { Greek philosopher of nature known for his discovery of the true cause of } \\
\text { eclipses. }\end{array}$ \\
\hline
\end{tabular}




\begin{tabular}{|c|c|c|}
\hline Aristarchus & 310-230 BCE & $\begin{array}{l}\text { A mathematician who used geometry to conclude the Sun was at the center of } \\
\text { the Universe. This was counter to Aristotle, who thought the Sun went around } \\
\text { the Earth. Also determined the size of the moon. }\end{array}$ \\
\hline Eratosthenes & 276-194 BCE & $\begin{array}{l}\text { Greek mathematician, geographer, poet, astronomer, and music theorist } \\
\text { known for calculating the circumference of the Earth. }\end{array}$ \\
\hline Hipparchus & $190-120$ BCE & $\begin{array}{l}\text { Greek mathematician who cataloged over } 1,000 \text { stars and invented } \\
\text { trigonometry. }\end{array}$ \\
\hline Ptolemy & 90-168 CE & $\begin{array}{l}\text { Greco-Egyptian mathematician, geographer, astrologer known for the use of } \\
\text { epicycles to explain the motions of the planets in his Earth-centered universe } \\
\text { model. }\end{array}$ \\
\hline $\begin{array}{l}\text { Nicolaus } \\
\text { Copernicus }\end{array}$ & $1473-1543$ CE & $\begin{array}{l}\text { First astronomer to propose a comprehensive heliocentric model with the Sun } \\
\text { at the center of the universe. }\end{array}$ \\
\hline al-Khwarizmi & 9th Century CE & $\begin{array}{l}\text { Islamic astronomer who invented algebra. He made detailed calculations of the } \\
\text { sun, moon, and planets, calculated eclipses. }\end{array}$ \\
\hline al-Farghani & 9th Century CE & $\begin{array}{l}\text { Islamic astronomer who built a large sextant and used it to measure precise } \\
\text { positions of celestial objects to the accuracy of one arc second. He also } \\
\text { precisely measured the tilt of the Earth's axis. }\end{array}$ \\
\hline $\begin{array}{l}\text { Omar } \\
\text { Khayyam }\end{array}$ & 1048-1131 CE & $\begin{array}{l}\text { Islamic scientist, philosopher, and poet who compiled many astronomical } \\
\text { tables, reformation of the calendar improving its accuracy, and calculated a } \\
\text { year accurate to six decimal places. }\end{array}$ \\
\hline Tycho Brahe & 1546-1601 CE & $\begin{array}{l}\text { Danish astronomer known for the instruments he built to very accurately } \\
\text { measure the positions of objects in the sky. He was the first known to create } \\
\text { catalogs of the positions of planets throughout their entire orbit. }\end{array}$ \\
\hline Galileo Galilei & 1564-1642 CE & $\begin{array}{l}\text { Italian physicist, mathematician, astronomer, and philosopher considered to } \\
\text { be the father of modern science. Used a telescope to observe the moons of } \\
\text { Jupiter and determine they were orbiting Jupiter (not the Sun or Earth). This } \\
\text { discovery proved that neither the Sun or the Earth were at the center of the } \\
\text { universe. }\end{array}$ \\
\hline
\end{tabular}

The modern and post-modern eras of astronomy saw significant advances in instrumentation, methodology, and discoveries. However, there was little change in the people who did astronomy, they remained predominantly white males of European descent. Fastforwarding through the post-modern period, what does the astronomy community look like today?

The National Science Foundation describes a scientist, as an individual with one or more science or science related degrees at bachelor's level or higher, or who has a non-science degree at bachelor's level or higher and is employed in a science related occupation (National Science Board, 2012). However, the necessary education required to perform duties as a scientist differs 
across disciplines. For example, geoscientists can often find employment with a bachelor or masters level degree, whereas an astronomer typically has a Ph.D. and one or more post-doc experiences before securing full-time employment (Impey, 2012). In 2008 nine percent of all postdocs were in physics/astronomy/astrophysics (National Science Board, 2012). Due to these varying education requirements, the age and years of experience for astronomers can vary. However, broadly speaking, the astronomy community is relatively older (Impey, 2012). In the year 2010 it is estimated there were 3,829,000 scientists employed in the U.S.: 34,000 in physics-astronomy (National Science Board, 2012). Of the 34,000 in physicsastronomy, it is estimated that 4000 are employed officially as astronomers in the United States (Impey, 2012) in a variety of positions, including postdoctoral fellowships, tenure track faculty, non-tenure track faculty, research, and research support (see Figure 2.1).

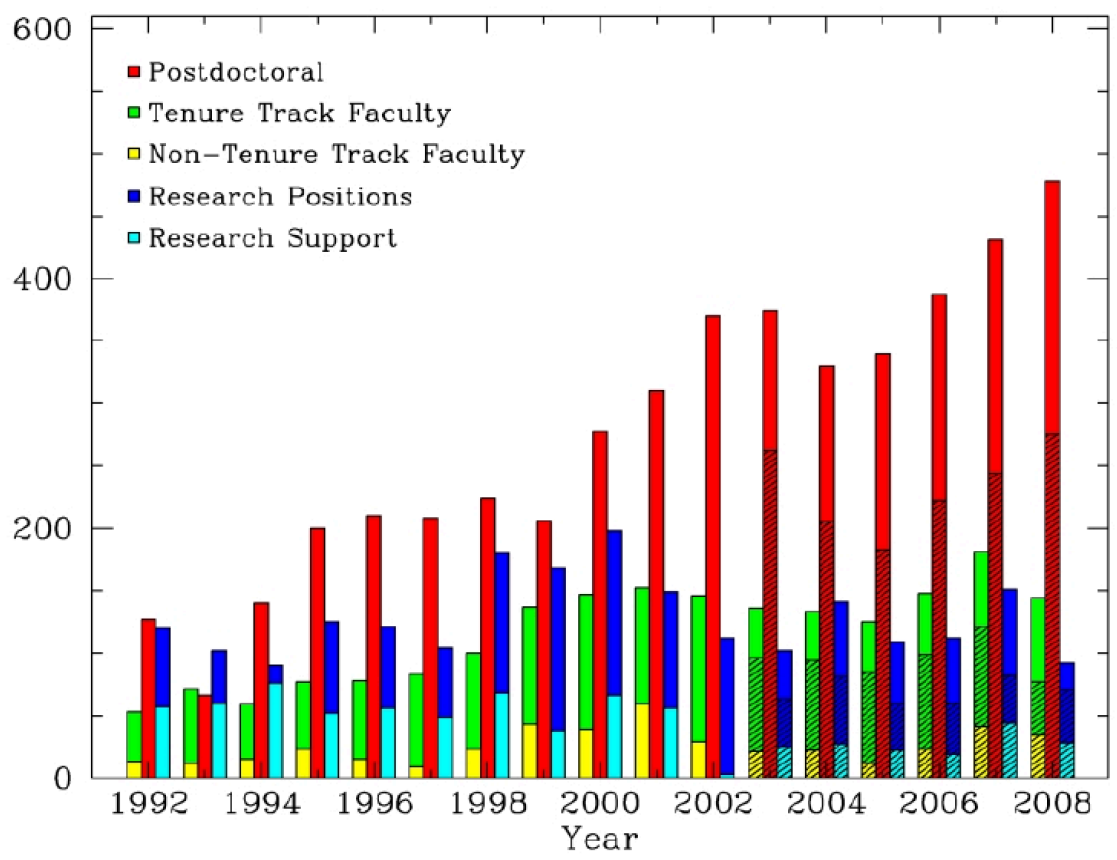

NOTE. Data from the American Astronomical Society Job Register, showing the number and type of positions advertised from 1992 to 2008. After 2002 the shaded regions of the histogram show the portions of the jobs that were in the U.S. Faculty positions are divided into tenure track (green) and non-tenure track (yellow) and research positions are divided into research (blue) and support (cyan). 
Figure 2.1. Distribution of Astronomers and Position Type. Figure above (courtesy Kevin Marvel and the AAS) and description is taken from (Impey, 2012).

Today, astronomers remain largely white and male (see Table 2.2). However, the demographics are slowly changing. In 1966 just five percent of those graduating with a $\mathrm{PhD}$ in astronomy were women. In 2001 that number rose to 22 percent. During this same time period the number of underrepresented minorities graduating with a $\mathrm{PhD}$ in astronomy remained consistently low at less than three percent (Impey, 2012).

Table 2.2

Astronomer gender and ethnicity distribution.

\begin{tabular}{|c|c|c|}
\hline Gender/Ethnicity & $\begin{array}{c}\text { Total U.S. Scientists } \\
(\%)\end{array}$ & $\begin{array}{l}\text { Employed Physicists- } \\
\text { astronomers (\%) }\end{array}$ \\
\hline Female & 33.6 & 20 \\
\hline Male & 66.4 & 80 \\
\hline Asian & 19.2 & 20.6 \\
\hline American Indian/Alaska Native & 0.2 & $\mathrm{D}$ \\
\hline Black or African American & 5.0 & $*$ \\
\hline Hispanic or Latino & 4.8 & 5.9 \\
\hline White & 69.2 & 73.5 \\
\hline Native Hawaiian/Pacific Islander & 0.2 & $\mathrm{D}$ \\
\hline Two or more races & 1.5 & $*$ \\
\hline \multicolumn{3}{|c|}{$\begin{array}{l}\text { Total employed U.S. scientists in } 2010=3,829,000 \text {. Total employed astronomers and } \\
\text { physicists }=34,000 \text {. Scientists are individuals with a bachelor's or higher degree living in the } \\
\text { United States with a science or science-related degree or occupation. }\end{array}$} \\
\hline \multicolumn{3}{|c|}{$\begin{array}{l}*=\text { estimate }<500 . \mathrm{D}=\text { suppressed for data confidentiality reason. } \mathrm{S}=\text { suppressed for } \\
\text { reliability; coefficient of variation exceeds publication standards. }\end{array}$} \\
\hline \multicolumn{3}{|c|}{ (American Astronomical Society, 2005; NSF, 2010) } \\
\hline
\end{tabular}

\section{Where Can We Find Astronomers Today?}

The modern era also impacted astronomers in other ways. Astronomy, like other sciences became institutionalized, and the research itself no longer required self-funding or funding from 
individual philanthropists. Astronomers found themselves working for universities, governments, and other institutions. Astronomy became professionalized.

Today, the institutionalization of astronomy remains largely unchanged. The vast majority of professional astronomers, like other scientists, find themselves employed at a college or university, government agency, industry, or some other institution (see Table 2.3). However, there are significant differences when it comes to where astronomers find employment compared to other scientists. For example, while just $18 \%$ of scientists and engineers overall are employed in the education sector, $54 \%$ of astronomers find themselves employed at universities or colleges (see Tables 2.3 and 2.4).

Table 2.3

Distribution of astronomers across employment sectors.

\begin{tabular}{|l|c|}
\hline \multicolumn{1}{|c|}{ Employment Sector } & \% \\
\hline College/University & 54 \\
\hline University Affiliated Research Institutions (e.g. NASA Center) or Observatory & 21 \\
\hline Federally Funded Research and Development Centers (FFR\&DC) & 7 \\
\hline Government & 7 \\
\hline Non-Profit & 5 \\
\hline Private Industry & 4 \\
\hline Military & 2 \\
\hline $\begin{array}{l}\text { Note: Distribution of astronomers, astrophysicists, and planetary scientists across } \\
\text { employment sectors in 2006 (Impey, 2012). }\end{array}$ \\
\hline
\end{tabular}

Table 2.4

Distribution of scientists and engineers across employment sectors.

\begin{tabular}{|l|c|}
\hline \multicolumn{1}{|c|}{ Employment Sector } & $\begin{array}{c}\text { \%o of S\&E } \\
\text { Workforce }\end{array}$ \\
\hline Business/industry (total) & $\mathbf{6 9 . 8}$ \\
\hline For-profit businesses & 53 \\
\hline Nonprofit organizations & 10.4 \\
\hline Self-employed, unincorporated businesses & 6.4 \\
\hline Education (total) & $\mathbf{1 8 . 0}$ \\
\hline
\end{tabular}




\begin{tabular}{|l|c|} 
4-year institutions & 7.5 \\
\hline 2-year institutions & 1 \\
\hline Precollege and other institutions & 9.5 \\
\hline Government (total) & $\mathbf{1 2 . 2}$ \\
\hline Federal & 4.5 \\
\hline State & 3.7 \\
\hline Local & 4 \\
\hline $\begin{array}{l}\text { NOTE. Scientists and engineers (S\&E Professionals) refers to all persons who have } \\
\text { received a bachelors degree or higher in a science or engineering (S\&E) field or S\&E- } \\
\text { related field or occupation. }\end{array}$ \\
\hline Source: Science \& Engineering Indicators 2012 (National Science Board, 2012). \\
\hline
\end{tabular}

Beyond the workplace, astronomers remain connected through various societies and organizations. There are two major professional astronomy organizations, the International Astronomical Union (IAU) with nearly 9200 individual members in 96 countries worldwide (International Astronomical Union, 2015) and the American Astronomical Society (AAS) with 7,000 members, with the vast majority being from the U.S. (American Astronomical Society, 2015).

\section{What Do Astronomers Do?}

As stated previously, activities astronomers engage in can be broken down into three broad categories, (1) attitudes, (2) tools and techniques, and (3) social interaction. Supporting this approach to classifying activities scientists [astronomers] engage in, A Framework for K-12 Science Education (National Research Council, 2011) identifies eight essential science practices that can be easily mapped to Edelson's framework (see Table 2.5).

Table 2.5

Mapping the Framework for $k-12$ science. 


\begin{tabular}{|l|c|}
\multicolumn{1}{|c|}{ Practices of Science } & $\begin{array}{l}\text { A - Attitudes } \\
\text { T - Tools and Techniques } \\
\text { S - Social Interactions }\end{array}$ \\
\hline Asking questions & $\mathrm{A}, \mathrm{T}$ \\
\hline Developing and using models & $\mathrm{T}$ \\
\hline Planning and carrying out investigations & $\mathrm{T}, \mathrm{S}$ \\
\hline Analyzing and interpreting data & $\mathrm{T}$ \\
\hline Using mathematics and computational thinking & $\mathrm{T}$ \\
\hline Constructing explanations & $\mathrm{T}$ \\
\hline Engaging in argument from evidence & $\mathrm{A}, \mathrm{S}$ \\
\hline Obtaining, evaluating, and communicating information & $\mathrm{T}, \mathrm{S}$ \\
\hline (National Research Council, 2011; Edelson 2003) & \multicolumn{2}{|c|}{} \\
\hline
\end{tabular}

While it can be argued that in Table 2.5 analyzing and interpreting data and constructing explanations are both "tools and techniques" and "social interactions", those activities become social interactions through argumentation of evidence or communicating information.

\section{Attitudes Practiced by Scientists}

Scientific practice is characterized by attitudes of uncertainty and commitment (Edelson 2003). Time is an essential component for real-world science (Bencze 2000; Anderson 2002; Chinn and Malhotra 2002; Rahm, Miller et al. 2003; Robinson 2004; Zion, Slezak et al. 2004). Scientists will often spend years investigating a single question. This effort requires strong personal and professional commitment. Further, scientists hold a respect for evidence and do not rush to judgment; they think critically, maintain an attitude of honesty and objectivity, and a willingness to change their minds when confronted with opposing evidence (Kozlow \& Nay, 1976). The questions that drive scientific research in astronomy also come out of uncertainty. Albert Einstein stated, "No amount of experimentation can ever prove me right; a single 
experiment can prove me wrong." (The Center for Informed Decision Making, 1998, p. 1) Even something believed to be true can and should be scrutinized by scientists.

Intuition, or as some might describe it, "a hunch," is also an important attitude and tool in the practice of science. Intuition is grounded in the accumulation of attitudes and beliefs that are derived from individual and cultural experience, and is often used to provide a conceptual framework from which new ideas, research questions, and research findings emerge (Wilder, 1967; Beveridge, 1950). Resent research indicates the human brain has two operating systems, a quick, instinctive and often unconscious system, linked to the right side of the brain, and a second, slower, more analytical and conscious system, connected to our left-brain. Intuition is grounded in the first, and some researchers have discovered that intuition often gives us the right answer long before our more analytical side (Turner, 2014). Closely linked to intuition is imagination. Imagination not only leads us to the discovery of new facts, but it is often the birthplace of ideas for new projects (Beveridge, 1950).

\section{Tools and Techniques of Astronomers}

While techniques and ways of doing science and coming to know new knowledge have been addressed previously in the section titled "Astronomy and the Evolution of Science," additional techniques and tools will be discussed here. "The practice of science in any modern discipline includes a set of tools and techniques that have been developed and refined over the history of the field." (Edelson, 2003) In addition to things like intuition and imagination, advancements in technology throughout human history have propelled changes in the way astronomers engage with their science or have come to know new knowledge. In 3000 B.C.E. Stonehenge was constructed to monitor the location of the sun and other celestial objects throughout the course of the year. The facility and data it produced was used for more than a 
thousand years to inform society when to plant and harvest crops (Hakim, 2004). Then came the invention of the astrolabe by the Greco-Roman scientist Claudius Ptolemy around 150 AD (Morrison, 2010). The instrument was used to more precisely measure the positions of the stars. These data were used to tell time, help travel great distances across both land and sea, and develop models of the solar system we live in. The astrolabe was used and its design improved by the Arabs, Europeans, and others for over 1500 years. Then came the telescope. Galileo first used the telescope to observe Jupiter, the Moon, and other celestial objects in the early 1600's sparking a science revolution (Drake, 1990). Observations of moons orbiting the planet Jupiter challenged the long held belief of an Earth centered solar system. Albert Einstein and Edwin Hubble in the early 1900's used more advanced telescopes to collect data on the location and motion of distant galaxies creating the foundation for the Big Bang Theory, and much more.

Today, highly sophisticated telescopes (see Table 2.6) combined with imaging systems and advanced software and computer technology, can accurately measure the positions and brightness of 1000's of celestial objects in a matter of seconds. Each of these instruments requires a team of people with expertise not just in astronomy, but also in engineering, computer programing, system design, and operations. As a result of these highly sophisticated instruments, astronomers are spending much less time at the observatory with the telescope collecting data (American Astronomical Society, 2005). In some cases (e.g. Hubble Space Telescope, Spitzer Space Telescope, the James Webb Space Telescope, etc.) the astronomer never visits the facility or uses the instrument, leaving the data collection up to a team of expert instrument operators and programmers. The scientist's first glimpse of the data being collected by the telescope may come months after the observation takes place. Still in other cases the astronomer requires no new data collected at all; using archived data collected years earlier instead. Indeed, 
advancement in technology, whether it is space telescopes, computer technology, robotics, etc.,

have had a profound impact on the practice of astronomy.

Table 2.6

Major telescopes of today and tomorrow.

\begin{tabular}{|c|c|c|}
\hline Telescope & Location & Description \\
\hline Keck Observatory & Hawaii & $\begin{array}{l}\text { Twin } 10 \text { meter telescopes that observe visible/IR light. Known for advancing } \\
\text { adaptive optics that use computer driven mirrors adjusting multiple times per } \\
\text { second to account for atmospheric disturbance. The technology allows for } \\
\text { increased resolution in images (Moseman, 2009)Began operations in } 1993 \text {. } \\
\text { (http://www.keckobservatory.org/) }\end{array}$ \\
\hline Hubble Space Telescope & Space & $\begin{array}{l}\text { A 2.4-meter telescope that observes visible/IR light. Was the most famous } \\
\text { orbiting telescope that allowed observations to be made outside the Earth's } \\
\text { atmosphere. Began operations in } 1990 \text { (Moseman, 2009) } \\
\text { (http://hubblesite.org/) }\end{array}$ \\
\hline Spitzer Space Telescope & Space & $\begin{array}{l}\text { A } 0.85 \text {-meter IR telescope. Spitzer allows astronomers to see through dusty } \\
\text { regions in space to explore star formation regions, new planets, and centers } \\
\text { of galaxies. Began operations in 2004. (http://www.spitzer.caltech.edu/) }\end{array}$ \\
\hline $\begin{array}{l}\text { Large Binocular } \\
\text { Telescope }\end{array}$ & Arizona & $\begin{array}{l}\text { Comprised of two } 8.4 \text { meter mirrors, the telescope provides } 10 \mathrm{X} \text { more light } \\
\text { gathering power than Hubble. The telescope uses an advanced adaptive } \\
\text { optics system to achieve high resolution imaging from the ground. Began } \\
\text { operations in } 2005 \text {. (http://www.lbto.org/) }\end{array}$ \\
\hline $\begin{array}{l}\text { Fermi Gamma-Ray } \\
\text { Space Telescope }\end{array}$ & Space & $\begin{array}{l}\text { This telescope observes gamma rays being emitted from supermassive black } \\
\text { holes, colliding neutron stars, and supernovae. Began operations in } 2008 \text {. } \\
\text { (http://fermi.gsfc.nasa.gov/) }\end{array}$ \\
\hline Kepler & Space & $\begin{array}{l}\text { A planet-hunting telescope that monitored about } 150,000 \text { stars looking for } \\
\text { transits of planets. The telescope has led to the discovery of nearly } 1000 \\
\text { confirmed exoplanets and another unconfirmed } 3200 \text { exoplanet candidates. } \\
\text { Began operations in 2009. (http://kepler.nasa.gov/) }\end{array}$ \\
\hline $\begin{array}{l}\text { Atacama Large } \\
\text { Millimeter/Submillimeter } \\
\text { Array }\end{array}$ & Chile & $\begin{array}{l}\text { This telescope is comprised of } 66 \text { dishes spread across up to } 10 \text { miles, and is } \\
\text { the world's most advanced radio telescope. ALMA will allow astronomers to } \\
\text { study galaxy and star formation in the early universe, explore the complex } \\
\text { chemistry in giant molecular clouds in space, and study planet formation } \\
\text { around stars. Began operations in 2013. (http://www.almaobservatory.org/) }\end{array}$ \\
\hline $\begin{array}{c}\text { James Webb Space } \\
\text { Telescope }\end{array}$ & Space & $\begin{array}{l}\text { The Webb telescope will replace Hubble but will observe primarily in the } \\
\text { infrared. The instrument will } 7 \text { times the light gathering power of Hubble, } \\
\text { and will help scientists peer back into the early universe, as well as } \\
\text { understand star and planet formation. Slated for launch in } 2018 \text {. } \\
\text { (http://www.jwst.nasa.gov/) }\end{array}$ \\
\hline $\begin{array}{c}\text { Large Synoptic Survey } \\
\text { Telescope }\end{array}$ & Chile & $\begin{array}{l}\text { LSST is an } 8.4 \text {-meter survey telescope with the world's largest digital } \\
\text { camera, } 3200 \text { Megapixels. It will survey the entire sky from northern Chile } \\
\text { every } 2.5 \text { nights for } 10 \text { years, catalog all sources, and make the data } \\
\text { immediately available to the public. The telescope will produce } 30 \text { Terabytes } \\
\text { of data nightly, and will produce more data in the first week of operations } \\
\text { than Hubble did in } 20 \text { years. Slated to begin early operations in } 2020 \text {. } \\
\text { (http://www.lsst.org/lsst/) }\end{array}$ \\
\hline
\end{tabular}




\begin{tabular}{|c|c|l|}
$\begin{array}{c}\text { Giant Magellan } \\
\text { Telescope }\end{array}$ & Chile & $\begin{array}{l}\text { The telescope will consist of seven 8.4-meter objective mirrors and will } \\
\text { observe primarily in the visible light. Images from the GMT will have } 10 \\
\text { times the resolution of the Hubble Space Telescope. Slated to begin } \\
\text { operations around 2021. (http://www.gmto.org/) }\end{array}$ \\
\hline Thirty-Meter Telescope & Hawaii & $\begin{array}{l}\text { The telescope will consist of a 30-meter objective mirror made up of 492 } \\
\text { smaller segments objective and will observe primarily in the visible light. } \\
\text { Slated to begin operations around 2021. (http://www.tmt.org/) }\end{array}$ \\
\hline
\end{tabular}

Massive data archives and data mining software are also becoming powerful tools for

today's astronomers. For example, beginning in the year 2022 the Large Synoptic Survey

Telescope (LSST) will continually image the sky from Chile non-stop for ten years, with data

being made available to astronomers and the general public alike immediately following each night of observation (LSST: A new telescope concept, 2014). By the end of its mission, LSST will have produced more that 50,000 Terabytes of data, identified 3 billion sources, and classified 840 million of those sources, the vast majority of which will be achieved through automated computer routines. Each of those classifications will require 5000 mathematical operations per pixel, requiring advanced methods in data processing (LSST: A new telescope concept, 2014).

Today, more and more astronomers are accessing archives for research purposes, or are working in support roles for these systems. The NASA/IPAC Extragalactic Database (http://ned.ipac.caltech.edu/), Sloan Digital Sky Survey (http://www.sdss.org/), All Sky Automated Survey (http://www.astrouw.edu.pl/asas/), Canadian Galactic Plane Survey (http://www.ras.ucalgary.ca/CGPS/), and the AAVSO Photometric All-Sky Survey (http://www.aavso.org/apass) represent a small sample of recent or ongoing surveys that produce large data sets used by astronomers for various research projects. Many scientists around the world use primary data from these types of surveys from which they produce derived data (Pepe, Goodman, Muench, Crosas, \& Erdmann, 2014). 
It is however important to note that while the use of remote telescopes and data archives is a growing trend, a great deal of astronomy is still done using smaller instruments, and in many cases the astronomer still visits the observatory to work with a telescope operator during data collection. For example, astronomers using the Cerro Tololo Inter-American Observatory (CTIO) in Chile and the National Radio Astronomy Observatory's Green Bank Telescope (GBT) facility are often at the telescope while their observations are being made (Smith, 2015).

Teams who use space-based telescopes often require ground-based follow-up observations. For example, a team working with the Spitzer Space Telescope Research Program for Teachers and Students identified a number of new T-Taui star candidates using the Spitzer Space Telescope. The group was awarded two nights of observing time on the Palomar 200-inch Hale Telescope to conduct follow-up spectroscopy (Guieu et al., 2010). Spectroscopy is a valuable tool to astronomers studying young stars since the spectral signature allows them to clearly distinguish a star from a distant background galaxy, as well as classify the star type and stage of development. The team traveled to Palomar for the observing run, however poor weather conditions forced the team to modify the observing routine "on the fly". Because they were physically present the necessary changes could be made and that resulted in at least some usable data. When the astronomer is not at the telescope, these types of modifications are often more difficult to make. As a result, some astronomers prefer to be at the telescope for their observing run when possible (Rebull, 2009).

Regardless of which telescope an astronomer might be using, they are limited to observing the position, brightness, color (wavelength or frequency), and polarity of the light from objects in space, and changes in these four properties that might occur over time. Unlike other scientists, astronomers, with the exception of planetary astronomers, must rely entirely on 
observation: they can not engage in experimentation (American Astronomical Society, 2005). With the exception of rock/soil samples brought back to Earth from the Moon, meteorites that have landed on the Earth, the Stardust spacecraft that returned small samples of interstellar dust and material from comet Wild 2 (Sandford et al., 2006), the Hayabusa mission that brought back a tiny sample of dust from asteroid 25143 Itokawa (Yurimoto et al., 2011) and the spacecraft that have visited planetary objects in our own solar system (e.g. Voyager, Curiosity, etc.), virtually everything astronomers know about the universe comes from observations of light, neutrinos, and more recently, gravity waves. The primary tools used by astronomers to study this light coming from space are CCD imaging cameras made of pixel arrays, single point detectors such as those used in radio telescopes, frequency filters, and spectrometers. Similar to digital cameras in cell phones, $\mathrm{CCD}$ cameras used by astronomers produce an image of a region of the sky. Filters can be placed in front of the CCD chip to look at a region of the sky at different wavelengths (colors), and photometric measures can be made of all sources in the image. Single point detectors work in a similar way, however they consist of a single "pixel" detector rather than an array. Astronomers also use spectrometers extensively in their work. These devices are attached to different types of telescopes and either sweep through a frequency band (e.g. radio) measuring intensity at the different frequencies, or spread the light out into its individual components, image the light (e.g. visible), and then measure intensity at the different wavelengths/frequencies. In addition, polarizing filters are used to observe the polarization of different types of electromagnetic radiation.

As in other science disciplines, computers are a powerful tool in astronomy. Once data is collected, astronomers use computers to clean and process data for further analysis. "The typical astronomer today spends several hours a day at a computer screen analyzing data, controlling 
and monitoring telescopes, writing papers, reading journal articles, or researching databases" (American Astronomical Society, 2005, p. 3).

Astronomers also use computers to write computer scripts and programs, and create simulations, or computer models. Modeling is a critical tool in the practice of science. "Models make it possible to go beyond observables and imagine a world not yet seen." (National Research Council, 2011, pg. 50) While models can take a variety of forms (e.g. physical models, mathematical models, computer models, etc.) they are used to help organize and explain observations, or they can be used to develop new hypothesis and predict possible outcomes (Van Der Valk, Van Driel, \& De Vos, 2007). In astronomy computer models and simulations are especially important because events in space often happen over great distances and very long periods of time: environments that are impossible to recreate inside a physical space here on Earth. Computer models in astronomy help us understand things like galaxy collisions, star and planet formation, and even the origin of the universe itself.

The vast majority of the data analysis, computer modeling, theory creation, etc. astronomers engage in, is grounded in mathematics. Students who are considering careers in astronomy are encouraged to take as many math courses as possible (American Astronomical Society, 2005). Some might consider mathematics to be simply a bunch of numbers and equations, but mathematics is made up of representative symbols and procedures that allow us to make sense of the universe. Through mathematics we can understand planetary orbits, black holes, and even the possibility of new dimensions outside our universe.

Astronomers also find themselves designing and building necessary equipment for data collection and analysis. While the concept of the next-generation radio telescope called the Square Kilometer Array (SKA) has been many years in the making, in a February 2000 design 
and development meeting a group of radio astronomers were among those who met. Among the many points addressed at the meeting were telescope design, how to prevent radio interference from affecting the instrument, how to write the software needed to operate the telescope, and where to locate the telescope itself to best mitigate many of the factors that could affect such a sensitive instrument (Cornell University, 2000). Astronomers also played a key role in the design and construction of the Dark Energy Camera (DECam) currently mounted on the 4-Meter Victor M. Blanco Telescope at CTIO (Smith, 2015). The practice of astronomy does not limit itself to currently available equipment and instrumentation. Rather the need often dictates the development of new instruments and methods, and astronomers appear to be very much involved in the process.

\section{Astronomers and Social Interactions}

Social interaction is another key feature of authentic scientific practice. Social interaction among scientists includes the same mix of co-operation and competition, agreement and argumentation that accompanies all human social activity (Edelson, 2003). However, one of the primary characteristics of research science is collaborative work (Eason, 2004). Astronomers, although often competitive, conduct research working in teams. Various team members bring diverse knowledge and skills to a project, enhancing the ability of the team and the research it conducts. Astronomers often share their expertise at weekly lecture luncheons, or present their own work for critical review at conferences and other meetings. Looking at the number of coauthors on journal publications indicates collaboration is becoming more common among astronomers (See Table 2.7).

Table 2.7

Astronomy journal publications. 


\begin{tabular}{|l|c|l|}
\hline \multicolumn{1}{|c|}{ Title } & $\begin{array}{c}\# \\
\text { Authors }\end{array}$ & \multicolumn{1}{|c|}{ Source } \\
\hline Physical Characteristics of the Cancer Cluster of Galaxies & 1 & (Zwicky, 1950b) \\
\hline The Motions of the Galactic Cluster-Type Variables & 1 & (Struve, 1950) \\
\hline The Cancer Cluster of Galaxies & 1 & (Zwicky, 1950a) \\
\hline $\begin{array}{l}\text { The Effects of the Terrestrial Ionosphere on the Radio } \\
\text { Waves from Discrete Sources in the Galaxy }\end{array}$ & 2 & (Ryle \& Hewish, 1950) \\
\hline $\begin{array}{l}\text { The Frequency Function of True Axial Ratio for the } \\
\text { Spheroidal Galaxies }\end{array}$ & 1 & (Wyatt, 1950) \\
\hline $\begin{array}{l}\text { He-like Ions as Practical Astrophysical Plasma } \\
\text { Diagnostics: From Stellar Coronae to Active Galactic } \\
\text { Nuclei }\end{array}$ & 3 & $\begin{array}{l}\text { (Porquet, Dubau, \& } \\
\text { Grosso, 2010) }\end{array}$ \\
\hline $\begin{array}{l}\text { GALEX NUV Lyman Break Galaxies } \\
\text { (Williger, Haberzettl, } \\
\text { Lehnert, Nesvadba, \& } \\
\text { Valls-Gabaud, 2010) }\end{array}$ \\
\hline $\begin{array}{l}\text { A SINFONI integral field spectroscopy survey for Galaxy } \\
\text { counterparts to damped Lyman- } \alpha \text { systems }\end{array}$ & 5 & $\begin{array}{l}\text { (Péroux, Bouché, } \\
\text { Kulkarni, York, \& Vladilo, } \\
\text { 2011) }\end{array}$ \\
\hline $\begin{array}{l}\text { Dwarf galaxies in the Local Group: cornerstones for } \\
\text { stellar astrophysics and cosmology }\end{array}$ & 21 & Bono et al., 2010) \\
\hline Open Clusters as tracers of the Galactic disk & 1 & (Bragaglia, 2010) \\
\hline
\end{tabular}

Table 2.7 displays the first five research publication results from two searches using SAO/NASA Astrophysics Data System (ADS). The first search identified all results that included the word "galaxy" in the title that were published in 1950. A total of 43 sources were identified from the year 1950. The second search identified all results with the word "galaxy" in the title that were published in 2010. A total of 6287 sources were identified from the year 2010 using the ADS search engine. Another study showed the number of authors on science and engineering articles increased from 1.9 authors in 1960 to 3.5 in the year 2000 (Wuchty, Jones, \& Uzzi, 2007). The collaborations between scientists aren't just increasing domestically either. The number of science and engineering articles published here in the U.S. including an international co-author has grown from 10\% in 1988 to $28 \%$ in 2007 (National Research Council, 2011). Nearly $24 \%$ of physical scientists engage with others internationally as part of their work (National Science Board, 2012). Clearly it is not just the amount of science that is taking place, but the level of collaboration has increased over time. 
The numbers also indicate sharing of science through written publications is playing a greater role among scientists. Over the years scientists have developed a peer review process that allows for the presentation and argument of methods used, evidence, and findings. The peer review process is an attempt to improve the quality of science being done (Yore et al., 2006). Prior to acceptance for publication the author's work is reviewed critically by colleagues familiar with the subject matter. The review does not simply address the science content, but also the way the science is being communicated through the written word. The acts of writing and revising, and the peer review process, not only works to ensure accurate communication, but also improves the quality of the science being done by scientists (Yore et al., 2006). Between the year 1950 and 2009 the total number of workers in the U.S. in science and engineering occupations grew from 182,000 to 5.4 million (National Science Board, 2012). This is an increase of $29 \mathrm{X}$ in the science \& engineering workforce. However, the growth in publications between 1950 and 2010 increased by 145X; nearly five times the growth rate of the workforce.

Astronomers are reaching out across other science disciplines as they engage in their work as well. Growing efforts in astrobiology, astrochemistry, planetary geology, archeoastronomy, and astroengineering are all examples of the interdisciplinary nature of astronomy. In addition, recent grant programs supported by the NSF, such as the Integrative Graduate Education and Research Traineeship, Collaboration in Mathematical Geosciences, and the Science, Engineering and Education for Sustainability demonstrate a focus on the interdisciplinary nature of today's science.

Teaching and motivating the next generation of scientists is another way astronomers interact socially through their work. Astronomy graduate students engage in their research with an advisor that mentors them throughout the process. In addition, many astronomers at academic 
institutions not only engage in research, but also teach undergraduate and graduate courses (National Science Board, 2012). Many astronomers also engage in education and public outreach activities. A 2004 survey found that $58 \%$ of scientists engage in some form of outreach (National Science Board, 2004). According to a survey of 2013 AAS members, $44 \%$ of respondents said they participated in EPO activities (G. Anderson \& Ivie, 2014).

Astronomers also take on a variety of management positions. For example research astronomers often move into facility management positions (Smith, 2015). These individuals do not necessarily stop doing research in their field, but management duties can consume a great deal of their time. Another example is Dr. Luisa Rebull at the Spitzer Space Telescope Center at Cal-Tech in Pasadena, CA. Dr. Rebull does not manage a facility, but she does manage an EPO program (Rebull, 2009). The management of the program consumes a great deal of her time, but she remains an active researcher in the field of young stellar objects.

Then there's the grant writing process that many astronomers engage in at some point in their career. The proposed federal research and development budget for 2013 is $\$ 142.2$ billion (AAAS, 2012) and the vast majority of this money will be awarded competitively. The competition is becoming tougher and more time consuming too. Between 1996 and 2007 the average applicant to the NSF submitted 30\% more funding proposals to achieve the same level of success (National Science Foundation, 2007). Further, as with any public funding, the focus, and subsequent success rate can be impacted by political and societal interests of the time.

\section{Summary}

The literature points to a science discipline that has changed with time. Through the years, rules of evidence and science attitudes astronomers practice have evolved. Today's 
astronomers also use new tools and techniques that simply did not exist 50 years ago, and that has brought about new knowledge and new ways of thinking. Those who engage in astronomy and the ways in which they interact socially have also changed. While Chapter 1 outlined personal observations that lead to the research question, as well as justification for a deeper understanding of what astronomers do, Chapter 2 has strengthened the case and provided a framework from which an instrument can be developed to more clearly asses the activities today's astronomers engage in. 


\section{Chapter 3}

\section{Methodology}

\section{Overview}

The cosmos have been explored by humans for 1000s of years. Early astronomers were limited to recording the positions of "stars" in the night sky and noting their movement over time. Today, astronomers continue to explore the cosmos but with much more advanced tools and methodologies. In addition, astronomy is seen by many as a way to motivate young learners and to teach the interdisciplinary nature of science and engineering. Astronomy has demonstrated its relevance to our daily lives, and as such there is significant value in understanding the current practice of astronomy. As outlined in Chapter 1 this study explores the activities astronomers engage in through their practice of astronomy, and further provides the importance of the study. The literature review in Chapter 2 supports the breakdown of these practices into three major categories: attitudes, tools and techniques, and social interactions.

\section{Research Questions}

This research study will provide deeper insight into the following questions:

What do U.S. astronomers do?

Sub-questions:

1) What science related attitudes are most important to U.S. astronomers in their practice of astronomy?

2) What tools and techniques are most frequently used by U.S. astronomers in their practice of astronomy?

3) What social interactions are most frequently engaged in by U.S. astronomers in their practice of astronomy? 
4) What are astronomers' perceptions about career influences, work related activities, personal motivations for doing astronomy, and how to make astronomy education more reflective of the practice of astronomy?

\section{Research Design}

Based on previous experience and a review of the literature this author has developed a survey instrument (see Appendix C). The research project will address the research questions using descriptive research methods via the survey instrument. Data collected will be selfreported. The study will present a detailed snapshot of the activities astronomers engage in, but will not make assertions as to their motives for doing so.

\section{The Survey Instrument}

The survey questions are the result of an in-depth analysis of the practice of astronomy (see Chapter 2), as well as numerous conversations with professional astronomers. The majority of the questions developed use a Likert scale because such instruments are most appropriate for statistical analysis (Jackson, 2009). The survey instrument has been initially field tested with four professional astronomers, and all felt the instrument effectively captured the activities which astronomers engage in.

During the proposal defense, it was recommended by the Committee that additional open ended questions be added to the survey in an effort to explore a fourth sub-question related to perceptions of astronomers. It was further recommended that due to the length of the survey, questions related to astronomers' perceptions be made optional for the survey respondents.

\section{Measuring Survey Validity}


Preliminary content validity for the instrument was established by asking four professional astronomers to review the survey instrument for understanding and content. The participants reviewed the survey initially, and then a second time after changes were made based on their initial comments.

\section{Research Participants}

The research participants will be practicing astronomers as defined in Chapter 1 who are primarily based in the United States. There are approximately 4000 astronomers employed in the United States (Impey, 2012). These astronomers are located in a variety of settings. Some astronomers practice in government sponsored laboratories, others at universities, and even a small percent in private industry. This study will focus dissemination of the survey instrument where astronomers are most likely to congregate.

The cover letter (see Appendix A) and link to the online survey via Survey Monkey (see Appendix C) will be sent to astronomers via email. Email addresses will be secured through the following:

- The vast majority of professional astronomers in the U.S. are members of the American Astronomical Society (AAS). Dr. Kevin Marvel, AAS Executive Director has agreed to send out the survey request on my behalf via the email addresses they have on file for all U.S. astronomers. Having the AAS send out the survey will lend significant credibility to the request and will likely increase response rates.

- The vast majority of astronomy research facilities (e.g. National Optical Astronomy Observatory, National Radio Astronomy Observatory, NASA Centers, Gemini Observatory, etc.) have online directories. These directories will be used to secure email 
addresses for astronomers. The cover letter and link to the survey will be sent out via these email addresses.

- The NSF has established a current list of doctorate-granting institutions by major science and engineering fields (NSF, 2015). The list identifies all institutions that have granted $\mathrm{PhD}$ 's in physics and astronomy in 2013. Institutions that grant PhD's in astronomy will also employ professional astronomers. The vast majority of universities have faculty directories online. These directories will be used to secure email addresses for astronomers. The cover letter and link to the survey will be sent out via these email addresses.

\section{Data Collection}

Participants for the study will be secured over a two-month time period based on nonrandom sampling methodology, in particular convenience sampling followed by quota sampling to ensure a sufficient sample size. Attaining a 95\% confidence level and confidence interval of five (5) is preferred, and will require a total of 351 participants (Creative Research Systems, 2014; Gay \& Airasian, 2000). However, even a smaller sample size could yield useful results. For example, a 95\% confidence level with a confidence interval of eight (8) could be achieved with just 145 participants. While the initial target for this study is 351 participants, it may be necessary to accept a lower response rate. Response rates will be monitored, and additional efforts (e.g. resending emails, possible follow-up phone calls to encourage completion of the survey, etc.) will be made on an as needed basis.

It is also important that the amount of time it takes a participant to complete the survey be constrained. In preliminary testing the survey instrument takes approximately 14 minutes to 
complete. If the survey were to take significantly more time to complete, it would be difficult to attract respondents. Once distribution of the survey begins, it is estimated that sufficient data collection can be concluded within a 2-month time frame. However, in the event additional survey results are needed, the data collection will be extended beyond the 2-month time frame.

\section{Data Analysis Plan}

The survey instrument being used in this study is designed to identify broadly what activities U.S. astronomers engage in and their perceptions about career influences, work related activities, personal motivations, and astronomy education. Questions from the survey instrument are divided into four "types". Type I questions are those that seek information about demographics of the respondent, or other information not related to the importance or frequency of an activity. Type II questions assess the importance of an activity in the practice of astronomy. Type III questions assess the frequency a respondent engages in an activity through their practice of astronomy. Type IV questions are open ended and responses will be collected through the online survey or a telephone interview.

Relative frequency tables and histograms will be generated for demographics (Type I) questions, and a comparison between the actual survey sample and values found in the literature will be made. Analysis of the histogram will be conducted to determine how closely the survey sample reflects the actual population of U.S. astronomers, and results will be reported. In addition, the mean, mode, standard deviation (SD), and confidence interval (CI) will be calculated and reported when possible and appropriate for responses to demographic-related questions. 
Due to the nature of attitudes in the practice of science, it would be difficult to assess attitudes in terms of frequency. As a result, questions related to attitudes will assess importance (Type II) rather than frequency. Type II responses will be assigned numerical values as follows; no importance $=1$, limited importance $=2$, average importance $=3$, much importance $=4$, and extreme importance $=5$. Relative frequency tables and histograms will be generated and presented for all items in questions 10 and 11 . The mean, mode, SD and CI for each item in questions 10 and 11 will also be determined and presented, and all items in each question will be ranked as to their importance based on their mean values.

Questions in the survey related to tools and techniques are either Type I or Type III questions. Responses to questions $12-16$, and $19-21$ relate to how often an astronomer engages in the use of various tools and techniques, or how long a process takes. In each case a relative frequency table and histogram will be created, and mean, mode, SD, and CI calculated and presented. In the case of questions 17 and 18, which are informative in nature, relative frequency tables and histograms will be created and presented.

Questions in the survey related to social interactions are of Type I or Type III. Responses to questions $22-28$ and question 30 relate to how often an astronomer engages in various social activities, or how many people they interact with. In each case a relative frequency table and histogram will be created and mean, mode, SD, and CI calculated and presented. In the case of question 29 , which is informative in nature, a relative frequency table and histogram will be created and presented.

Questions related to perceptions about career influences, work related activities, personal motivations, and astronomy education are either Type I or Type IV questions. In this case a relative frequency table will be created for Question 1 in the survey, and additional qualitative 
analysis using interpretive research methods with a focus on grounded theory will be used in the analysis of all open-ended questions.

\section{IRB Requirements}

The West Virginia University Internal Review Board reviewed and approved the protocol (number 1512954745) for this study. The data for this study is limited to adults completing a survey instrument. Through the survey, participants will provide demographics data as well as information about job-related activities they engage in. Participant responses will remain anonymous, unless a participant wishes to participate in a telephone interview. In those specific cases, participant names will be associated with the data collected, and their information will remain confidential to the researcher. In meeting with IRB requirements, all data collected will be destroyed after five years. The proposed study presents minimal risk to participants, and falls within the exempt category for research. 


\section{CHAPTER 4}

\section{FINDINGS AND DISCUSSION}

\section{Review of Research Questions and Design}

This study used a mixed methods research design, collecting and analyzing both quantitative and qualitative data, in an attempt to provide deeper insight into the principal question: What do U.S. astronomers do? This study sought to answer the following:

- Research Question 1: What science related attitudes are most important to U.S. astronomers in their practice of astronomy?

- Research Question 2: What tools and techniques are most frequently used by U.S. astronomers in their practice of astronomy?

- Research Question 3: What social interactions are most frequently engaged in by U.S. astronomers in their practice of astronomy?

- Research Question 4: What are astronomers' perceptions about career influences, work related activities, personal motivations for doing astronomy, and how to make astronomy education more reflective of the practice of astronomy?

○ Sub-question 4a: What are astronomers' perceptions about factors that influenced them to pursue a career in astronomy?

○ Sub-question 4b: What are astronomers' perceptions about their work-related activities?

- Sub-question 4c: What are astronomers' perceptions about what makes doing astronomy personally meaningful? 
○ Sub-question 4d: What are astronomers' perceptions about how pre-K through college astronomy education should be changed to be more reflective of astronomy as it is practiced today?

The study included both open-ended and closed questions with the majority of responses to questions being secured via an online survey. Data for research questions $4 \mathrm{~b}, 4 \mathrm{c}$, and $4 \mathrm{~d}$ were collected via three optional open-ended questions at the end of the survey. Participants could choose to respond online, request a telephone interview, or skip the questions. Five respondents participated in an optional telephone interview where they responded to the three open-ended questions focusing on perceptions of astronomers related to their activities, their motivations, and education. Data for all other questions were collected via an online survey.

The survey instrument was designed and field-tested with practicing astronomers to ensure content validity. All quantitative data were collected via the online survey. A combination of Survey Monkey and Excel tools were used to analyze the data and determine mean, median, mode, standard deviation, and confidence interval of the mean. Frequency tables and histograms were also created using Excel.

This investigation also used qualitative data and interpretive research with a focus on grounded theory. Text provided by astronomers via open-ended questions and telephone interviews were analyzed using grounded theory methodology. According to sociologist Norman Denzin, the grounded theory approach is the most influential paradigm for qualitative research in the social sciences today (Patton, 2002). Grounded theory is rooted in the researcher looking for patterns in the data, making connections, and coding for concepts that lead to the development of theory (Reiff, 2005). In addition, grounded theory requires the researcher to get close to the subject of the investigation in order to ensure findings are grounded in the empirical world 
(Blumer, 1979; Patton, 2002). Research Question 4 is analyzed and reported as a separate subsection.

As stated in Chapter 2 there are an estimated 4000 astronomers employed in the United States (Impey, 2012). Respondents from this community were secured via convenience sampling methodology. While it is recognized that non-random sampling (convenience sampling in this case) is susceptible to significant bias and is not as trustworthy as random sampling, sometimes it is possible to consider convenience sampling as random sampling (Freedman, 2010, pg. 23).

With the exception of the open-ended questions related to perceptions, the questions asked in the survey are related directly to activities astronomers engage in, rather than their opinions. In addition, respondents tracked closely to the current distribution of women/men and employment at academic/non-academic intuitions in U.S. astronomy today. While the risk of potential bias is noted, it is believed the nature of the study, and the rather benign questions being asked, limit risk of bias. As such, in the presentation and analysis of the data this study treats the data collected via convenience sampling similar to data collected using random sampling methods.

\section{Recruitment of Participants}

Active recruitment efforts took place January 4 through February 29, 2016. Email invites were sent to:

- U.S. astronomers listed in the International Astronomical Union (IAU) online directory; and

- astronomers listed in the NOAO, NRAO, Gemini Observatory, NASA, and the Institute for Astronomy - University of Hawaii online directories.

In addition, invites to participate in the study were posted via the Web and social media at: 
- the AAS website at https://aas.org/posts/opportunity/2016/01/your-input-mattersastronomers-needed-research-study;

- the Astronomers Facebook page at https://www.facebook.com/groups/123898011017097/; and

- the Astronomy Education Facebook page at https://www.facebook.com/groups/astronomyeducation/.

During the recruitment period a second email invite was sent to all original recipients, and a second post was made to the Astronomers, and Astronomy Education Facebook pages.

\section{Data Analysis Overview}

Data were collected via the survey instrument between January 4, 2016 and March 11, 2016. A total of 503 individuals responded to the survey. Using Survey Monkey's filtering feature, responses from 25 individuals were removed from the final data set. This included individuals who:

- skipped Question 3 or did not have a Master's Degree or higher;

- skipped Question 6 or did not select at least one astronomy sub-discipline into which their current professional scientific work is best categorized; or

- skipped Question 12 or were not engaged in at least one investigation or research project. The filtering process decreased the respondent total (n) from 503 to 478. It is assumed that the contents of the invite letter, and the fact that information about the study was sent to known U.S. astronomers, was sufficient to ensure all respondents were primarily based in the U.S., a U.S. territory, or a U.S. facility in another country. 
A confidence level (CL) threshold of $95 \%$ and $5 \%$ confidence interval (CI) is generally required for survey results to be significantly representative of the entire population when using random sampling methods. In order to achieve the desired CL and CI for a population of this size (4000 astronomers), a minimum of 351 respondents is necessary. This study includes results from a total of 478 astronomers. While a small number of respondents skipped individual questions, in no case, across questions one (1) through question 29, did more than 20 respondents skip any one question, maintaining a total well above the target of 351 respondents.

Data in this study were also disaggregated by gender (male/female) and institution type (academic/non-academic) and CI were calculated. Statistical significance can be claimed between two populations when the confidence intervals for the populations do not overlap (Penn State, 2017). Women make up nearly $28 \%$ or 1,120 of the 4,000 U.S. astronomers. A total of 124 respondents identified themselves as women. Across questions one (1) through 29 no more than three (3) women respondents skipped any one question. As a result, a sample size of 121 women respondents was the established value used in the calculation of CI for women. Men, on the other hand, made up slightly more than $71 \%$ (340) of survey respondents, and across questions one (1) through 29 a maximum of thirteen (13) men skipped any one question. A sample size of 327 respondents was used in the calculation of CI for men. It is important to note that 13 respondents did not provide data on gender, and one person identified as "other" gender. Respondents who did not provide gender data and the lone individual who responded "other" gender were not considered in the disaggregated gender data.

When it comes to institution type, astronomers employed at non-academic institutions make up $46 \%$ or 1,840 of the 4,000 U.S. astronomers. A total of 176 respondents identified themselves as working at a non-academic institution. Across questions one (1) through 29 no 
more than eight (8) respondents from non-academic institutions skipped any one question, and as such, 168 was the sample size used in determining the CI for this subgroup. In comparison, a total 233 respondents are employed at academic institutions. Of these individuals, no more than 16 respondents skipped any one question. A sample size of 217 was used in the calculation of a CI for this subgroup.

A number of questions in the survey provided an opportunity for respondents to select "other" and provide an additional text response related to the question. "Other" responses were not disaggregated based on gender or institution type. While these "other" responses provide important insight relative to something the survey might have missed, and may be valuable in informing future modification of the survey instrument or future areas of exploration, the number of respondents is insufficient to provide meaningful conclusions from disaggregating the data.

In each case where "other" was a potential response to a question, and respondents provided additional comments, a reiterative process was used to identify additional categories. Through this process all comments were reviewed, and categories from the text were identified. The original text from each individual response was coded and categorized. Since clustering survey results may improve reliability (Gay \& Airasian, 2000), clustering was used where appropriate, and final categories were identified. Additional categories required a) identification by $5 \%$ or more of respondents providing additional comments to a given question, and $b$ ) the category was not one of the potential responses in the original question.

In the case of the three open-ended questions $(33,34$, and 35$)$ a similar reiterative process and clustering were used. As recommended by Ryan \& Bernard in Techniques to Identify Themes (2003), emerging categories were first identified, and then where appropriate, categories were clustered into themes. A theme was considered emergent when $20 \%$ or more of the 
respondents identified with a particular concept or idea, while an emerging category required identification by just $5 \%$ of respondents.

Telephone interviews, open-ended online interview questions and closed-ended questions from the online survey provided both quantitative and qualitative data. Triangulation of data within the survey instrument was utilized to support findings when appropriate.

\section{Statistical Analysis}

Basic statistical analysis was conducted. Mode (Mo), Median (Mdn), mean (M), standard deviation (SD), and CI at a 95\% CL were determined. Methods were as follows:

- Mo is the response that appeared most often in the data set for an individual question;

- Mdn was determined by arranging the data in order of magnitude and selecting the middle score for the data set;

- M was determined using Survey Monkey statistical analysis tools, and is calculated as follows:

$$
M=\frac{\sum R}{n}
$$

where $\mathrm{R}=$ responses, and $\mathrm{n}=$ total number of respondents;

- SD was determined using Survey Monkey statistical analysis tools, and was calculated as follows:

$$
S D=\sqrt{\frac{\sum(x-\bar{x})^{2}}{n-1}}
$$

where $S D$ is the sample standard deviation, $x$ is the respondent value, $\bar{x}$ is the sample mean, and $n$ is the number of respondents; and

- Confidence interval of the mean, was determined as follows: 


$$
\bar{x} \pm c v_{t} * \frac{s}{\sqrt{n}}
$$

where $\bar{x}$ is the sample mean, $s$ is the sample standard deviation, $n$ is the sample size, and $c v$ is the critical values for confidence intervals for means at the $95 \%$ confidence level (CL). The following $c v$ values were used in calculating the confidence interval:

- Aggregated data where $\mathrm{n}$ is between 458-478, and CL $=95 \%: c v_{t}=1.97$;

- Disaggregated data for women where $\mathrm{n}=121$, and $\mathrm{CL}=95 \%: c v_{t}=1.98$;

- $\quad$ Disaggregated data for men where $\mathrm{n}=327$, and $\mathrm{CL}=95 \%: c v_{t}=1.97$;

- Disaggregated data for astronomers at academic institutions where $\mathrm{n}=217$, and $\mathrm{CL}=$ $95 \%: c v_{t}=1.97$

- Disaggregated data for astronomers at non-academic institutions where $\mathrm{n}=168$, and CL $=95 \%: c v_{t}=1.97$.

In an ideal situation with a symmetrically distributed data set, the Mo, Mdn, and M would all be equal. However, a number of the data sets in this study contained strong outliers and did not have a normal Gaussian distribution. Caution is urged when drawing conclusions from the $\mathrm{M}$ value in these cases. When dealing with data sets that do not follow a normal distribution curve, the central tendency can be better indicated by the Mdn or Mo values than the M (Laerd Statistics, 2017).

Data in the tables and charts that follow are coded one (1), two (2), three (3), etc., depending on the number of answer options available to the respondent. One (1) will always indicate lowest frequency of engagement or lowest level of importance. Also, statistical data in the tables below use the following abbreviations:

- $\mathrm{CI}$ - Confidence Interval;

- Mo-mode; 
- $\quad M d n-$ median;

- $\mathrm{M}-$ mean;

- $\mathrm{Mw}$ - mean of women who responded;

- $\quad \mathrm{Rw}$ - response from women as a percentage or count of women who responded;

- $\mathrm{Mm}$ - mean of men who responded;

- $\mathrm{Rm}$ - response from men as a percentage or count of men who responded;

- $\mathrm{Ma}-$ mean of astronomers at academic institutions who responded (unless otherwise noted in the table, Ma includes only individuals who responded "at a K-12 education institution", "at a 2-year academic institution", or "at a college or university", to question two (2) in reference to employment status);

- $\mathrm{Ra}$ - response from astronomers at academic institutions as a percentage or count of the astronomers from academic institutions (unless otherwise noted in the table, Ra includes only individuals who responded "at a K-12 education institution”, "at a 2-year academic institution", or "at a college or university", to question two (2) in reference to employment status);

- $\mathrm{Mn}$ - mean of astronomers at non-academic institutions who responded (Unless otherwise noted in the table Mn includes only individuals who responded "at an informal science education institution", "in private industry", "at a research facility supported by government”, “at a non-research institution supported by government", “at an NGO”, or "I am self-employed" to question two (2) in reference to employment status);

- $\mathrm{Rn}$ - response from astronomers at non-academic institutions as a percentage or count of the astronomers from non-academic institutions (Unless otherwise noted in the table Rn includes only individuals who responded "at an informal science education institution", 
"in private industry", "at a research facility supported by government", "at a non-research institution supported by government", "at an NGO", or "I am self-employed" to question two (2) in reference to employment status);

- $\mathrm{RC}-$ Response Count. This is the total number of individuals that responded to a particular question;

- SD - Standard Deviation;

- (\#) - In the figures that follow, there are cases where there is insufficient room to fully label the $\mathrm{x}$-axis of a chart. In those cases, the corresponding code from the related data table is used to label the different responses.

The relative frequency tables present data as well as the results of statistical analysis. While relative frequency tables will vary, Figure 4.1 below provides a general explanation of table format and where various pieces of information are located within the table.

\begin{tabular}{|c|c|c|c|c|c|c|c|c|}
\hline $\begin{array}{l}\text { Number of } \\
\text { individuals who } \\
\text { chose a response }\end{array}$ & \multicolumn{7}{|c|}{$\begin{array}{l}\text { Q20 - In your work as an astronomer, on average over the past year, what } \\
\text { percentage of your time was spent working at your computer and/or } \\
\text { tablet (e.g. iPad, etc.)? }\end{array}$} & $\begin{array}{l}\text { Question from } \\
\text { online survey }\end{array}$ \\
\hline \multirow{9}{*}{$\begin{array}{l}\text { In this example the } \\
\text { responses are coded } 1 \\
\text { through } 10 . \text { The } \\
\text { number inside the } \\
\text { parenthesis is the } \\
\text { coded value. Note the } \\
\text { Mo, } \mathrm{M}, \mathrm{SD} \text {, and the CI } \\
\text { of the } \mathrm{M} \text { all correspond } \\
\text { to the coded value for } \\
\text { responses. }\end{array}$} & $\begin{array}{l}\text { \% of Time Working at } \\
\text { Computer and/er Tablet }\end{array}$ & $\begin{array}{l}\text { All } \\
\text { RC }\end{array}$ & $\begin{array}{l}\text { All } \\
\text { Response } \\
\%\end{array}$ & $\underset{\%}{\mathbf{R w}}$ & $\underset{\%}{\mathbf{R m}}$ & $\begin{array}{c}\mathbf{R a} \\
\%\end{array}$ & $\begin{array}{c}\mathbf{R n} \\
\%\end{array}$ & \multirow{4}{*}{$\begin{array}{l}\text { Response as a \% of } \\
\text { the total number of } \\
\text { respondents for a } \\
\text { population (e.g. } \\
\text { women, men, all) }\end{array}$} \\
\hline & (1) $0-10 \%$ & 6 & 1.3 & 0.0 & 1.5 & 0.4 & 0.6 & \\
\hline & (2) $10-20 \%$ & 10 & 2.1 & 0.8 & 2.4 & 1.8 & 1.2 & \\
\hline & (3) $20-30 \%$ & 14 & 3.0 & 0.0 & 4.2 & 4.0 & 1.2 & \\
\hline & (4) $30-40 \%$ & 16 & 3.4 & 1.7 & 4.2 & 1.8 & 3.5 & \multirow{4}{*}{$\begin{array}{l}\text { Total number of } \\
\text { individuals who } \\
\text { answered the } \\
\text { question }\end{array}$} \\
\hline & (5) $40-50 \%$ & 22 & 4.7 & 3.3 & 5.4 & 4.8 & 4.6 & \\
\hline & (6) $50-60 \%$ & 33 & 7.0 & 5.0 & 8.1 & 7.9 & 6.3 & \\
\hline & (7) $60-70 \%$ & 46 & 9.8 & 7.4 & 10.8 & 12.7 & 6.3 & \\
\hline & (8) $70-80 \%$ & 115 & 24.5 & 19.8 & 26.0 & 21.9 & 30.5 & \multirow{5}{*}{$\begin{array}{l}\text { Total number of } \\
\text { individuals who } \\
\text { skipped the } \\
\text { question }\end{array}$} \\
\hline \multirow{2}{*}{ Mean of coded value } & (9) $80-90 \%$ & 90 & 19.2 & 28.9 & 15.6 & 20.6 & 18.4 & \\
\hline & (10) $90-100 \%$ & 117 & 24.9 & 33.1 & 21.9 & 24.1 & 27.6 & \\
\hline \multirow{3}{*}{$\begin{array}{c}\text { Confidence interval of } \\
\text { the mean }\end{array}$} & Answered Question (RC) & & 469 & 121 & 334 & 228 & 174 & \\
\hline & Skipped Question & & $9-$ & 3 & 6 & 5 & 2 & \\
\hline & Mo & & $(10)-$ & $(10)$ & $(8)$ & $(10)$ & $(8)$ & \multirow{3}{*}{$\begin{array}{l}\text { Mode - coded value } \\
\text { most frequently } \\
\text { selected }\end{array}$} \\
\hline Median of coded value & $\mathbf{M}$ & & 7.81 & 8.56 & 7.54 & 7.86 & 8.10 & \\
\hline \multirow{3}{*}{$\begin{array}{l}\text { Standard deviation for } \\
\text { the coded value mean }\end{array}$} & CI of the $\mathrm{M}$ & & 0.19 & 0.28 & 0.24 & 0.27 & 0.28 & \\
\hline & Mdn & & 8.0 & 9.0 & 8.0 & 8.0 & 8.0 & \\
\hline & $\longrightarrow$ SD & & 2.15 & 1.56 & 2.25 & 2.04 & 1.88 & \\
\hline
\end{tabular}

Figure 4.1. Relative Frequency Tables Explained. The figure above outlines information typically found in the tables presented throughout Chapter 4. 


\section{Overview of Major Findings}

This study presents a great deal of data and significant opportunity for additional research. The major findings are listed below.

- The vast majority of U.S. astronomers are white: $91 \%$ of the respondents identified their ethnicity as white.

- U.S. Astronomers are "older:" more than $65 \%$ of U.S. astronomers have been practicing for more than 20 years.

- Today, approximately $27 \%$ of U.S. astronomers are women, but this demographic may be changing. Women astronomers make up 19\% of U.S. astronomers with more than 15 years of experience, however women make up 50\% of U.S. astronomers with less that 15 years of experience. It is important to note that this finding may also be attributed to the "leaky pipeline" in astronomy.

- Overall, there are minimal differences in the practice of astronomy as experienced by women and men, and between astronomers at academic and non-academic institutions.

- Thinking critically, respect for evidence, honesty, objectivity, commitment, openness to uncertainty, imagination, not rushing to judgment, and intuition are attitudes that U.S. astronomers consider either of much importance or extreme importance in the practice of astronomy.

- U.S. astronomers today spend, on average, just 10-20 hours per year at the instrument (e.g., telescope) collecting data for their research.

- U.S. astronomers spend on average $70 \%$ of their time working at a computer, I-pad, or similar device. 
- U.S. Astronomers engage in multiple research projects (nearly 5 on average) at the same time.

- U.S. astronomers do not just use models to organize and explain observations, they use them to come up with new questions, and develop new hypothesis.

- The most common types of data used by U.S. astronomers in their research include images and spectral line or continuum data from visible light and infrared telescopes.

- Arithmetic, algebra, and statistics are the types of mathematics most frequently used by U.S. astronomers.

- Research projects in astronomy, on average, take approximately 2 years to complete.

- The performance of administrative/management duties and other bureaucratic tasks are identified by U.S. astronomers as the most frequent social interaction they engage in, as well as something they would like to do less of.

- U.S. astronomers would like to engage in more education and public outreach activities, and this is equally true for both men and women.

- Astronomers spend a lot of time writing. More than $70 \%$ of U.S. astronomers are considered an author or co-author on 40 or more research publications.

- U.S. astronomers collaborate with 6-10 colleagues per week.

- U.S. astronomers have more limited collaborations internationally and with scientists from other disciplines. Fifty-five (55) percent report three (3) or fewer collaborations annually with colleagues in another country, and 51\% report no collaborations annually with colleagues in a science/engineering discipline outside astronomy. 
- U.S. astronomers at non-academic institutions have a greater number of collaborators in general, as well as more collaborations with individuals outside astronomy, compared to astronomers at academic institutions.

- The primary factors that influenced U.S. astronomers in their career choice fall into three categories; pop culture, a personal experience, and a mentor.

- The exploratory nature of astronomy and making discoveries, and sharing (e.g. mentoring, teaching, education and public outreach (EPO)) with others are the things that make astronomy most meaningful to U.S. astronomers.

- The vast majority of the changes in astronomy education recommended by U.S. astronomers are in alignment with the major U.S. science education reform initiatives.

\section{Demographics of Astronomer Participants}

The respondents in this study are reflective of the current U.S. astronomy community. Approximately half are from academic institutions, and half from non-academic institutes. The majority (73\%) are white males. Respondents, by a large margin $(95 \%)$, have earned a PhD. These individuals also practice in a wide variety of astronomy sub disciplines, but a large majority identify astrophysics, observational astronomy, extra galactic, or stellar astronomy as their primary area(s) of focus. Most U.S. astronomers (75\%) from this study have been practicing in the field for more than 15 years, and on average astronomers have been employed at more than three (3) different institutions.

\section{Employment Status, Gender and Ethnicity}

Table 4.1 below combines responses from questions one and four from the survey and identifies the gender and institution-type affiliation for the sample population. According to 
Impy (2006) 54\% of astronomers are employed at colleges and universities, and the remainder are at various non-academic institutions. In addition, roughly $28 \%$ of astronomers today are women (Kirkpatrick, 2014). When it comes to institutional affiliation, not including those who responded "other" or "retired but still active in the field of astronomy," there were 409 respondents: 233 from academic institutions and 176 from non-academic institutions. It is only these 409 respondents that are considered in Mo, M, SD, or CI for the academic institution, and non-academic institution sub-groups. The sample of astronomers in this study closely reflects that of the national demographic with $57 \%$ of respondents from academic institutions, and women making up $27 \%$ of respondents.

Table 4.1

Employment status and gender of U.S. astronomer participants.

\begin{tabular}{|c|c|c|c|}
\hline Current Employment Status & $\begin{array}{l}\text { All } \\
\text { RC }\end{array}$ & Rw \# & $\mathbf{R m} \#$ \\
\hline - College or university & 231 & 60 & 164 \\
\hline - $\mathrm{K}-12$ education institution & 1 & 0 & 1 \\
\hline $\begin{array}{l}\text { - 2-year academic institution (e.g. community college, } \\
\text { technical school) }\end{array}$ & 1 & 0 & 1 \\
\hline Total from Academic Institute & 233 & 60 & 166 \\
\hline $\begin{array}{l}\text { - Informal science education institution (e.g. museum, } \\
\text { science center, planetarium, etc.) }\end{array}$ & 4 & 1 & 3 \\
\hline - $\quad$ Private industry & 12 & 4 & 7 \\
\hline $\begin{array}{l}\text { - Research facility supported by government (e.g. National } \\
\text { Observatory, NASA, etc.) }\end{array}$ & 147 & 43 & 101 \\
\hline $\begin{array}{l}\text { - Non-research institution supported by government (e.g. } \\
\text { NSF, serving an internship on Capitol Hill, etc.) }\end{array}$ & 2 & 0 & 2 \\
\hline - $\quad \mathrm{NGO}$ & 9 & 2 & 7 \\
\hline - $\quad$ Self employed & 2 & 0 & 2 \\
\hline Total from Non-Academic Institute & 176 & 50 & 122 \\
\hline Total retired but still active in the field of astronomy & 50 & 8 & 40 \\
\hline Total "other" & 14 & 6 & 8 \\
\hline
\end{tabular}




\begin{tabular}{|r|r|r|r|}
\hline Answered Question (RC) & 473 & 124 & 336 \\
\hline Skipped Question 2 & 5 & 0 & 4 \\
\hline
\end{tabular}

Approximately $69 \%$ of U.S. scientists are white, and $73.5 \%$ of those employed as physicists or astronomers are white (see Table 2.2). Based on the data from this study, U.S. astronomy remains heavily dominated by whites and is not reflective of the U.S. population. Approximately $91 \%$ of respondents identify themselves as white (see Table 4.2 ). This finding is in agreement with recent studies that estimate $90 \%$ of professional astronomers are white (Sokal, 2016).

Table 4.2

Ethnicity of U.S. astronomer participants.

Q5 - Ethnicity (Please feel free to skip this question if you would like.) Select all that apply.

\begin{tabular}{|c|c|c|c|c|c|c|}
\hline Ethnicity & $\begin{array}{l}\text { All } \\
\text { RC }\end{array}$ & $\begin{array}{c}\text { All } \\
\text { Response } \\
\% \\
\end{array}$ & $\begin{array}{c}\text { Rw } \\
\%\end{array}$ & $\underset{\%}{\mathrm{Rm}}$ & $\begin{array}{l}\mathrm{Ra} \\
\%\end{array}$ & $\begin{array}{l}\mathrm{Rn} \\
\%\end{array}$ \\
\hline Asian / Pacific Islander & 30 & 6.7 & 8.3 & 5.8 & 6.9 & 8.3 \\
\hline Black or African American & 4 & 0.9 & 0.8 & 0.9 & 0.9 & 1.2 \\
\hline Hispanic or Latino & 14 & 3.1 & 3.3 & 3.1 & 3.2 & 3.0 \\
\hline Native American or American Indian & 4 & 0.9 & 0.0 & 1.2 & 0.5 & 1.8 \\
\hline White & 410 & 90.9 & 89.3 & 91.7 & 90.8 & 88.8 \\
\hline Other & 11 & 2.4 & 1 & & & $\theta$ \\
\hline Answered Question (RC) & \multicolumn{2}{|c|}{451} & 121 & 327 & 217 & 169 \\
\hline Skipped Question & \multicolumn{2}{|c|}{27} & 3 & 13 & 16 & 7 \\
\hline
\end{tabular}

\section{Degree(s) Earned}

The vast majority of astronomers today earn a $\mathrm{PhD}$ (Impey, 2012). The findings of this study (see Table 4.3) support those of Impey with more than $95 \%$ of respondents having earned a PhD. 
Table 4.3

Degree(s) earned by U.S. astronomer participants.

\begin{tabular}{|l|c|c|}
\hline \multicolumn{1}{|c|}{ Q3 - Please select all degrees completed. } \\
\hline Degree(s) Completed & $\begin{array}{c}\text { All } \\
\text { Response } \\
\text { Percent }\end{array}$ & $\begin{array}{c}\text { All } \\
\text { RC }\end{array}$ \\
\hline PhD & $95.4 \%$ & 456 \\
\hline MD & $1.1 \%$ & 5 \\
\hline MA & $14.0 \%$ & 67 \\
\hline MS & $45.4 \%$ & 217 \\
\hline MBA & $0.4 \%$ & 2 \\
\hline MPH & $1.1 \%$ & 5 \\
\hline BS & $52.7 \%$ & 252 \\
\hline BA & $25.9 \%$ & 124 \\
\hline JD & $0.0 \%$ & 0 \\
\hline $\begin{array}{l}\text { Other professional/health } \\
\text { degrees (e.g. EDM, EDD, } \\
\text { DDS, DVM) }\end{array}$ & $0.6 \%$ & 3 \\
\hline \multicolumn{3}{|c|}{ Answered Question (RC) } \\
\hline \multicolumn{2}{|c|}{ Skipped Question } & 478 \\
\hline
\end{tabular}

\section{Research and Associated Astronomy Sub-disciplines}

Table 4.4 below indicates the frequency at which U.S. astronomers identify their research being associated with various astronomy sub-disciplines. While U.S. astronomers engage in a variety of astronomy sub-disciplines five sub-disciplines were identified by more than $20 \%$ of respondents as work/research focus areas: observational astronomy (49.8\%), astrophysics (46\%), extragalactic astronomy (31.6\%), stellar astronomy (31\%), and galactic astronomy (23.6\%). There is also a small difference between sub-discipline focus area and institution type. Respondents with a focus in extragalactic astronomy are more likely to be located at academic institutions, and respondents with a focus in planetary science are more likely to be from nonacademic institutions. It is also important to note that no women respondents identified celestial mechanics as an area of focus for their work. 
Table 4.4

Current area(s) of research for U.S. astronomer participants.

Q6 - Into which astronomy sub-discipline(s) is your current professional scientific work and/or research best categorized? (Please check all that apply.)

\begin{tabular}{|c|c|c|c|c|c|c|}
\hline Astronomy Sub-discipline & $\begin{array}{l}\text { All } \\
\text { RC }\end{array}$ & $\begin{array}{c}\text { All } \\
\text { Response } \\
\%\end{array}$ & $\begin{array}{c}\text { Rw } \\
\%\end{array}$ & $\underset{\%}{\mathbf{R m}}$ & $\begin{array}{c}\text { Ra } \\
\%\end{array}$ & $\begin{array}{c}\text { Rn } \\
\%\end{array}$ \\
\hline Archaeoastronomy & 2 & 0.4 & 0.0 & 0.6 & 0.4 & 0.0 \\
\hline Astrobiology & 15 & 3.1 & 1.6 & 3.8 & 2.6 & 4.6 \\
\hline Astrochemistry & 21 & 4.4 & 3.2 & 4.7 & 2.2 & 7.4 \\
\hline Astroengineering & 14 & 2.9 & 0.8 & 3.8 & 1.3 & 5.1 \\
\hline Astrometry & 47 & 9.8 & 5.6 & 11.5 & 9.0 & 11.4 \\
\hline Astronomy Education & 51 & 10.7 & 7.3 & 11.5 & 9.9 & 9.1 \\
\hline Astrophysics & 220 & 46.0 & 45.2 & 46.5 & 50.6 & 44.3 \\
\hline Celestial mechanics & 19 & 4.0 & 0.0 & 5.6 & 3.0 & 4.0 \\
\hline Computational astronomy & 71 & 14.9 & 8.9 & 16.8 & 16.3 & 13.1 \\
\hline Physical cosmology & 26 & 5.4 & 4.0 & 5.6 & 6.4 & 4.6 \\
\hline Extragalactic astronomy & 151 & 31.6 & 37.1 & 28.8 & 36.9 & 29.0 \\
\hline Galactic astronomy & 113 & 23.6 & 21.0 & 25.0 & 22.3 & 24.4 \\
\hline Gamma-ray astronomy & 22 & 4.6 & 2.4 & 5.6 & 6.0 & 4.6 \\
\hline Gravitational-wave astronomy & 11 & 2.3 & 2.4 & 2.4 & 2.6 & 2.8 \\
\hline Neutrino astronomy & 3 & 0.6 & 0.8 & 0.6 & 0.9 & 0.6 \\
\hline Observational astronomy & 238 & 49.8 & 50.0 & 49.4 & 48.5 & 52.3 \\
\hline Planetary science & 82 & 17.2 & 16.9 & 17.6 & 13.3 & 21.6 \\
\hline Radio astronomy & 86 & 18 & 14.5 & 18.8 & 16.3 & 19.9 \\
\hline Solar Astronomy & 32 & 6.7 & 4.0 & 7.6 & 4.7 & 10.2 \\
\hline Stellar astronomy & 148 & 31.0 & 25.8 & 33.8 & 33.1 & 28.4 \\
\hline X-ray astronomy & 67 & 14.0 & 15.3 & 13.5 & 16.7 & 14.8 \\
\hline Other & 46 & 9.6 & & & & $\mathbb{Z O H}$ \\
\hline Answered Question (RC) & \multicolumn{2}{|c|}{478} & 124 & 340 & 233 & 176 \\
\hline Skipped Question & \multicolumn{2}{|c|}{0} & 0 & 0 & 0 & 0 \\
\hline
\end{tabular}

In question six, 46 respondents selected "Other" and provided additional comments about their current areas of research. Based on these comments, additional sub-disciplines or areas of research have been identified in Table 4.5.

Table 4.5 
Other current area(s) of research.

\begin{tabular}{|c|c|}
\hline \multicolumn{2}{|l|}{ Q6 - “Other" Response Summary } \\
\hline Additional Current Research Area Categories & RC \\
\hline Instrument Development & 11 \\
\hline Exoplanets & 5 \\
\hline Infrared Astronomy & 4 \\
\hline Astrostatistics & 3 \\
\hline Star Formation & 3 \\
\hline \# Respondents Who Replied "Other" & 46 \\
\hline
\end{tabular}

\section{Time as a Practicing Astronomer}

Table 4.6 below identifies the number of years U.S. astronomers have been practicing in their field. The vast majority of respondents $(75.2 \%)$ have been practicing astronomers for 15 or more years. Further, the Mdn indicates U.S. astronomers, on average, have been practicing for more than 20 years, while women astronomers have been engaged in their practice for 15 to 20 years. These results support the findings of Impey (2012) that the astronomy community in general is "older".

However, a key demographic of the astronomy community may be changing. Based on data presented in Table 4.6 there is a significant shift in the number of women entering the astronomy profession compared to men. Just over $45 \%$ of women respondents have been practicing astronomers for more than 20 years compared to $73 \%$ of men. Looking at this as a percent of the total number of respondents is revealing as well. Women make up just $19.3 \%$ of U.S. astronomers who have been practicing for more than 15 years. However, women make up $49.9 \%$ of U.S. astronomers who report less than 15 years as a practicing astronomer. If this pattern is real and persists, it could lead to a gender balance within the astronomy research community. It is however important to be cautious in this interpretation of the data. The "leaky pipeline" or loss of women early on in their career within the field of astronomy is well-known 
(Clancy, Lee, Rodgers, \& Richey, 2017; Cheryan, Ziegler, Montoya, \& Jiang, 2016; Ivie, White, \& Chu, 2016). These results are likely influenced, at least in part, by women leaving astronomy early in their career.

Table 4.6

Time as a practicing astronomer.

Q7 - For how many years have you been a practicing astronomer?

\begin{tabular}{|c|c|c|c|c|c|c|}
\hline Answer Options & $\begin{array}{l}\text { All } \\
\text { RC }\end{array}$ & $\begin{array}{c}\text { All } \\
\text { Response } \\
\% \\
\end{array}$ & $\begin{array}{c}\text { Rw } \\
\%\end{array}$ & $\underset{\%}{\mathbf{R m}}$ & $\begin{array}{l}\mathrm{Ra} \\
\%\end{array}$ & $\begin{array}{l}\text { Rn } \\
\%\end{array}$ \\
\hline (1) less than 2 years & 1 & 0.2 & 0.8 & 0.0 & 0.0 & 0.0 \\
\hline (2) between $2-5$ years & 17 & 3.6 & 7.3 & 2.1 & 5.2 & 2.9 \\
\hline (3) between $5-10$ years & 52 & 10.9 & 24.2 & 6.2 & 13.3 & 11.4 \\
\hline (4) between $10-15$ years & 48 & 10.1 & 13.7 & 8.9 & 12.0 & 10.3 \\
\hline (5) between $15-20$ years & 48 & 10.1 & 8.9 & 9.8 & 11.2 & 10.9 \\
\hline (6) more than 20 years & 310 & 65.1 & 45.2 & 73.1 & 58.4 & 64.6 \\
\hline Answered Question (RC) & \multicolumn{2}{|c|}{476} & 124 & 338 & 233 & 175 \\
\hline Skipped Question & \multicolumn{2}{|c|}{2} & 0 & 2 & 0 & 1 \\
\hline Mo & \multicolumn{2}{|c|}{$(6)$} & $(6)$ & $(6)$ & $(6)$ & $(6)$ \\
\hline $\mathbf{M}$ & \multicolumn{2}{|c|}{5.22} & 4.58 & 5.46 & 5.04 & 5.23 \\
\hline $\mathrm{CI}$ of the $\mathrm{M}$ & \multicolumn{2}{|c|}{0.11} & 0.26 & 0.11 & 0.17 & 0.18 \\
\hline $\mathrm{Mdn}$ & \multicolumn{2}{|c|}{6.0} & 5.0 & 6.0 & 6.0 & 6.0 \\
\hline SD & \multicolumn{2}{|c|}{1.22} & 1.47 & 1.02 & 1.30 & 1.19 \\
\hline
\end{tabular}

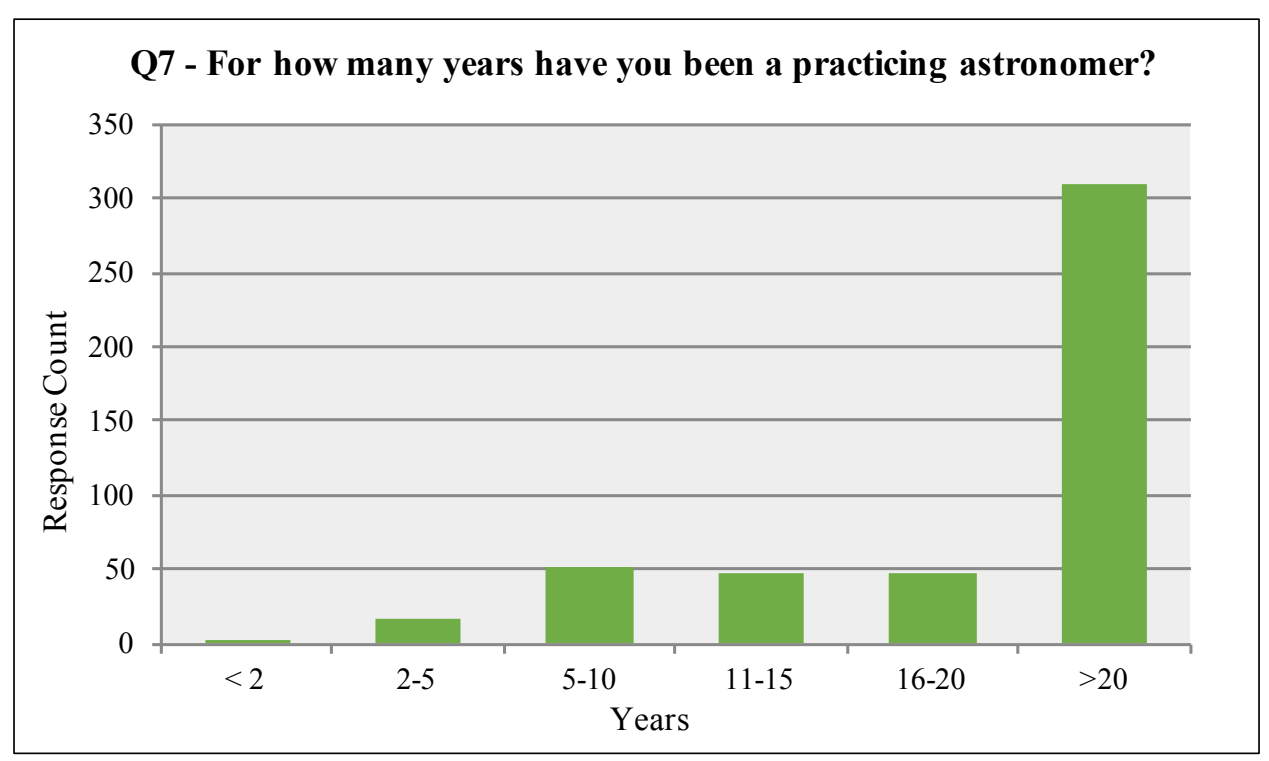


Figure 4.2. Time as a Practicing Astronomer. This figure shows the number of years U.S. astronomers in this study have been practicing in their field.

While astronomy does seem to be moving toward gender balance, if respondents to this survey accurately represent the astronomy community demographics, that does not appear to be the case when it comes to race and ethnicity (see Table 4.7). Participation among African Americans remains flat at $0.9 \%$ and Hispanics show minimal growth. Both Hispanics and African Americans in astronomy remain well below their respective national numbers, while participation of Whites in astronomy remains well above $(+20 \%)$ the Nation's demographics. These findings support those of Impey (2012).

Table 4.7

Ethnicity versus time as an astronomer.

\begin{tabular}{|c|c|c|c|}
\hline \multicolumn{4}{|c|}{ Ethnicity vs. Time as a Practicing Astronomer } \\
\hline Ethnicity & $\begin{array}{c}* \text { U.S. } \\
\text { Demographics }\end{array}$ & $\begin{array}{c}\text { Less Than } 15 \\
\text { Years }\end{array}$ & $\begin{array}{c}\text { More Than } 15 \\
\text { Years }\end{array}$ \\
\hline Asian / Pacific Islander & $4.8 \%$ & $4.5 \%$ & $7.4 \%$ \\
\hline Black or African American & $12.6 \%$ & $0.9 \%$ & $0.9 \%$ \\
\hline Hispanic or Latino/Latina & $16.3 \%$ & $4.5 \%$ & $2.7 \%$ \\
\hline Native American or American Indian & $0.2 \%$ & $0.0 \%$ & $1.2 \%$ \\
\hline White & $72.4 \%$ & $92.8 \%$ & $90.2 \%$ \\
\hline \multicolumn{2}{|r|}{ Answered Question } & 111 & 338 \\
\hline \multicolumn{2}{|r|}{ Skipped Question } & 7 & 20 \\
\hline
\end{tabular}

\section{Employment Change and Time at Institution}

On average U.S. astronomers have been at their current place of employment between 10 and 15 years (see Table 4.8). Women indicate they have been at their current place of employment for fewer years than men, however this may be impacted by the fact that a greater percentage of women than men have been practicing in the field for less than 15 years. It is 
further important to point out that nearly one-third of all respondents indicate they have been at their current place of employment for more than 20 years.

Table 4.8

Time at current place of employment.

Q8 - How long have you been at your current place of employment?

\begin{tabular}{|c|c|c|c|c|c|c|}
\hline Answer Options & $\begin{array}{l}\text { All } \\
\text { RC }\end{array}$ & $\begin{array}{c}\text { All } \\
\text { Response } \\
\%\end{array}$ & $\begin{array}{c}\text { Rw } \\
\%\end{array}$ & $\underset{\%}{\mathrm{Rm}}$ & $\begin{array}{l}\text { Ra } \\
\%\end{array}$ & $\begin{array}{c}\mathrm{Rn} \\
\%\end{array}$ \\
\hline (1) less than 2 years & 46 & 9.8 & 12.2 & 8.7 & 12.1 & 8.1 \\
\hline (2) between $2-5$ years & 75 & 16.0 & 23.6 & 13.2 & 19.5 & 15.5 \\
\hline (3) between $5-10$ years & 79 & 16.8 & 20.3 & 15.3 & 17.3 & 17.2 \\
\hline (4) between $10-15$ years & 61 & 13.0 & 13.0 & 13.2 & 13.9 & 14.4 \\
\hline (5) between $15-20$ years & 57 & 12.2 & 13.0 & 12.0 & 13.0 & 13.2 \\
\hline (6) more than 20 years & 151 & 32.2 & 17.9 & 37.5 & 24.2 & 31.6 \\
\hline Answered Question (RC) & \multicolumn{2}{|c|}{469} & 123 & 333 & 231 & 174 \\
\hline Skipped Question & \multicolumn{2}{|c|}{9} & 1 & 7 & 2 & 2 \\
\hline $\mathrm{Mo}$ & \multicolumn{2}{|c|}{$(6)$} & (2) & (6) & (6) & (6) \\
\hline $\mathbf{M}$ & \multicolumn{2}{|c|}{4.00} & 3.45 & 4.19 & 3.69 & 4.04 \\
\hline CI of the M & \multicolumn{2}{|c|}{0.16} & 0.30 & 0.19 & 0.23 & 0.26 \\
\hline Mdn & \multicolumn{2}{|c|}{4.0} & 3.0 & 4.0 & 4.0 & 4.0 \\
\hline SD & \multicolumn{2}{|c|}{1.76} & 1.67 & 1.75 & 1.75 & 1.71 \\
\hline
\end{tabular}

Q8 - How long have you been at your current place of employment?

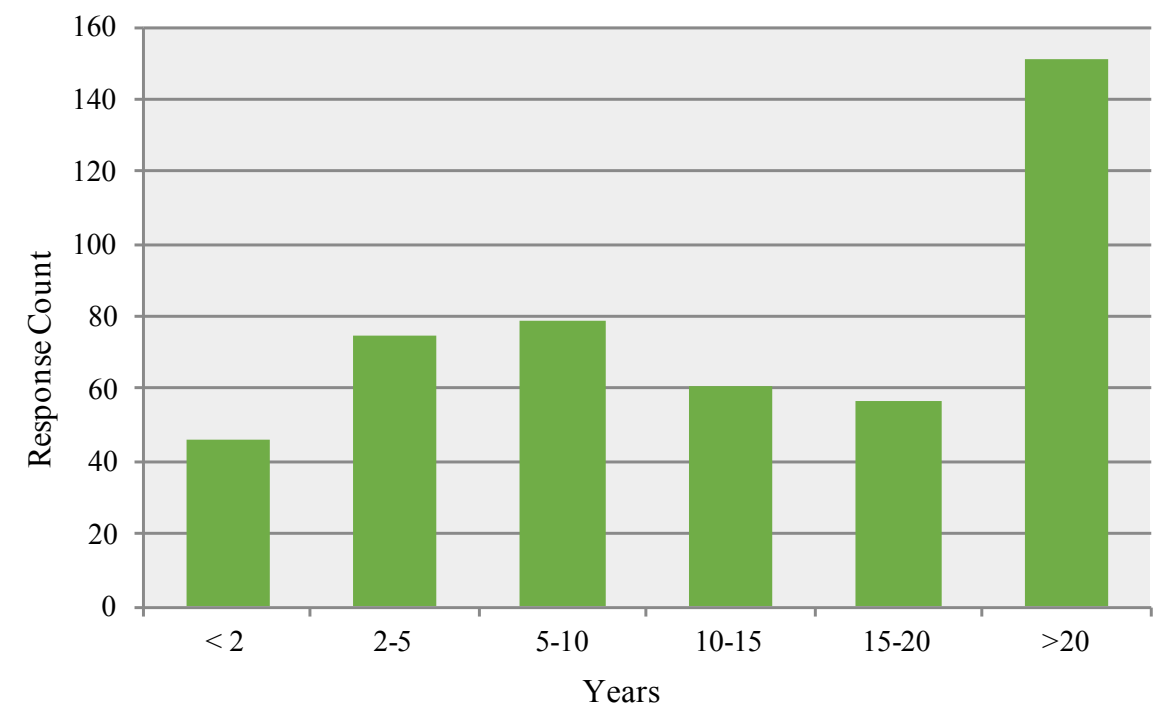


Figure 4.3. Time at Current Place of Employment. The figure above shows how long U.S. astronomers from this study have been at their current place of employment.

According to the U.S. Bureau of Labor Statistics (2016) the average number of years a worker stays with the same employer is 4.2 years. Table 4.9 below identifies the number of different institutions astronomers have been employed at throughout their career. As with most professional jobs today, U.S. astronomers do move from institution to institution. On average, U.S. astronomers have been employed at 3.25 institutions, and have worked in the field for 10-15 years, indicating they stay at the same workplace for approximately the same numbers of years as the average U.S. worker. Further, approximately $40 \%$ of astronomers in the study from nonacademic institutions report being employed at 2 or fewer different institutions, while the same is true for $29 \%$ of astronomers at academic institutions. These findings indicate astronomers at nonacademic institutions change jobs less frequently that those at academic institutions.

Table 4.9

U.S. astronomers' number of institutions employed.

\begin{tabular}{|c|c|c|c|c|c|c|}
\hline \multicolumn{7}{|c|}{$\begin{array}{l}\text { Q9 - Throughout your professional career as a scientist, at how many different } \\
\text { institutions have you been employed? }\end{array}$} \\
\hline Answer Options & $\begin{array}{l}\text { All } \\
\text { RC }\end{array}$ & $\begin{array}{c}\text { All } \\
\text { Response } \\
\%\end{array}$ & $\begin{array}{l}\text { Rw } \\
\%\end{array}$ & $\begin{array}{c}\mathbf{R m} \\
\%\end{array}$ & $\begin{array}{l}\mathrm{Ra} \\
\%\end{array}$ & $\begin{array}{c}\text { Rn } \\
\%\end{array}$ \\
\hline (1) none & 2 & 0.4 & 0.8 & 0.3 & 0.9 & 0.0 \\
\hline (2) 1 institution & 48 & 10.1 & 8.9 & 9.7 & 6.4 & 13.1 \\
\hline (3) 2 institutions & 118 & 24.7 & 33.1 & 21.8 & 21.9 & 27.3 \\
\hline (4) 3 institutions & 132 & 27.7 & 27.4 & 28.3 & 29.2 & 29.0 \\
\hline (5) 4 institutions & 86 & 18.0 & 16.1 & 18.9 & 21.0 & 15.9 \\
\hline (6) 5 institutions & 52 & 10.9 & 6.5 & 12.4 & 13.3 & 7.4 \\
\hline (7) 6 institutions & 19 & 4.0 & 2.4 & 4.7 & 3.0 & 4.0 \\
\hline (8) 7 institutions & 12 & 2.5 & 3.2 & 2.1 & 2.6 & 2.8 \\
\hline (9) 8 institutions & 4 & 0.8 & 0.8 & 0.9 & 0.9 & 0.6 \\
\hline (10) more than 8 institutions & 4 & 0.8 & 0.8 & 0.9 & 0.9 & 0.0 \\
\hline Answered Question (RC) & \multicolumn{2}{|c|}{477} & 124 & 339 & 233 & 176 \\
\hline Skipped Question & \multicolumn{2}{|c|}{1} & 0 & 1 & 0 & 0 \\
\hline Mo & \multicolumn{2}{|c|}{$(4)$} & $(3)$ & $(4)$ & $(4)$ & $(4)$ \\
\hline $\mathbf{M}$ & \multicolumn{2}{|c|}{4.25} & 4.05 & 4.34 & 4.39 & 4.03 \\
\hline
\end{tabular}




\begin{tabular}{|r|c|r|r|r|r|}
\hline CI of the M & 0.14 & 0.28 & 0.17 & 0.20 & 0.22 \\
\hline $\mathrm{Mdn}$ & 4.0 & 4.0 & 4.0 & 4.0 & 4.0 \\
\hline $\mathrm{SD}$ & 1.59 & 1.55 & 1.58 & 1.53 & 1.48 \\
\hline
\end{tabular}

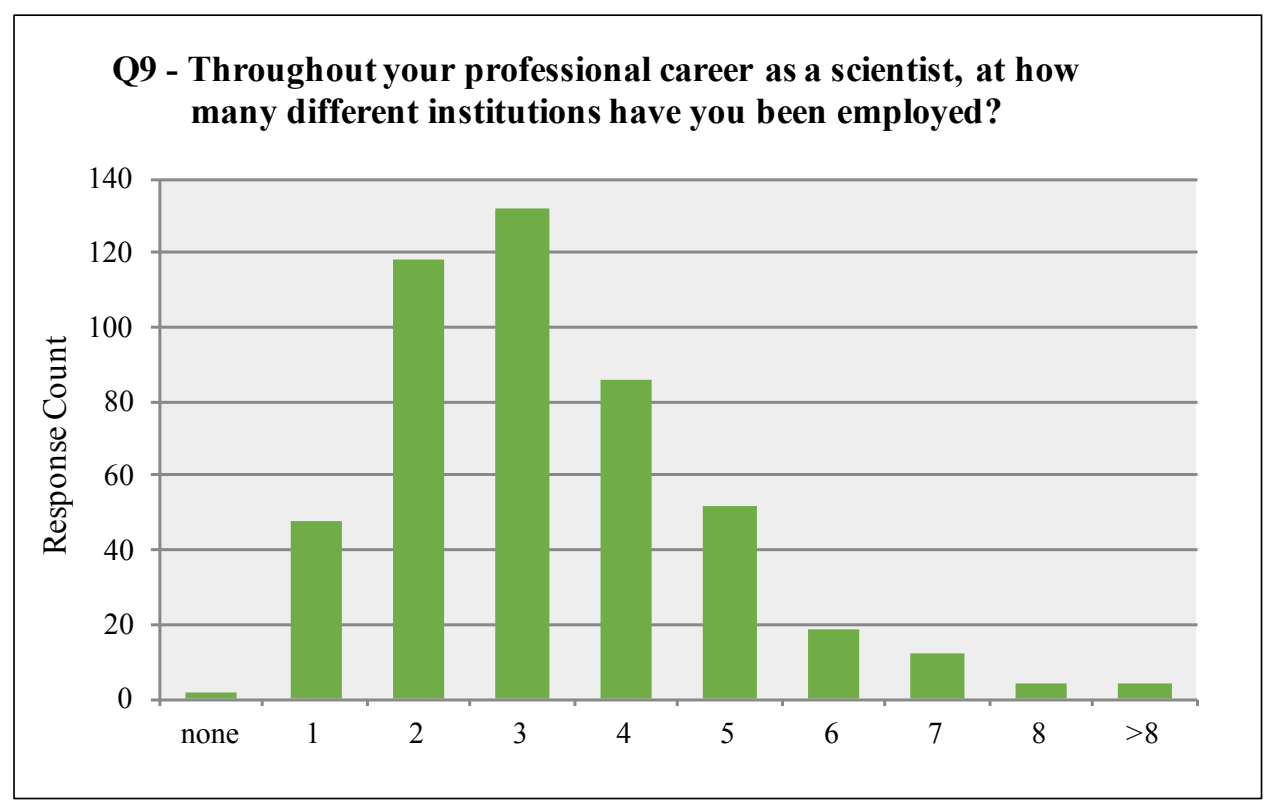

Figure 4.4. U.S. Astronomers and Number of Institutions Employed. The figure above shows the number of different institutions U.S. astronomers from this study have been employed at throughout their career.

In addition, nearly 59\% of U.S. astronomers report working, on average, between 41 and 55 hours per week, while just over $25 \%$ of astronomers report working more than 55 hours per week engaged in job related activities (see Table 4.10). There is no significant difference between the average number of hours worked per week by women compared to men astronomers, or between those working at academic and non-academic institutions.

Table 4.10

Hours worked by U.S. astronomers.

Q30 - As an astronomer, over the past year, what is the average number of hours per week you spent engaged in all work-related activities? 


\begin{tabular}{|c|c|c|c|c|c|c|}
\hline $\begin{array}{c}\text { Hours Per Week } \\
\text { Worked }\end{array}$ & $\begin{array}{l}\text { All } \\
\text { RC }\end{array}$ & $\begin{array}{c}\text { All } \\
\text { Response } \\
\% \\
\end{array}$ & $\begin{array}{c}\mathrm{Rw} \\
\%\end{array}$ & $\begin{array}{c}\mathrm{Rm} \\
\%\end{array}$ & $\begin{array}{l}\text { Ra } \\
\%\end{array}$ & $\begin{array}{l}\mathrm{Rn} \\
\%\end{array}$ \\
\hline (1) $1-10$ & 4 & 1.0 & 0.9 & 1.1 & 1.7 & 0.0 \\
\hline (2) $11-20$ & 3 & 0.7 & 0.0 & 1.1 & 0.4 & 1.1 \\
\hline (3) $21-30$ & 12 & 3.0 & 0.9 & 3.5 & 3.5 & 2.3 \\
\hline (4) $31-35$ & 9 & 2.2 & 4.6 & 1.4 & 2.6 & 1.7 \\
\hline (5) $36-40$ & 34 & 8.4 & 10.1 & 6.7 & 8.7 & 8.0 \\
\hline (6) $41-45$ & 71 & 17.5 & 23.9 & 15.4 & 13.5 & 22.9 \\
\hline (7) $46-50$ & 120 & 29.6 & 22.0 & 32.6 & 27.4 & 32.6 \\
\hline (8) $51-55$ & 49 & 12.1 & 8.3 & 13.7 & 14.8 & 8.6 \\
\hline (9) $56-60$ & 55 & 13.6 & 14.7 & 13.3 & 13.9 & 13.1 \\
\hline (10) $61-65$ & 13 & 3.2 & 4.6 & 2.8 & 3.9 & 2.3 \\
\hline (11) $66-70$ & 18 & 4.4 & 4.6 & 4.6 & 6.1 & 2.3 \\
\hline (12) more than 70 & 17 & 4.2 & 5.5 & 3.9 & 3.5 & 5.1 \\
\hline Answered Question (RC) & \multicolumn{2}{|c|}{405} & 109 & 285 & 230 & 175 \\
\hline Skipped Question & \multicolumn{2}{|r|}{4} & 1 & 3 & 3 & 1 \\
\hline Mo & \multicolumn{2}{|c|}{ (7) } & (6) & (7) & (7) & (7) \\
\hline $\mathbf{M}$ & \multicolumn{2}{|c|}{7.25} & 7.30 & 7.28 & 7.31 & 7.18 \\
\hline $\mathrm{CI}$ of the $\mathrm{M}$ & \multicolumn{2}{|c|}{0.20} & 0.41 & 0.24 & 0.28 & 0.29 \\
\hline Mdn & \multicolumn{2}{|c|}{7.0} & 7.0 & 7.0 & 7.0 & 7.0 \\
\hline $\mathrm{SD}$ & \multicolumn{2}{|c|}{2.09} & 2.15 & 2.07 & 2.19 & 1.95 \\
\hline
\end{tabular}

Note: Individuals who responded "retired" or "other" as their employment status are not included in the data above. 


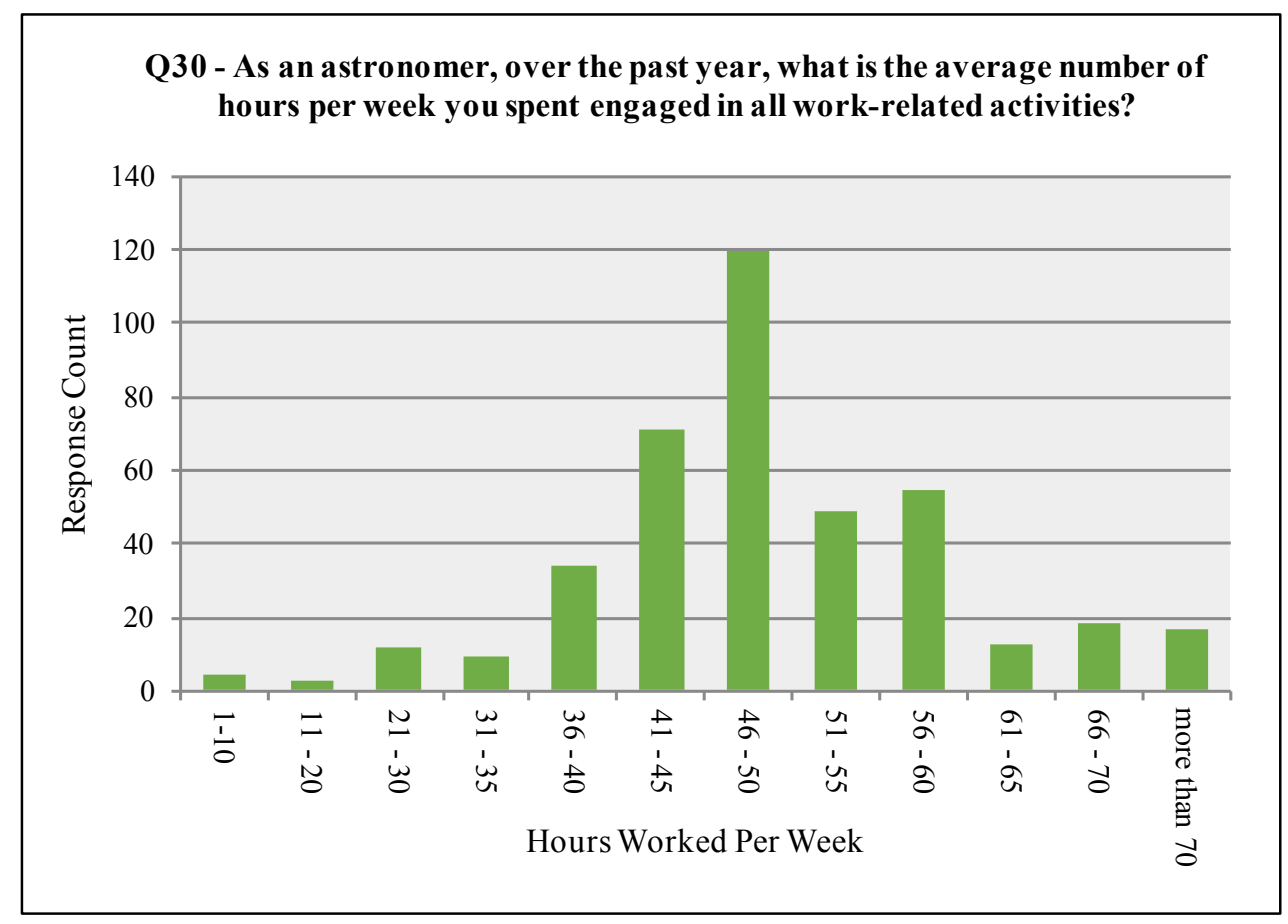

Figure 4.5. Hours Worked by U.S. Astronomers. The figure above shows the number of hours per week, on average, U.S. astronomers from this study engage in work related activities.

\section{Attitudes Practiced by U.S. Astronomers}

- Research Question 1: What science related attitudes are most important to U.S. astronomers in their practice of astronomy?

Scientists find themselves practicing a variety of attitudes through their work (R. D. Anderson, 2002; Bencze, 2000; Chinn \& Malhotra, 2002; Edelson, 2003; Kozlow \& Nay, 1976; Rahm et al., 2003; Robinson, 2004; Zion et al., 2004). More recent science education reform efforts have also called for the engagement of students in the practice of science attitudes. Science for All Americans (Rutherford \& Ahlgren, 1990, pg. 17) states, "Scientists share certain basic beliefs and attitudes about what they do and how they view their work." These attitudes include: 
- the presumption that the universe is understandable, scientific ideas are subject to change,

- acceptance of some uncertainty as part of nature while understanding most scientific knowledge is durable, and

- science cannot provide complete answers to all questions (Rutherford \& Ahlgren, 1990). In addition, Project 2061: Benchmarks for Science Literacy identifies honesty, curiosity, openmindedness and skepticism as habits of mind critical in the practice of science (American Association for the Advancement of Science, 1994). More recently, the Next Generation Science Standards (NGSS) identifies "intellectual honesty, tolerance of ambiguity, skepticism, openness to new ideas, and evidenced-based argumentation as habits of mind that guide those who practice science and engineering” (NGSS Lead States, 2013, pg. 69).

Astronomers consider many of these attitudes of significant importance as well. Of greatest importance in the practice of astronomy is thinking critically, respecting the evidence, honesty, objectivity, commitment, openness to uncertainty, imagination, withholding a rush to judgement, and intuition (see Table 4.11). In addition, while being considerate of others, empathy, and compassion were all inserted into the survey as "distractors", all were considered of average importance or greater. Perhaps most notably is the similarity in the order that men and women, and academic and non-academic astronomers ranked the importance of various attitudes (see Table A.1 in Appendix D). However, one difference did appear, men ranked the importance of intuition in the practice of astronomy significantly higher than women. This may be attributed to the role experience plays in the use of intuition and the fact that women participating in this study reported fewer years of experience practicing astronomy than men.

Table 4.11

Attitudes in the practice of astronomy. 
Q10 - In doing your work as an astronomer, how important are the following attitudes?

(1) no importance, (2) limited importance, (3) average importance, (4) much importance, (5) extreme importance

\begin{tabular}{|l|c|c|c|c|c|c|c|c|c|c|c|}
\hline \multicolumn{1}{|c|}{ Attitude } & $\mathbf{( 1 )}$ & $\mathbf{( 2 )}$ & $\mathbf{( 3 )}$ & $\mathbf{( 4 )}$ & $\mathbf{( 5 )}$ & $\mathbf{R C}$ & $\begin{array}{c}\text { All } \\
\text { Mo }\end{array}$ & $\begin{array}{c}\text { All } \\
\text { M }\end{array}$ & $\begin{array}{c}\text { CI } \\
\text { M }\end{array}$ & Mdn & $\begin{array}{c}\text { All } \\
\text { SD }\end{array}$ \\
\hline Think Critically & 0 & 0 & 3 & 103 & 367 & 473 & $(5)$ & $\mathbf{4 . 7 7}$ & 0.04 & 5.0 & 0.44 \\
\hline Respect for Evidence & 0 & 2 & 10 & 105 & 357 & 474 & $(5)$ & $\mathbf{4 . 7 2}$ & 0.05 & 5.0 & 0.52 \\
\hline Honesty & 0 & 4 & 26 & 108 & 337 & 475 & $(5)$ & $\mathbf{4 . 6 4}$ & 0.06 & 5.0 & 0.63 \\
\hline Objectivity & 0 & 1 & 25 & 151 & 296 & 473 & $(5)$ & $\mathbf{4 . 5 7}$ & 0.05 & 5.0 & 0.60 \\
\hline Commitment & 1 & 1 & 46 & 180 & 245 & 473 & $(5)$ & $\mathbf{4 . 4 1}$ & 0.06 & 5.0 & 0.69 \\
\hline Open to Uncertainty & 0 & 2 & 40 & 196 & 236 & 474 & $(4)$ & $\mathbf{4 . 4 1}$ & 0.06 & 4.0 & 0.66 \\
\hline Imagination & 2 & 10 & 49 & 214 & 199 & 474 & $(4)$ & $\mathbf{4 . 2 6}$ & 0.07 & 4.0 & 0.76 \\
\hline No Rush to Judgment & 2 & 13 & 112 & 209 & 136 & 472 & $(4)$ & $\mathbf{3 . 9 8}$ & 0.07 & 4.0 & 0.82 \\
\hline Intuition & 1 & 19 & 99 & 229 & 126 & 474 & $(4)$ & $\mathbf{3 . 9 7}$ & 0.07 & 4.0 & 0.81 \\
\hline Considerate of Others & 6 & 46 & 172 & 181 & 69 & 474 & $(4)$ & $\mathbf{3 . 5 5}$ & 0.08 & 4.0 & 0.90 \\
\hline Empathy & 25 & 112 & 196 & 109 & 31 & 473 & $(3)$ & $\mathbf{3 . 0 2}$ & 0.09 & 3.0 & 0.97 \\
\hline Compassion & \multicolumn{6}{|c|}{100} & \multicolumn{7}{|c|}{209} & 103 & 30 & 471 & $(3)$ & $\mathbf{3 . 0 1}$ & 0.09 & 3.0 & 0.97 \\
\hline $\begin{array}{l}\text { Responses were randomized in } \\
\text { NOTE: \# Respondents that skipped sub-question }=478-\mathrm{RC}\end{array}$ & & & & & \\
\hline
\end{tabular}




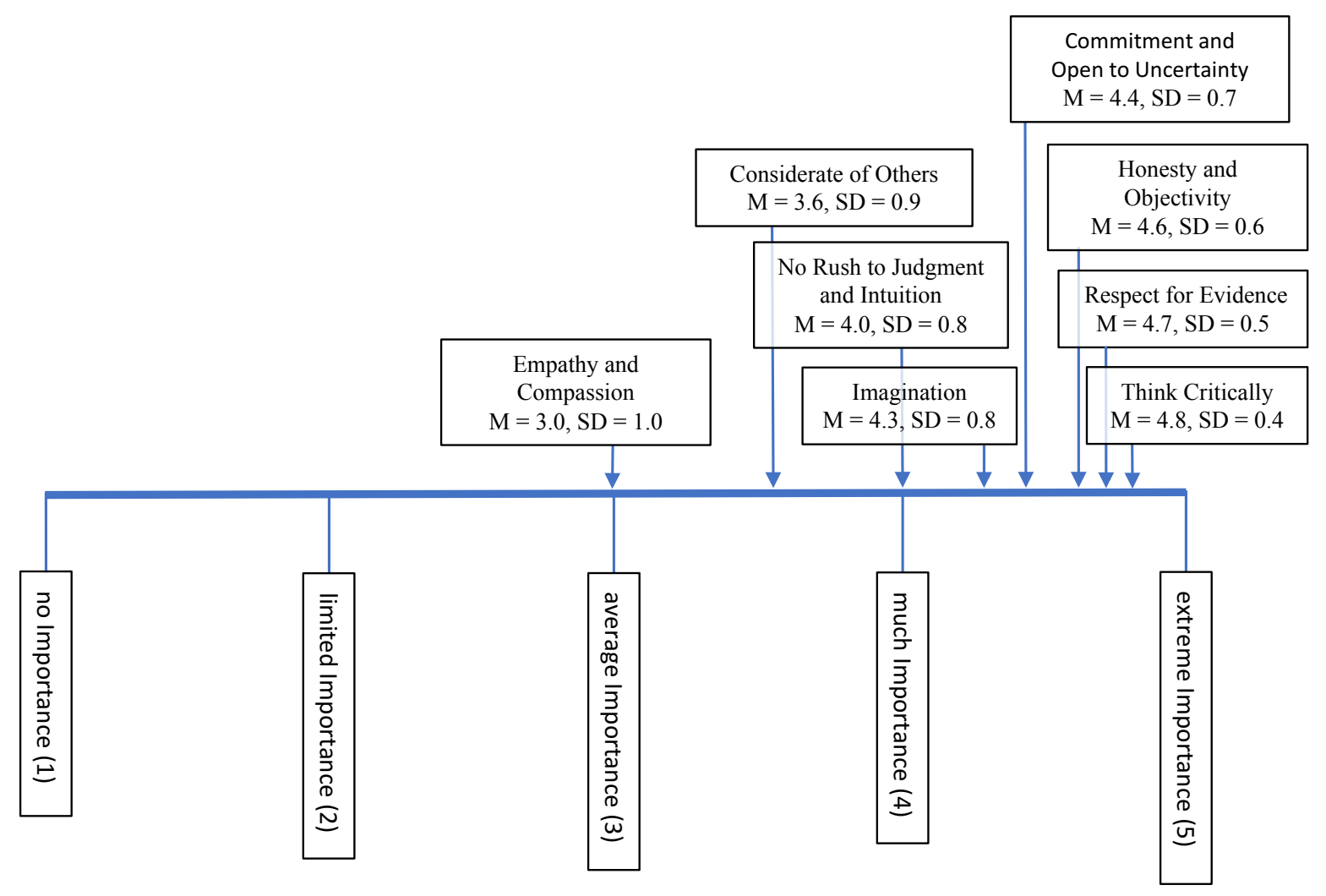

Figure 4.6. Attitudes in the Practice of Astronomy. The figure above shows how U.S. astronomers rank the importance of various attitudes in their practice of astronomy.

Table 4.12 below identifies how important U.S. astronomers feel it is to consider personal bias and opinion, and impact on society in their practice of astronomy. The majority of U.S. astronomers in this study feel it is of either "much importance" or "extreme importance" to consider their own personal bias (68\% of respondents) and opinions ( $56 \%$ of respondents) in their research. Only $24 \%$ of astronomers felt the same when it came to considering the impact their research might have on society (see Table 4.12). While astronomers at non-academic institutions consider the impact their research might have on society more important than those at academic institutions, there were no other significant differences between men and women astronomers or between those employed at academic or non-academic institutions (see Table A.2 in Appendix D). 
Table 4.12

Bias, opinion, and societal impact in astronomy.

\begin{tabular}{|l} 
Q11 - When engaging in your activities as an astronomer, how important is it to consider \\
\hline $\begin{array}{l}\text { (1) no importance, (2) limited importance, (3) average importance, (4) much importance, (5) extreme } \\
\text { importance }\end{array}$ \\
\hline Consideration
\end{tabular}

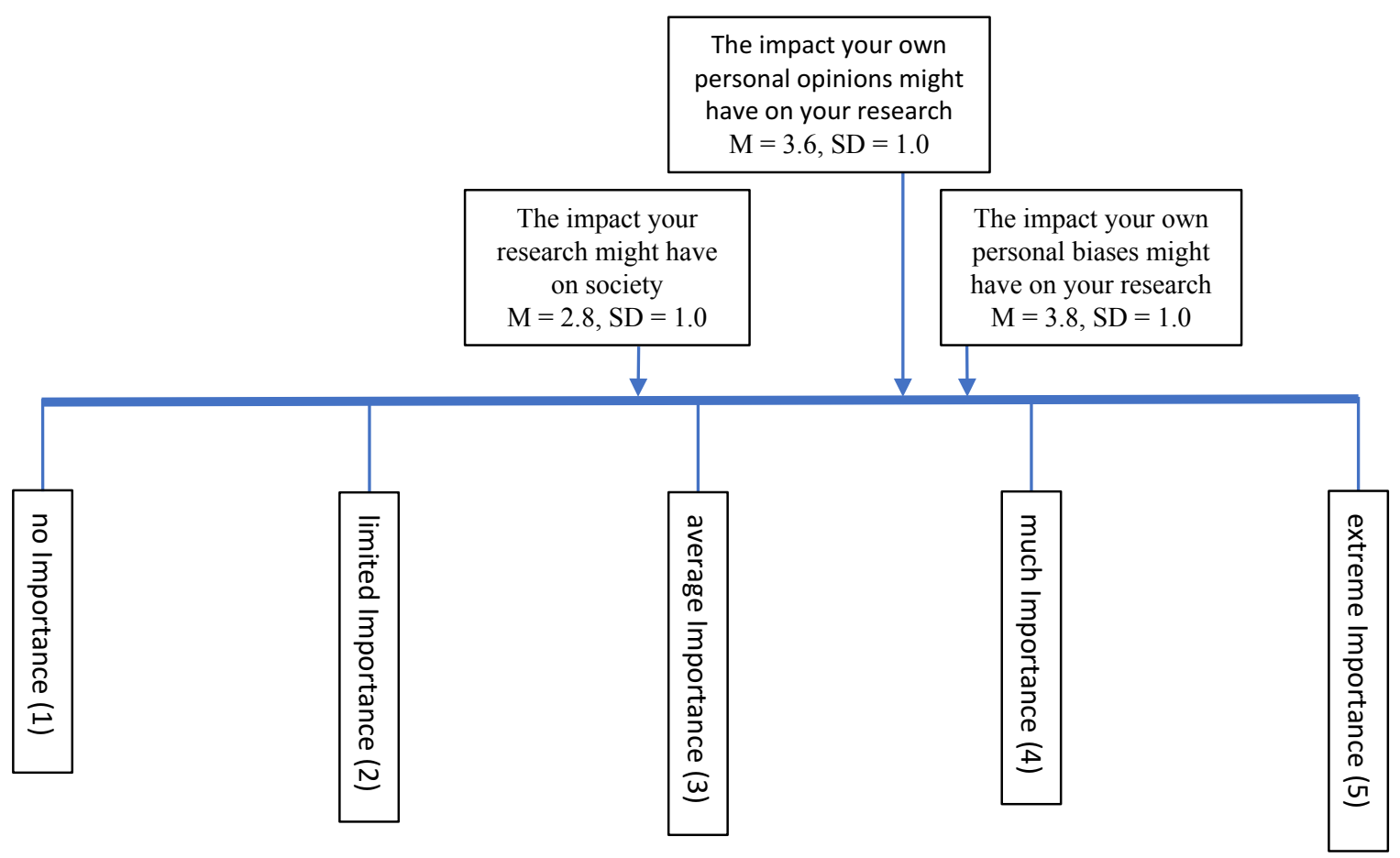


Figure 4.7. Bias, Opinion, and Societal Impact in Astronomy. The figure above indicates how important U.S. astronomers feel it is to consider personal bias and opinion, and impact on society in their practice of astronomy.

\section{Tools and Techniques Used by U.S. Astronomers}

- Research Question 2: What tools and techniques are most frequently used by U.S. astronomers in their practice of astronomy?

Astronomers today use a variety of tools and techniques as they engage in their work and research. Unlike what many might think, the most frequently used tool by astronomers is not the telescope, but rather the computer. While the M indicates U.S. astronomers in this study spent just 10-20 hours a year at the telescope during data collection Mdn more closely represents the actual situation: the majority of astronomers spent no time at the instrument during data collection in the past year. Further, astronomers indicate they engaged in the collection of new data less than once a month on average (see Table 4.13 and Table 4.17), and spent more than $70 \%$ of their time working at their computer completing a variety of tasks. This is significantly greater than the "several hours a day" reported in 2005 by the American Astronomical Society (American Astronomical Society, 2005, p. 3). Women astronomers reported spending significantly more time, on average, at the computer than their male counterparts (see Table 4.14). Historically of course astronomers spent much more time at the telescopes collecting data, but today, many observatories use queue-based observing where a team at the observatory decides, based on sky conditions, moon phase, etc., when the astronomer's request is best completed, and the observation is made absent the astronomer, and sent to them at a later date. 
Further, in some cases, the telescopes today are located in space (e.g. Hubble, Spitzer, etc.) and it is impossible for an observer to travel to the telescope.

Table 4.13

Time spent at the instrument/telescope.

\begin{tabular}{|c|c|c|c|c|c|c|}
\hline $\begin{array}{l}\text { Q16 - In your work as } \\
\text { hours were you at the i } \\
\text { instrument/telescope co } \\
\text { your research project(s }\end{array}$ & rol i & $\begin{array}{l}\text { lomer, ove } \\
\text { nt/telescop } \\
\text { om, when }\end{array}$ & $\begin{array}{l}\text { or in } \\
\text { a we }\end{array}$ & bein & w m & \\
\hline $\begin{array}{l}\text { Hours at the } \\
\text { Instrument/Telescope }\end{array}$ & $\begin{array}{l}\text { All } \\
\text { RC }\end{array}$ & $\begin{array}{c}\text { All } \\
\text { Response } \\
\%\end{array}$ & $\begin{array}{c}\mathrm{Rw} \\
\%\end{array}$ & $\underset{\%}{\mathrm{Rm}}$ & $\begin{array}{l}\mathrm{Ra} \\
\%\end{array}$ & $\begin{array}{l}\mathrm{Rn} \\
\%\end{array}$ \\
\hline (1) none (in the past year) & 264 & 55.7 & 57.3 & 54.8 & 53.7 & 52.8 \\
\hline (2) $1-10$ & 34 & 7.2 & 4.8 & 7.4 & 7.4 & 8.5 \\
\hline (3) $10-20$ & 31 & 6.5 & 6.5 & 6.8 & 6.9 & 6.3 \\
\hline (4) $20-30$ & 19 & 4.0 & 4.8 & 3.9 & 3.0 & 5.7 \\
\hline (5) $30-40$ & 15 & 3.2 & 4.0 & 3.0 & 3.5 & 4.0 \\
\hline (6) $40-50$ & 16 & 3.4 & 3.2 & 3.6 & 2.6 & 4.6 \\
\hline (7) $50-100$ & 41 & 8.6 & 9.7 & 8.0 & 11.3 & 6.3 \\
\hline (8) $100-150$ & 19 & 4.0 & 4.8 & 3.9 & 4.3 & 4.0 \\
\hline (9) $150-200$ & 11 & 2.3 & 1.6 & 2.7 & 2.6 & 2.3 \\
\hline (10) $200-250$ & 5 & 1.1 & 0.0 & 1.5 & 0.9 & 0.6 \\
\hline (11) $250-300$ & 9 & 1.9 & 1.6 & 2.1 & 2.2 & 1.7 \\
\hline (12) more than 300 & 10 & 2.1 & 1.6 & 2.4 & 1.7 & 3.4 \\
\hline Answered Question (RC) & & 474 & 124 & 336 & 231 & 176 \\
\hline Skipped Question & & 4 & 0 & 4 & 2 & 0 \\
\hline Mo & & $(1)$ & $(1)$ & $(1)$ & $(1)$ & $(1)$ \\
\hline $\mathbf{M}$ & & 3.12 & 3.03 & 3.20 & 3.24 & 3.20 \\
\hline CI of the M & & 0.28 & 0.52 & 0.34 & 0.40 & 0.46 \\
\hline $\mathrm{Mdn}$ & & 1.0 & 1.0 & 1.0 & 1.0 & 1.0 \\
\hline SD & & 3.07 & 2.92 & 3.15 & 3.10 & 3.12 \\
\hline
\end{tabular}




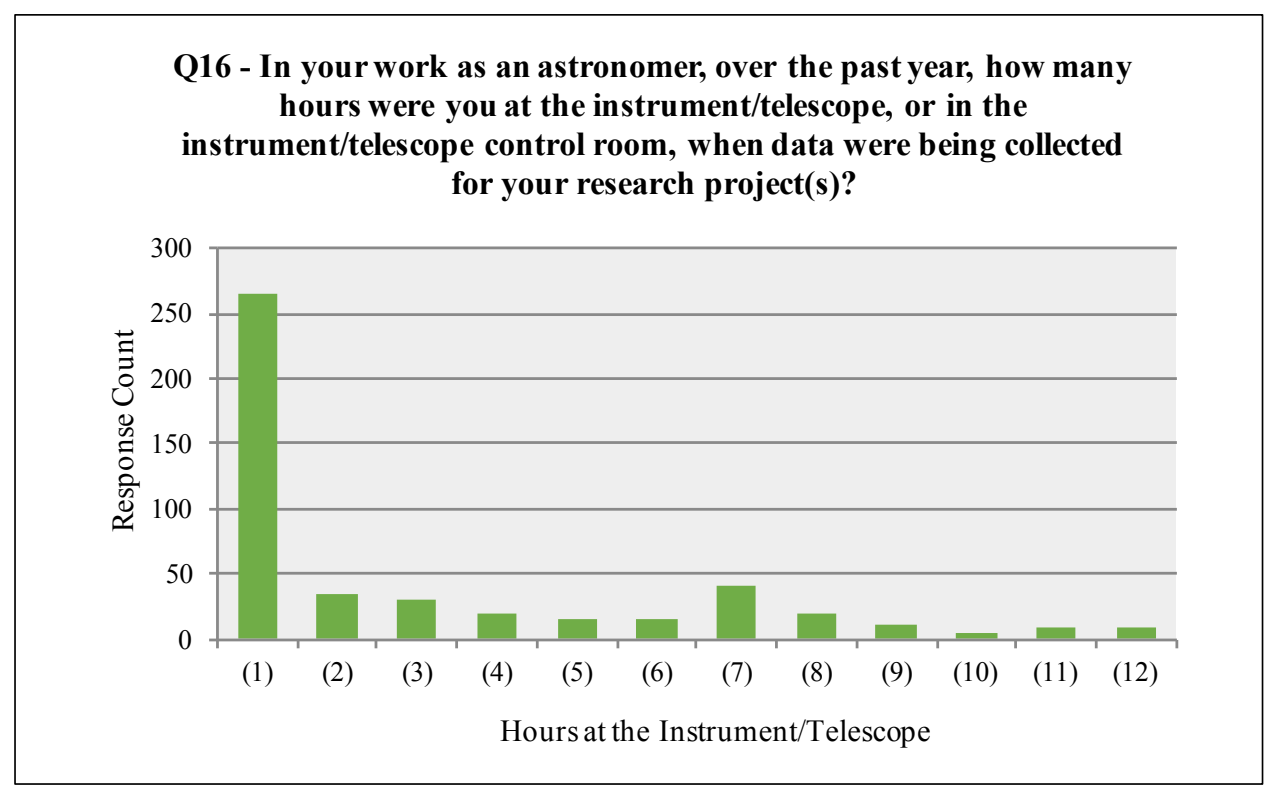

Figure 4.8. Time Spent at the Instrument/Telescope. The figure above shows how much time, on average, U.S. astronomers spend at the instrument/telescope, per year, collecting data.

Table 4.14

Time spent at a computer.

Q20 - In your work as an astronomer, on average over the past year, what percentage of your time was spent working at your computer and/or tablet (e.g. iPad, etc.)?

\begin{tabular}{|c|c|c|c|c|c|c|}
\hline $\begin{array}{l}\% \text { of Time Working at } \\
\text { Computer and/or Tablet }\end{array}$ & $\begin{array}{l}\text { All } \\
\text { RC }\end{array}$ & $\begin{array}{c}\text { All } \\
\text { Response } \\
\%\end{array}$ & $\begin{array}{l}\text { Rw } \\
\%\end{array}$ & $\begin{array}{c}\mathrm{Rm} \\
\%\end{array}$ & $\begin{array}{l}\text { Ra } \\
\%\end{array}$ & $\begin{array}{l}\text { Rn } \\
\%\end{array}$ \\
\hline (1) $0-10 \%$ & 6 & 1.3 & 0.0 & 1.5 & 0.4 & 0.6 \\
\hline (2) $10-20 \%$ & 10 & 2.1 & 0.8 & 2.4 & 1.8 & 1.2 \\
\hline (3) $20-30 \%$ & 14 & 3.0 & 0.0 & 4.2 & 4.0 & 1.2 \\
\hline (4) $30-40 \%$ & 16 & 3.4 & 1.7 & 4.2 & 1.8 & 3.5 \\
\hline (5) $40-50 \%$ & 22 & 4.7 & 3.3 & 5.4 & 4.8 & 4.6 \\
\hline (6) $50-60 \%$ & 33 & 7.0 & 5.0 & 8.1 & 7.9 & 6.3 \\
\hline (7) $60-70 \%$ & 46 & 9.8 & 7.4 & 10.8 & 12.7 & 6.3 \\
\hline (8) $70-80 \%$ & 115 & 24.5 & 19.8 & 26.0 & 21.9 & 30.5 \\
\hline (9) $80-90 \%$ & 90 & 19.2 & 28.9 & 15.6 & 20.6 & 18.4 \\
\hline (10) $90-100 \%$ & 117 & 24.9 & 33.1 & 21.9 & 24.1 & 27.6 \\
\hline Answered Question (RC) & \multicolumn{2}{|r|}{469} & 121 & 334 & 228 & 174 \\
\hline Skipped Question & \multicolumn{2}{|c|}{9} & 3 & 6 & 5 & 2 \\
\hline Mo & \multicolumn{2}{|c|}{ (10) } & $(10)$ & $(8)$ & $(10)$ & $(8)$ \\
\hline $\mathbf{M}$ & \multicolumn{2}{|c|}{7.81} & 8.56 & 7.54 & 7.86 & 8.10 \\
\hline CI of the M & \multicolumn{2}{|c|}{0.19} & 0.28 & 0.24 & 0.27 & 0.28 \\
\hline $\mathrm{Mdn}$ & \multicolumn{2}{|r|}{8.0} & 9.0 & 8.0 & 8.0 & 8.0 \\
\hline
\end{tabular}




\begin{tabular}{l|l|l|l|l|l|} 
SD & 2.15 & 1.56 & 2.25 & 2.04 & 1.88 \\
\hline
\end{tabular}



Figure 4.9. Time Spent at a Computer. The figure above shows the percentage of a U.S. astronomers' workday spent at a computer, tablet, iPad, etc.

Table 4.15 below identifies the number of investigations U.S. astronomers are currently engaged in and Table 4.16 indicates the time period it takes U.S. astronomers to complete an astronomy-related research project from start (the time when an astronomer begins seriously thinking about the question and begin preliminary research relevant to the question) to finish (submission of the work for publication). Although limited time is spent collecting data at the telescope, the $\mathrm{M}$ of the data indicates U.S. astronomers today are engaged in five (5) different investigations/research projects at any one time (see Table 4.15), and each investigation takes an average of two years to complete (see Table 4.16). It is, however, important to note that $18.4 \%$ of astronomers report being engaged in eight or more different investigations/research projects, and the Mo indicates $27.4 \%$ of these projects take more than 36 months to complete. The majority of their time doing research related work is spent searching and/or reading literature related to their 
research or science interests, analyzing and interpreting scientific data, thinking about and/or developing scientific questions, writing or modifying computer programs/scripts or app development, designing procedures for scientific investigations, and using preexisting data archives for their own research (See Figure 4.12). There are few differences between men and women when it comes to research related work activities engaged in, with two exceptions.

Women astronomers, on average, report engaging in the development of computer simulations and construction or performance of maintenance on scientific instrumentation less frequently than men (see Table A.3 in Appendix D). In addition, U.S. astronomers at non-academic institutions engage in the design of new scientific equipment more frequently than those at academic institutions.

Table 4.15

Number of investigations engaged in by U.S. Astronomers.

\begin{tabular}{|c|c|c|c|c|c|c|}
\hline \multicolumn{7}{|c|}{$\begin{array}{l}\text { Q12 - In your work as an astronomer today, how many different } \\
\text { investigations (research projects) are you engaged in? }\end{array}$} \\
\hline $\begin{array}{c}\text { Number of } \\
\text { Investigations/Research } \\
\text { Projects Engaged In } \\
\end{array}$ & $\begin{array}{l}\text { All } \\
\text { RC }\end{array}$ & $\begin{array}{c}\text { All } \\
\text { Response } \\
\%\end{array}$ & $\begin{array}{c}\text { Rw } \\
\%\end{array}$ & $\underset{\%}{\mathbf{R m}}$ & $\begin{array}{c}\text { Ra } \\
\%\end{array}$ & $\begin{array}{l}\text { Rn } \\
\%\end{array}$ \\
\hline (1) none & 0 & 0.0 & 0.0 & 0.0 & 0.0 & 0.0 \\
\hline (2) 1 & 19 & 4.0 & 0.8 & 4.7 & 2.2 & 2.3 \\
\hline (3) 2 & 63 & 13.2 & 12.9 & 12.9 & 10.3 & 12.5 \\
\hline (4) 3 & 88 & 18.4 & 21.8 & 17.6 & 15.5 & 17.0 \\
\hline (5) 4 & 76 & 15.9 & 14.5 & 16.5 & 16.7 & 18.2 \\
\hline (6) 5 & 84 & 17.6 & 21.2 & 15.3 & 20.2 & 18.8 \\
\hline (7) 6 & 35 & 7.3 & 8.9 & 7.1 & 7.3 & 9.1 \\
\hline (8) 7 & 20 & 4.2 & 2.4 & 5.0 & 5.6 & 3.4 \\
\hline (9) 8 & 5 & 1.0 & 0.0 & 1.5 & 1.3 & 1.1 \\
\hline (10) more than 8 & 88 & 18.4 & 14.5 & 19.4 & 21.0 & 17.6 \\
\hline Answered Question (RC) & \multicolumn{2}{|r|}{478} & 124 & 340 & 233 & 176 \\
\hline Skipped Question & \multicolumn{2}{|r|}{0} & 0 & 0 & 0 & 0 \\
\hline Mo & \multicolumn{2}{|c|}{$(4),(10)$} & (4) & $(10)$ & $(10)$ & (6) \\
\hline M & \multicolumn{2}{|c|}{5.84} & 5.72 & 5.90 & 6.19 & 5.91 \\
\hline
\end{tabular}




\begin{tabular}{|r|c|r|r|r|r|}
\hline CI of the M & 0.22 & 0.39 & 0.27 & 0.31 & 0.35 \\
\hline $\mathrm{Mdn}$ & 5.0 & 4.5 & 4.0 & 5.0 & 4.5 \\
\hline $\mathrm{SD}$ & 2.44 & 2.18 & 2.51 & 2.41 & 2.34 \\
\hline
\end{tabular}

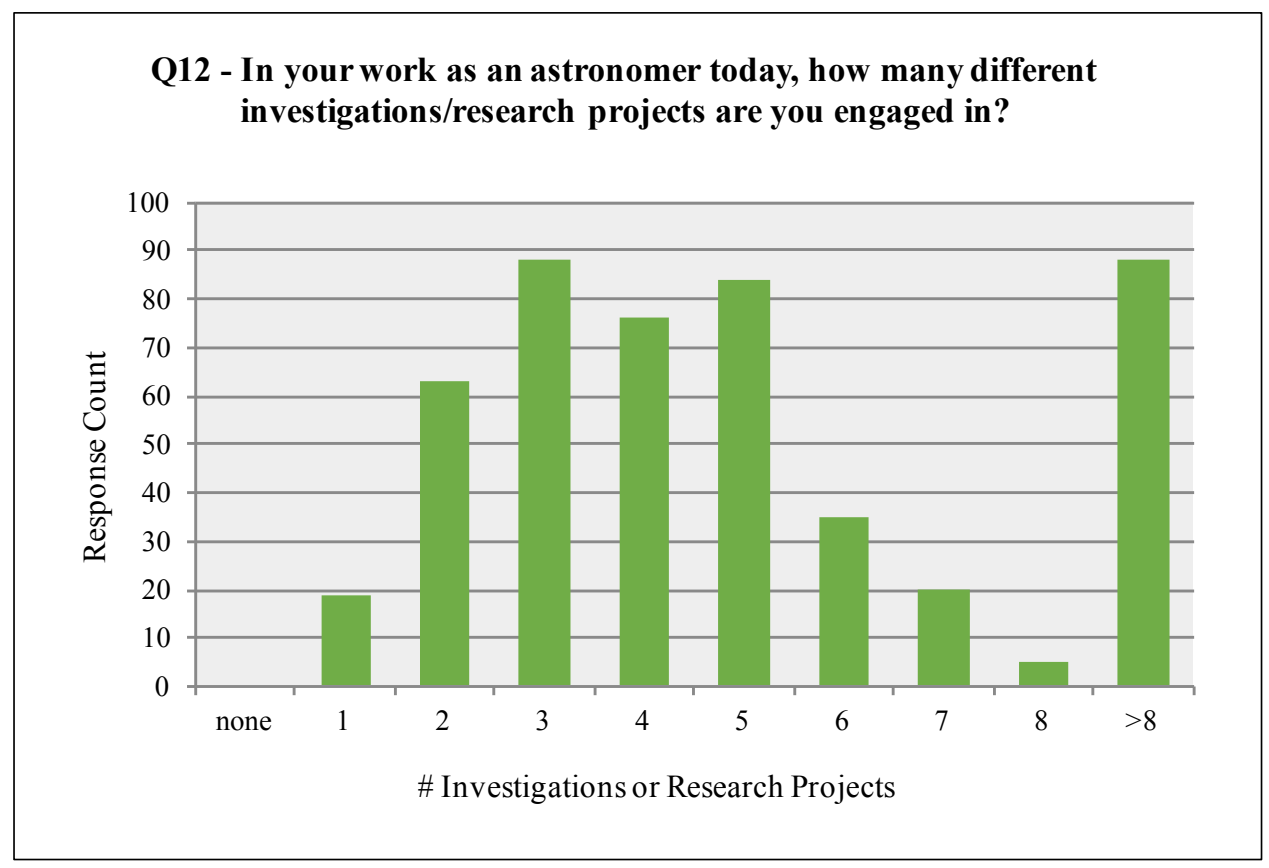

Figure 4.10. Number of Investigations Engaged In. The figure above shows the number of investigations or research projects U.S. astronomers are currently engaged in.

Table 4.16

Research project time to completion.

Q21 - From start to conclusion, on average, how long have your astronomy-related research projects taken to complete?

\begin{tabular}{|l|c|c|c|c|c|c|}
\hline $\begin{array}{c}\text { Months to Complete a } \\
\text { Research Project }\end{array}$ & $\begin{array}{c}\text { All } \\
\text { RC }\end{array}$ & $\begin{array}{c}\text { All } \\
\text { Response } \\
\mathbf{\%}\end{array}$ & $\begin{array}{c}\text { Rw } \\
\mathbf{\%}\end{array}$ & $\begin{array}{c}\mathbf{R m} \\
\mathbf{\%}\end{array}$ & $\begin{array}{c}\text { Ra } \\
\mathbf{\%}\end{array}$ & $\begin{array}{c}\text { Rn } \\
\mathbf{\%}\end{array}$ \\
\hline (1) less than 1 & 1 & 0.2 & 0.0 & 0.3 & 0.4 & 0.0 \\
\hline (2) $1-4$ & 6 & 1.3 & 0.8 & 1.5 & 0.9 & 1.7 \\
\hline (3) $5-8$ & 20 & 4.3 & 4.9 & 3.9 & 6.6 & 1.2 \\
\hline (4) $9-12$ & 43 & 9.2 & 4.9 & 11.2 & 9.2 & 11.6 \\
\hline (5) $13-16$ & 31 & 6.6 & 6.5 & 6.6 & 8.3 & 6.4 \\
\hline (6) $17-20$ & 34 & 7.3 & 9.8 & 6.3 & 5.7 & 9.3 \\
\hline (7) $21-24$ & 104 & 22.2 & 25.2 & 21.1 & 26.6 & 20.4 \\
\hline (8) $25-28$ & 24 & 5.1 & 4.9 & 4.8 & 5.2 & 6.4 \\
\hline (9) $29-32$ & 18 & 3.8 & 4.1 & 3.6 & 3.1 & 4.1 \\
\hline
\end{tabular}




\begin{tabular}{|r|c|c|r|r|r|r|}
\hline \multicolumn{1}{|l|}{$(10) 33-36$} & 59 & 12.6 & 13.8 & 12.4 & 10.9 & 14.5 \\
\hline (11) More than 36 & 128 & 27.4 & 25.2 & 28.1 & 23.1 & 24.4 \\
\hline Answered Question (RC) & 468 & 123 & 331 & 229 & 172 \\
\hline Skipped Question & 10 & 1 & 9 & 4 & 4 \\
\hline Mo & $(11)$ & $(7)$ & $(11)$ & $(7)$ & $(11)$ \\
\hline M & $\mathbf{7 . 8 7}$ & $\mathbf{7 . 9 4}$ & $\mathbf{7 . 8 3}$ & $\mathbf{7 . 5 4}$ & $\mathbf{7 . 8 5}$ \\
\hline CI of the M & 0.24 & 0.45 & 0.30 & 0.35 & 0.39 \\
\hline Mdn & 7.0 & 7.0 & 7.0 & 7.0 & 7.0 \\
\hline SD & 2.68 & 2.53 & 2.75 & 2.69 & 2.59 \\
\hline
\end{tabular}

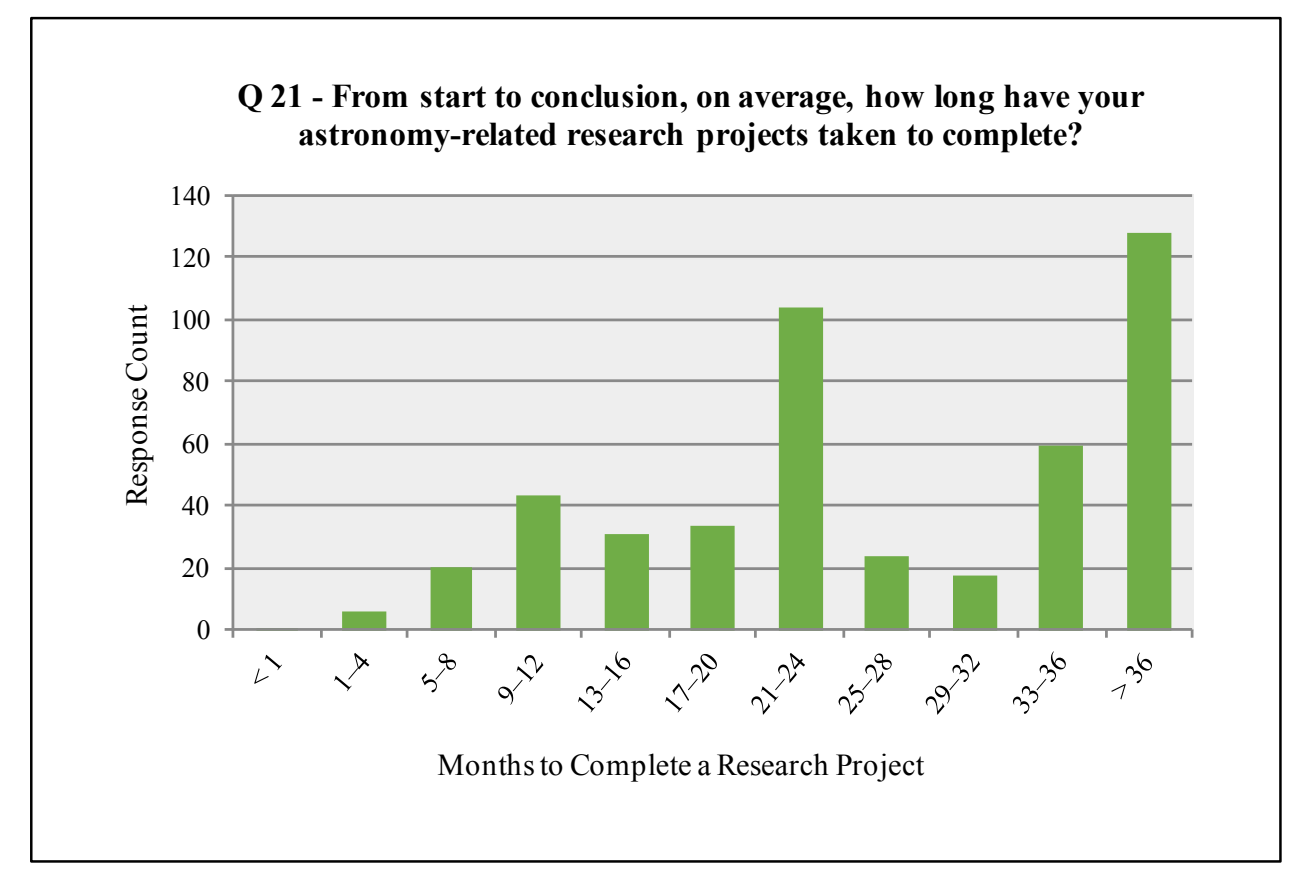

Figure 4.11. Research Project Time to Completion. The figure above shows the time it takes U.S. astronomers to complete an astronomy-related research project.

Table 4.17

U.S. Astronomer research related activities.

Q13 - In your work as an astronomer, on average over the past year, how often did you engage in ...

(1) never, (2) once a year, (3) 2 - 6 times a year, (4) 7 - 11 times a year, (5) once a month, (6) several times a month, (7) several times a week, (8) daily

\begin{tabular}{|l|l|l|l|l|l|l|l|l|l|l|l|l|l|l|}
\hline Tool/Technique & $(1)$ & $(2)$ & $(3)$ & $(4)$ & $(5)$ & $(6)$ & $(7)$ & $(8)$ & RC & $\begin{array}{c}\text { All } \\
\text { Mo }\end{array}$ & $\begin{array}{c}\text { All } \\
\text { M }\end{array}$ & $\begin{array}{c}\text { CI } \\
\text { M }\end{array}$ & Mdn & $\begin{array}{c}\text { All } \\
\text { SD }\end{array}$ \\
\hline
\end{tabular}




\begin{tabular}{|c|c|c|c|c|c|c|c|c|c|c|c|c|c|c|}
\hline $\begin{array}{l}\text { Searching and/or } \\
\text { reading literature } \\
\text { related to your } \\
\text { research or } \\
\text { science interests }\end{array}$ & 0 & 2 & 15 & 9 & 26 & 103 & 156 & 164 & 475 & (8) & 6.81 & 0.11 & 7.0 & 1.24 \\
\hline $\begin{array}{l}\text { The analysis and } \\
\text { interpretation of } \\
\text { scientific data }\end{array}$ & 6 & 8 & 35 & 11 & 30 & 83 & 137 & 159 & 469 & (8) & 6.50 & 0.15 & 7.0 & 1.68 \\
\hline $\begin{array}{l}\text { Thinking about } \\
\text { and/or } \\
\text { developing } \\
\text { scientific } \\
\text { questions } \\
\end{array}$ & 1 & 15 & 49 & 14 & 43 & 116 & 118 & 119 & 475 & (8) & 6.15 & 0.15 & 6.0 & 1.71 \\
\hline $\begin{array}{l}\text { Writing or } \\
\text { modifying } \\
\text { computer } \\
\text { programs/scripts } \\
\text { or app } \\
\text { development }\end{array}$ & 41 & 30 & 39 & 17 & 29 & 78 & 112 & 129 & 475 & (8) & 5.72 & 0.21 & 7.0 & 2.31 \\
\hline $\begin{array}{l}\text { Designing } \\
\text { procedures for } \\
\text { scientific } \\
\text { investigations } \\
\end{array}$ & 15 & 31 & 92 & 29 & 79 & 108 & 81 & 38 & 473 & (6) & 5.04 & 0.17 & 5.0 & 1.89 \\
\hline $\begin{array}{l}\text { The use of data } \\
\text { from preexisting } \\
\text { data archives for } \\
\text { your own } \\
\text { research } \\
\text { project(s) }\end{array}$ & 28 & 39 & 99 & 34 & 51 & 117 & 64 & 39 & 471 & (6) & 4.79 & 0.18 & 5.0 & 2.03 \\
\hline $\begin{array}{l}\text { The collection of } \\
\text { new scientific } \\
\text { data for your own } \\
\text { research } \\
\text { project(s) }\end{array}$ & 55 & 72 & 142 & 35 & 47 & 66 & 35 & 20 & 472 & (3) & 3.82 & 0.18 & 3.0 & 1.98 \\
\hline $\begin{array}{l}\text { The development } \\
\text { of computer } \\
\text { simulations }\end{array}$ & 149 & 87 & 67 & 17 & 30 & 53 & 38 & 29 & 470 & (1) & 3.31 & 0.21 & 2.0 & 2.34 \\
\hline $\begin{array}{l}\text { Constructing or } \\
\text { performing } \\
\text { maintenance on } \\
\text { scientific } \\
\text { equipment and/or } \\
\text { instrumentation }\end{array}$ & 280 & 54 & 42 & 15 & 24 & 26 & 21 & 10 & 472 & (1) & 2.28 & 0.18 & 1.0 & 1.99 \\
\hline $\begin{array}{l}\text { Designing new } \\
\text { scientific } \\
\text { equipment and/or } \\
\text { instrumentation }\end{array}$ & 268 & 100 & 28 & 10 & 18 & 18 & 14 & 13 & 469 & (1) & 2.12 & 0.17 & 1.0 & 1.85 \\
\hline
\end{tabular}




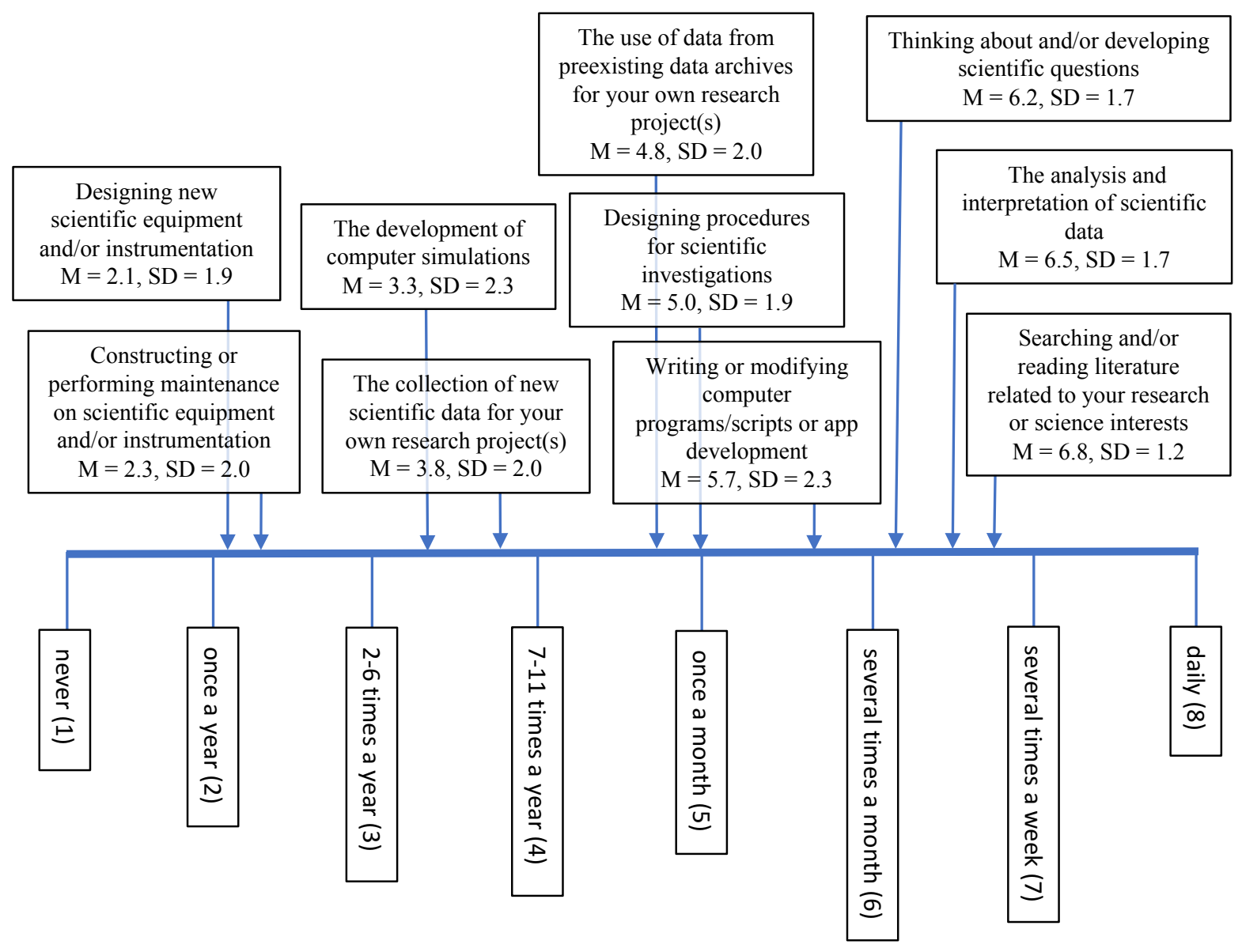

Figure 4.12. U.S. Astronomer Research Related Activities. The figure above shows how often, on average, astronomers engage in various research-related activities.

Although astronomers engage in limited data collection themselves, they do use large amounts of data in their research. Tables 4.18 and 4.19 identify the types of data most frequently used by U.S. astronomers. Over $80 \%$ of astronomers report using data from visible light telescopes. This is followed by $62 \%$ who report using infrared data, $36 \%$ using UV, $35 \%$ using radio, and 30\% using x-ray data (see Table 4.18). There were some differences between U.S. astronomers based on institution type and gender. Most noticeably astronomers at academic institutions report using data from visible light telescopes more frequently than those at non- 
academic institutions, and men report using microwave data more frequently than women astronomers.

Table 4.18

Type of data used in astronomy research.

\begin{tabular}{|c|c|c|c|c|c|c|}
\hline $\begin{array}{l}\text { Q17 - In your current work } \\
\text { used by you for your resear }\end{array}$ & an a & $\begin{array}{l}\text { ronomer, } \\
\text { ts? Select }\end{array}$ & $\begin{array}{l}\text { iich type } \\
\text { ll that a }\end{array}$ & $\begin{array}{l}\text { of data } \\
\text { ply. }\end{array}$ & re typi & \\
\hline Data Type & $\begin{array}{l}\text { All } \\
\text { RC }\end{array}$ & $\begin{array}{c}\text { All } \\
\text { Response } \\
\%\end{array}$ & $\begin{array}{c}\mathrm{Rw} \\
\%\end{array}$ & $\underset{\%}{\mathrm{Rm}}$ & $\begin{array}{l}\mathbf{R a} \\
\%\end{array}$ & $\begin{array}{l}\text { Rn } \\
\%\end{array}$ \\
\hline gamma-ray & 32 & 6.9 & 4.1 & 8.2 & 9.4 & 5.0 \\
\hline $\mathrm{x}$-ray & 141 & 30.4 & 27.9 & 31.6 & 32.6 & 33.0 \\
\hline ultraviolet & 167 & 36.0 & 35.2 & 37.1 & 38.8 & 35.0 \\
\hline visible & 374 & 80.6 & 86.1 & 78.7 & 84.8 & 74.7 \\
\hline infrared & 287 & 61.9 & 63.1 & 61.1 & 66.1 & 60.9 \\
\hline microwave & 103 & 22.2 & 13.1 & 25.5 & 18.8 & 23.6 \\
\hline radio & 162 & 34.9 & 31.1 & 35.9 & 36.6 & 31.6 \\
\hline gravitational wave & 14 & 3.0 & 2.5 & 3.3 & 4.5 & 1.7 \\
\hline other & 30 & 6.4 & 11 & $\mathbb{Z 1 1}$ & & \\
\hline Answered Question (RC) & & 464 & 122 & 329 & 224 & 174 \\
\hline Skipped Question & & 14 & 2 & 11 & 9 & 2 \\
\hline Mo & & isible & visible & visible & visible & visible \\
\hline
\end{tabular}

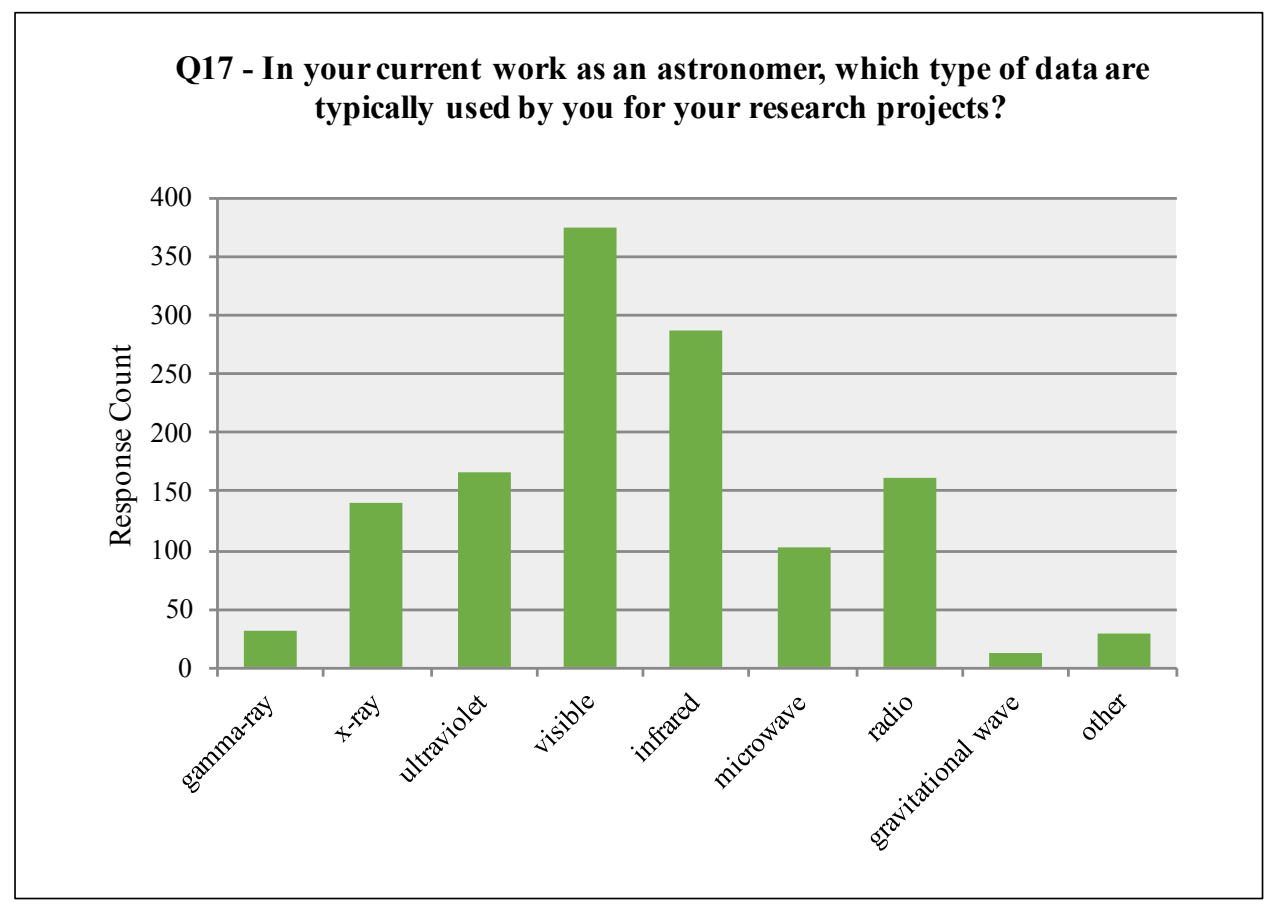


Figure 4.13. Type of Data Used in Astronomy Research. The figure above shows type of data used most frequently by U.S. astronomers in their research.

In addition to different classes of electromagnetic radiation and gravity waves, particle physics does play a significant role in astronomy today, and would be considered a type of data used in the study of astronomy (See Table 4.19 below).

Table 4.19

Other data typically used in astronomy research.

\begin{tabular}{|c|c|}
\hline \multicolumn{2}{|l|}{ Q17 - Other Response Summary } \\
\hline Additional Types of Data Used in Research & RC \\
\hline Neutrinos/particle data & 7 \\
\hline $\mathrm{mm} / \mathrm{sub}-\mathrm{mm}$ & 2 \\
\hline engineering data & 2 \\
\hline \# Respondents Who Replied "Other" & 30 \\
\hline
\end{tabular}

When it comes to data format, more than $75 \%$ of astronomers report using both images and spectral line data, and 50\% report using data from computer generated models in their current research (see Table 4.20). There are reported differences between usage by men and women, as well as by astronomers at academic and non-academic institutions. Eleven percent more men than women report using data from computer-generated models, and 15\% more astronomers at non-academic institutions report using spectral data (line or continuum) than their counterparts at academic institutions.

Table 4.20

Data format used in astronomy research. 


\begin{tabular}{|c|c|c|c|c|c|c|}
\hline \multicolumn{7}{|c|}{$\begin{array}{l}\text { Q18 - In your current work as an astronomer, what kind of data do you typically } \\
\text { work with for the research projects you are engaged in? Select all that apply. }\end{array}$} \\
\hline Data Formats & $\begin{array}{l}\text { All } \\
\text { RC }\end{array}$ & \begin{tabular}{|c|} 
All \\
Response \\
$\%$
\end{tabular} & $\begin{array}{l}\mathbf{R w} \\
\%\end{array}$ & $\begin{array}{c}\mathbf{R m} \\
\%\end{array}$ & $\begin{array}{l}\mathrm{Ra} \\
\%\end{array}$ & $\begin{array}{l}\text { Rn } \\
\%\end{array}$ \\
\hline (1) images & 362 & 79.0 & 75.4 & 79.9 & 81.7 & 79.2 \\
\hline (2) spectral data (line or continuum) & 346 & 75.5 & 78.7 & 74.4 & 75.3 & 90.0 \\
\hline $\begin{array}{l}\text { (3) data from computer generated } \\
\text { models }\end{array}$ & 228 & 49.8 & 42.6 & 53.1 & 51.1 & 50.1 \\
\hline other & 51 & 11.1 & & & & \\
\hline Answered Question (RC) & \multicolumn{2}{|r|}{458} & 122 & 324 & 223 & 168 \\
\hline Skipped Question & \multicolumn{2}{|r|}{20} & 2 & 16 & 10 & 8 \\
\hline Mo & \multicolumn{2}{|r|}{ (1) } & $(1)$ & $(1)$ & $(1)$ & $(1)$ \\
\hline
\end{tabular}

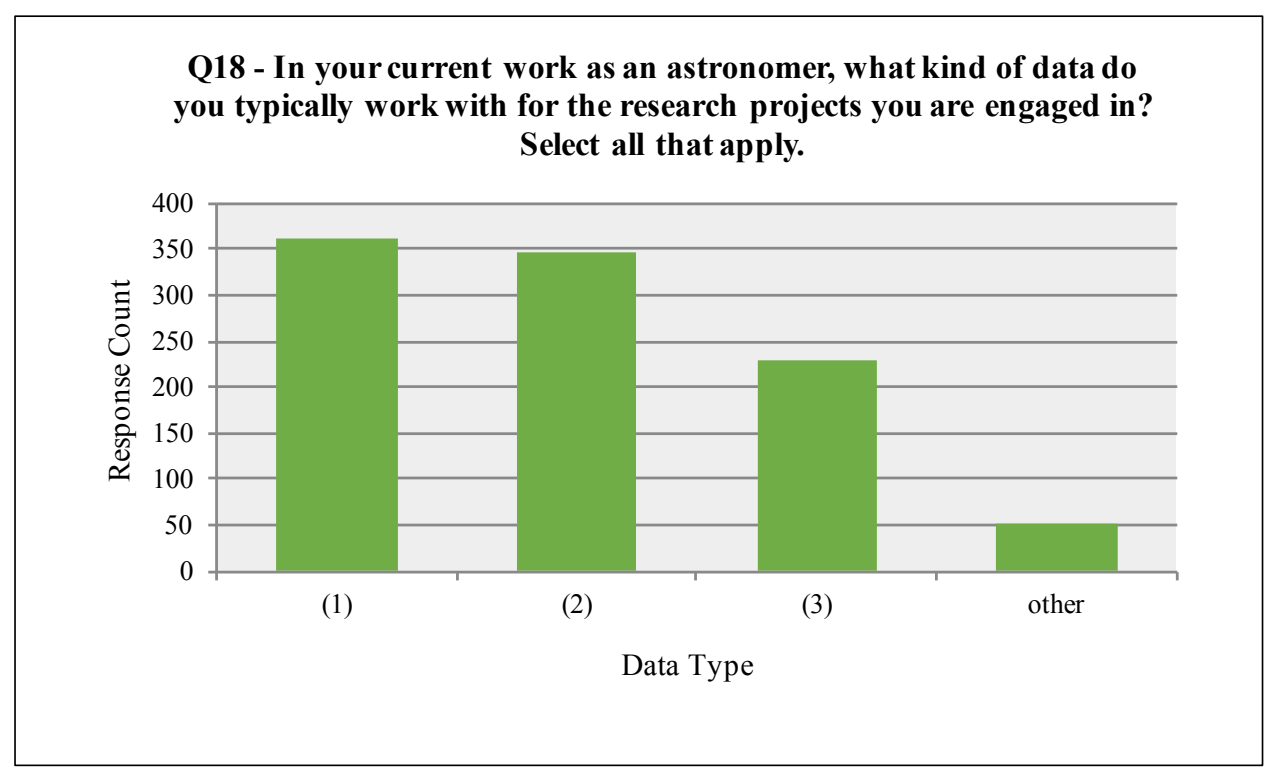

Figure 4.14. Data Formats Used in Astronomy Research. The figure above shows the various data formats most frequently used by U.S. astronomers in their research.

Table 4.21

Other data formats used in astronomy research.

\begin{tabular}{|l|c|}
\hline Q18 - Other Response Summary \\
\hline Categories of Additional Kinds of Data Worked with in Research & $\begin{array}{c}\text { Response } \\
\text { Count }\end{array}$ \\
\hline photometry & 12 \\
\hline time series/domain & 10 \\
\hline archive/historical & 6 \\
\hline
\end{tabular}


The construction of models is important in the practice of science. This is reflected in the A Framework for K-12 Science Education: Practices, Crosscutting Concepts, and Core Ideas (National Research Council, 2012) and the Next Generation Science Standards: For States, by States (NGSS Lead States, 2013) that followed. Table 4.22 below identifies astronomy-related models outlined by the NGSS as student performance expectations (NGSS Lead States, 2013). While the scope of the astronomy-related models called for in the NGSS is somewhat limited (see Table 4.22), the Framework (National Research Council, 2012, pg. 91) and NGSS do call for a greater focus in the use of models across disciplines.

Table 4.22

NGSS astronomy-related models.

\begin{tabular}{|c|l|l|}
\hline \multicolumn{3}{|c|}{ NGSS Astronomy-related Models } \\
\hline Grades & \multicolumn{1}{|c|}{ Disciplinary Core Idea } & \multicolumn{1}{c|}{ Student Performance Expectation } \\
\hline $3,4,5$ & $\begin{array}{l}\text { PS4-2 Waves and Their } \\
\text { Applications in Technologies } \\
\text { for Information Transfer }\end{array}$ & $\begin{array}{l}\text { Develop a model to describe that light } \\
\text { reflecting from objects and entering the eye } \\
\text { allows objects to be seen. }\end{array}$ \\
\hline $6,7,8$ & $\begin{array}{l}\text { PS4-2 Waves and their } \\
\text { Applications in Technologies } \\
\text { for Information Transfer }\end{array}$ & $\begin{array}{l}\text { Develop and use a model to describe that } \\
\text { waves are reflected, absorbed, or transmitted } \\
\text { through various materials. }\end{array}$ \\
\hline $6,7,8$ & $\begin{array}{l}\text { MS-ESS1 Earth's Place in the } \\
\text { Universe }\end{array}$ & $\begin{array}{l}\text { Develop and use a model of the Earth-sun- } \\
\text { moon system to describe the cyclic patterns } \\
\text { of lunar phases, eclipses of the sun and } \\
\text { moon, and seasons. }\end{array}$ \\
\hline $9,7,8$ & $\begin{array}{l}\text { MS-ESS1-2 Earth's Place in } \\
\text { the Universe }\end{array}$ & $\begin{array}{l}\text { Develop and use a model to describe the role } \\
\text { of gravity in the motions within galaxies and } \\
\text { the solar system. }\end{array}$ \\
\hline $9,10,11,12$ & $\begin{array}{l}\text { PS1-8 Matter and its } \\
\text { Interactions }\end{array}$ & $\begin{array}{l}\text { Develop models to illustrate the changes in } \\
\text { the composition of the nucleus of the atom } \\
\text { and the energy released during the processes } \\
\text { of fission, fusion, and radioactive decay. }\end{array}$ \\
\hline $9,10,11,12$ & PS3-5 Energy & $\begin{array}{l}\text { Develop and use a model of two objects } \\
\text { interacting through electric or magnetic } \\
\text { fields to illustrate the forces between objects } \\
\text { and the changes in energy of the objects due } \\
\text { to the interaction. }\end{array}$ \\
\hline
\end{tabular}




\begin{tabular}{|l|l|l|}
\hline $9,10,11,12$ & $\begin{array}{l}\text { ESS1-1 Earth's Place in the } \\
\text { Universe }\end{array}$ & $\begin{array}{l}\text { Develop a model based on evidence to } \\
\text { illustrate the life span of the sun and the role } \\
\text { of nuclear fusion in the sun's core to release } \\
\text { energy that eventually reaches Earth in the } \\
\text { form of radiation. }\end{array}$ \\
\hline
\end{tabular}

Both models and mathematics are critical to astronomy as well as science more generally.

Table 4.23 below identifies how often astronomers engage in the use of models to develop hypothesis, come up with new questions, or help explain observations. Most frequently U.S. astronomers use models to help explain observations, but they also use models 7 to 11 times per year in the development of new questions and hypothesis related to their research (see Table 4.23). However, the use of models in the development of questions and hypotheses does not appear to be addressed in the NGSS, leaving perhaps a disconnect between what is being taught in schools and the authentic practice of astronomy, or science in general.

Table 4.23

Use of models in astronomy.

Q14 - In your work as an astronomer, on average over the past year, how often did you engage in the use of models (e.g. computer, physical, mathematical, etc.) to ...

(1) never, (2) once a year, (3) 2 - 6 times a year, (4) 7 - 11 times a year, (5) once a month, (6) several times a month, (7) several times a week, (8) daily

\begin{tabular}{|l|c|c|c|c|c|c|c|c|c|c|c|c|c|c|}
\hline \multicolumn{1}{|c|}{ Tool/Technique } & $\mathbf{( 1 )}$ & $\mathbf{( 2 )}$ & $\mathbf{( 3 )}$ & $\mathbf{( 4 )}$ & $\mathbf{( 5 )}$ & $\mathbf{( 6 )}$ & $\mathbf{( 7 )}$ & $\mathbf{( 8 )}$ & $\mathbf{R C}$ & $\begin{array}{c}\text { All } \\
\text { Mo }\end{array}$ & $\begin{array}{c}\text { All } \\
\text { M }\end{array}$ & $\begin{array}{c}\text { CI } \\
\text { M }\end{array}$ & Mdn & $\begin{array}{c}\text { All } \\
\text { SD }\end{array}$ \\
\hline $\begin{array}{l}\text { Help organize or } \\
\text { explain observations }\end{array}$ & 26 & 36 & 84 & 16 & 48 & 108 & 89 & 63 & 470 & $(6)$ & $\mathbf{5 . 1 7}$ & 0.19 & 6.0 & 2.12 \\
\hline $\begin{array}{l}\text { Come up with new } \\
\text { questions }\end{array}$ & 55 & 65 & 125 & 33 & 66 & 65 & 40 & 17 & 466 & $(3)$ & $\mathbf{3 . 9 2}$ & 0.18 & 3.0 & 1.98 \\
\hline $\begin{array}{l}\text { Develop new } \\
\text { hypothesis }\end{array}$ & 59 & 77 & 122 & 26 & 60 & 62 & 44 & 18 & 468 & $(3)$ & $\mathbf{3 . 8 6}$ & 0.18 & 3.0 & 2.04 \\
\hline \\
$\begin{array}{l}\text { Responses were randomized in the online survey. } \\
\text { NOTE: \# Respondents that skipped sub-question }=478-\text { RC }\end{array}$ \\
\hline
\end{tabular}




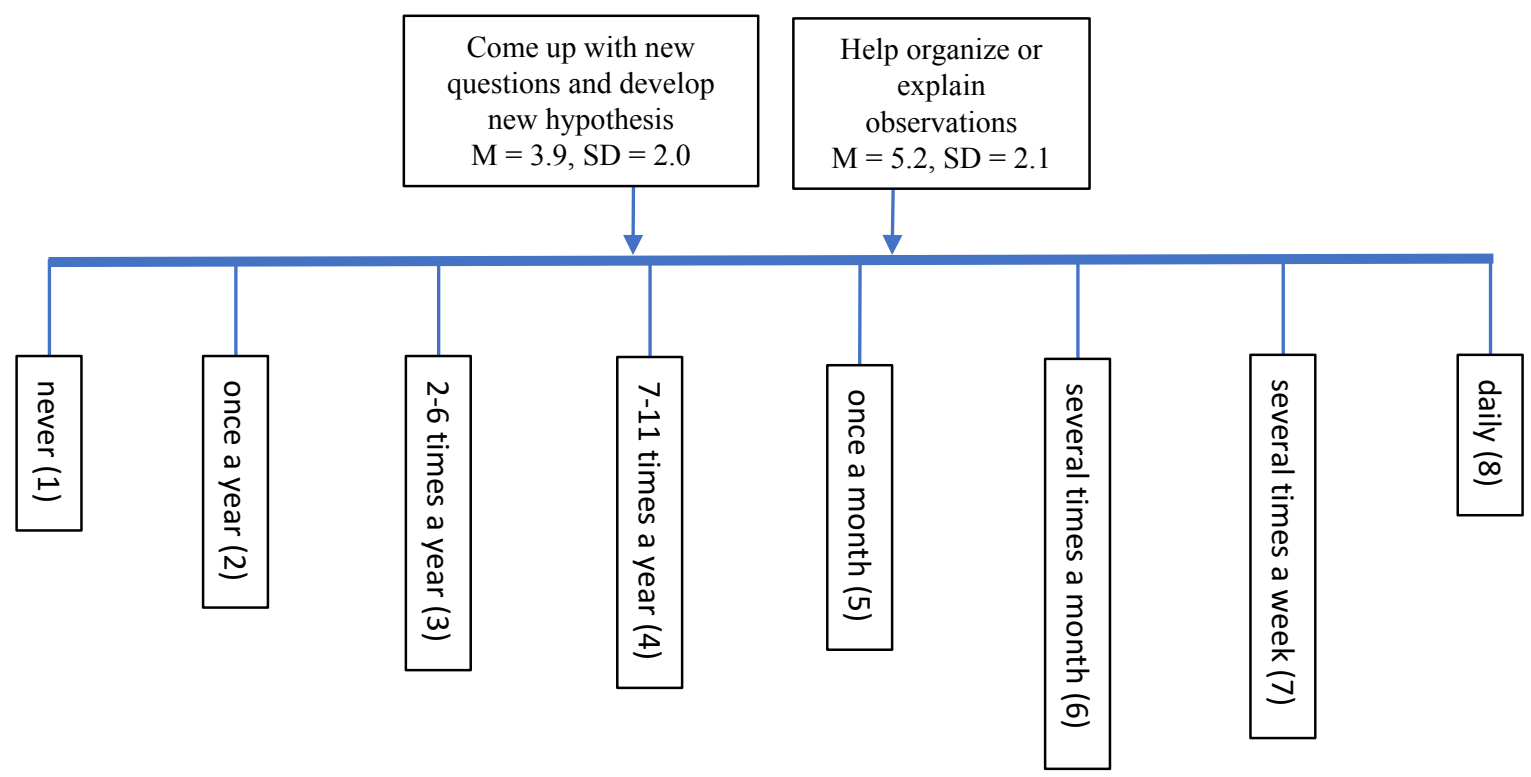

Figure 4.15. Use of Models in Astronomy. The figure above shows how often, on average, astronomers engage in the use of models (e.g. computer, physical, mathematical, etc.) to develop hypothesis, come up with new questions, or help explain observations.

Over the past four decades science education reform efforts have called for a greater integration of mathematics into science instruction, in particular statistics (Rutherford \& Ahlgren, 1990; American Association for the Advancement of Science, 1994; National Research Council, 2012; NGSS Lead States, 2013). Further supporting the role of statistics and mathematics in science, the Guidelines for Assessment and Instruction in Statistics Education College Report 2016 calls for statistics to be taught "as an investigative process of problem solving and decision making” (GAISE College Report ASA Revision Committee, 2016, pg. 6). Astronomy is seen as a computation-intensive science, requiring practitioners to use high-level mathematics and mathematical/computer modeling on a regular basis. Those who consider entering into the field of astronomy are often told to take as a many math courses as possible (American Astronomical Society, 2005). 
In the practice of astronomy, U.S. astronomers in this study use arithmetic on a daily basis, algebra several times a week, and statistical analysis on a weekly basis. In addition, trigonometry and geometry are all used several times a month or more, and calculus is used monthly, if not more frequently. It is worth noting that while there was agreement among astronomers on how frequently arithmetic was used $(\mathrm{SD}=0.70)$, there was significantly less agreement on frequency of use for other types of mathematics (see Table 4.24). Further, women astronomers report using trigonometry and geometry less frequently than men (see Table A.6 in Appendix D).

Table 4.24

Use of math in astronomy.

Q19 - In doing your work as an astronomer, on average over the past year, how often did you use the following types of mathematics?

(1) - never, (2) once a year, (3) - 2 - 6 times a year, (4) - 7 - 11 times a year, (5) - several times a month, (6) several times a week, (7) - daily

\begin{tabular}{|l|c|c|c|c|c|c|c|c|c|c|c|c|c|}
\hline \multicolumn{1}{|c|}{ Tool/Technique } & $\mathbf{( 1 )}$ & $\mathbf{( 2 )}$ & $\mathbf{( 3 )}$ & $\mathbf{( 4 )}$ & $\mathbf{( 5 )}$ & $\mathbf{( 6 )}$ & $\mathbf{( 7 )}$ & $\mathbf{R C}$ & $\begin{array}{c}\text { All } \\
\text { Mo }\end{array}$ & $\begin{array}{c}\text { All } \\
\mathbf{M}\end{array}$ & $\begin{array}{c}\text { CI } \\
\text { M }\end{array}$ & Mdn & $\begin{array}{c}\text { All } \\
\text { SD }\end{array}$ \\
\hline Arithmetic (+, -, x, /) & 1 & 0 & 2 & 8 & 15 & 70 & 373 & 469 & $(7)$ & $\mathbf{6 . 7 1}$ & 0.06 & 7.0 & 0.70 \\
\hline Algebra & 7 & 4 & 16 & 28 & 69 & 125 & 223 & 472 & $(7)$ & $\mathbf{6 . 0 0}$ & 0.12 & 6.0 & 1.29 \\
\hline Statistics & 14 & 10 & 30 & 49 & 105 & 144 & 118 & 470 & $(6)$ & $\mathbf{5 . 3 9}$ & 0.13 & 6.0 & 1.48 \\
\hline Trigonometry & 20 & 14 & 43 & 58 & 117 & 121 & 93 & 466 & $(6)$ & $\mathbf{5 . 0 9}$ & 0.14 & 5.0 & 1.58 \\
\hline Geometry & 15 & 18 & 53 & 61 & 124 & 117 & 81 & 469 & $(5)$ & $\mathbf{5 . 0 0}$ & 0.14 & 5.0 & 1.54 \\
\hline Calculus & 41 & 22 & 78 & 76 & 89 & 83 & 79 & 468 & $(5)$ & $\mathbf{4 . 5 3}$ & 0.16 & 5.0 & 1.81 \\
\hline NOTE: \# Respondents that skipped sub-question $=478-$ RC \\
\hline
\end{tabular}




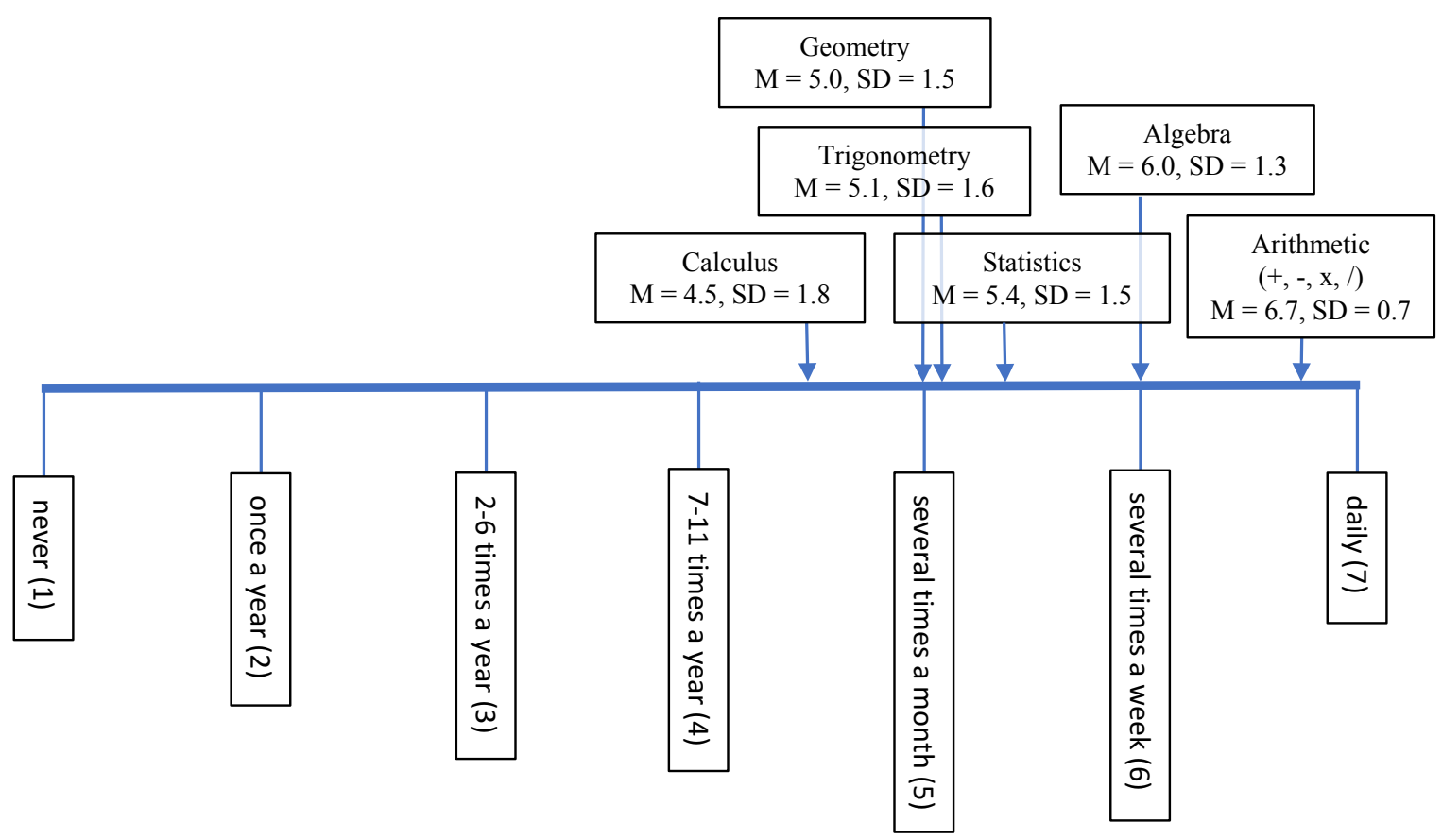

Figure 4.16. Use of Math in Astronomy. The figure above shows the frequency at which U.S. astronomers use various types of mathematics in their practice of astronomy.

In addition to being grounded in computation, science is also a blend of logic and imagination where imagination is used in coming up with hypotheses and theories or new scientific ideas, but sooner or later conclusions must conform to logical argumentation (National Research Council, 2012, pg. 79; Rutherford \& Ahlgren, 1990). Nearly 60\% of U.S. astronomers in this study say they use their imagination either daily or several times per week in their work (see Table 4.25). Closely linked to imagination is intuition (Beveridge, 1950). Although not as regularly as their imagination, astronomers do use intuition in the practice of their science. Nearly $60 \%$ of astronomers use their intuition at least once a month to come up with new questions to study, and 55\% say they use their intuition monthly to identify new knowledge resulting from their research (see Table 4.25). There are no significant differences in the frequency at which imagination and intuition are used by women compared to men, or by 
astronomers at academic institutions compared to those at non-academic institutions. However, it is notable that women astronomers in this study ranked the importance of intuition significantly lower than men in response to Question 10 (see Table A.1 in Appendix D). It is further interesting to note that intuition is not addressed in the NGSS (2013), or in the earlier National Science Education Standards (1996).

Table 4.25

Use of imagination and intuition in astronomy.

Q15 - In your work as an astronomer, on average over the past year, how often did you

(1) never, (2) once a year, (3) 2 - 6 times a year, (4) 7 - 11 times a year, (5) once a month, (6) several times a month, (7) several times a week, (8) daily

\begin{tabular}{|c|c|c|c|c|c|c|c|c|c|c|c|c|c|c|}
\hline Tool/Technique & (1) & (2) & (3) & (4) & (5) & (6) & (7) & (8) & RC & $\begin{array}{l}\text { All } \\
\text { Mo }\end{array}$ & $\begin{array}{c}\text { All } \\
\mathbf{M}\end{array}$ & $\begin{array}{l}\text { CI } \\
\mathbf{M} \\
\end{array}$ & Mdn & $\begin{array}{l}\text { All } \\
\text { SD }\end{array}$ \\
\hline Use your imagination & 10 & 9 & 37 & 11 & 43 & 80 & 124 & 154 & 468 & (8) & 6.36 & 0.16 & 7.0 & 1.79 \\
\hline $\begin{array}{l}\text { Use your intuition to } \\
\text { come up with new } \\
\text { questions to study }\end{array}$ & 26 & 42 & 95 & 25 & 63 & 120 & 52 & 44 & 467 & (6) & 4.81 & 0.18 & 5.0 & 2.02 \\
\hline $\begin{array}{l}\text { Use your intuition to } \\
\text { identify new knowledge } \\
\text { resulting from your } \\
\text { research }\end{array}$ & 36 & 45 & 89 & 40 & 58 & 98 & 51 & 45 & 462 & (6) & 4.65 & 0.19 & 5.0 & 2.09 \\
\hline
\end{tabular}




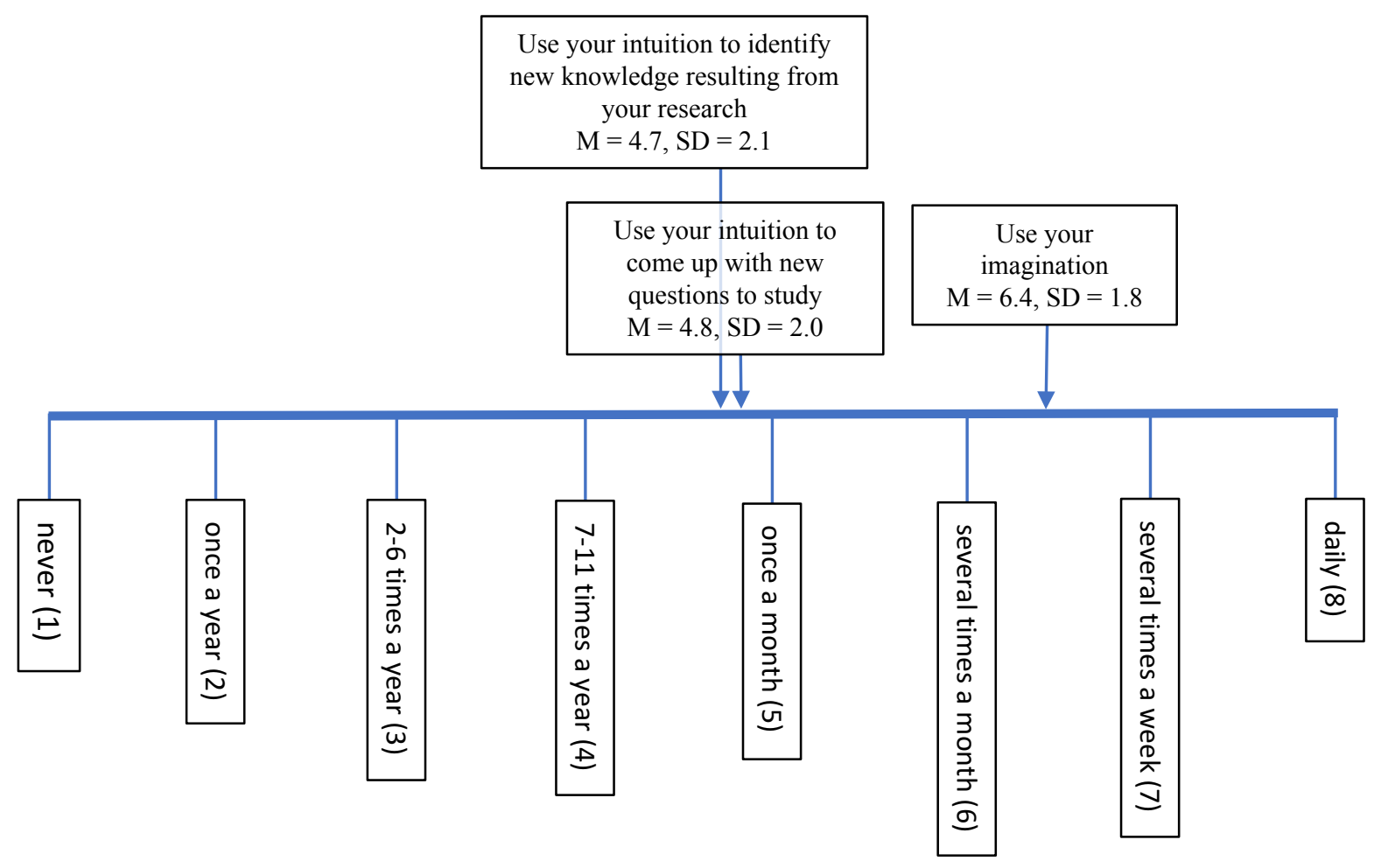

Figure 4.17. Use of Imagination and Intuition in Astronomy. The figure above shows how often, on average, astronomers use their imagination and intuition in their practice of astronomy.

\section{Social Interactions Engaged in by U.S. Astronomers}

- Research Question 3: What social interactions are most frequently engaged in by U.S. astronomers in their practice of astronomy?

According to Eason (2004) and Edelson (2003) social interaction is a key feature of scientific practice, and includes a mix of co-operation and competition, agreement and argumentation, and collaboration. Just as in science in general, U.S. astronomers engage in a variety of social activities where they interact with others either face-to-face, virtually, or through various written communications. 
On average the most frequent social interaction-related activities U.S. astronomers engage in include the performance of administrative/management duties, mentoring others, writing research articles or other scientific documentation, and reviewing documents for other scientists (see Table 4.26).

Astronomers in this study also spend a significant amount of time teaching and mentoring others if they are employed at academic institutions. While astronomers at academic institutions reported "mentoring others" several times a month, those at non-academic institutions engaged in such activity less than once per month. In addition, those at academic institutions reported preparing for, or teaching, a class slightly more than once per month as compared to those at non-academic institutions who engage in such activities, on average, once per year (see Table A.7 in Appendix D). It is important to note that a large SD for astronomers at academic institutions in preparation for $(\mathrm{SD}=2.8)$ or teaching $(\mathrm{SD}=2.71)$ a class indicates there is a large variance across this population. Some astronomers from academic institutions teach very little, if at all, and others teach on a much more regular basis.

In addition to teaching, astronomers also indicate that on average they engage in education and public outreach activities somewhere between 2-6 times per year and 7-11 times per year. Further, they engage in activities related to securing funding for future projects 2-6 times per year.

Table 4.26

Social interactions in astronomy. Q22 - In your work as an astronomer, on average over the past year, how often did you engage in (1) - never, (2) once a year, (3) - 2 - 6 times a year, (4) - 7 - 11 times a year, (5) - once a month, (6) - several times a month, (7) - several times a week, (8) - daily

\begin{tabular}{|c|c|c|c|c|c|c|c|c|c|c|c|c|c|c|}
\hline $\begin{array}{c}\text { Social } \\
\text { Interaction }\end{array}$ & (1) & (2) & (3) & (4) & (5) & (6) & (7) & (8) & RC & $\begin{array}{c}\text { All } \\
\text { Mo }\end{array}$ & $\begin{array}{c}\text { All } \\
\text { M }\end{array}$ & $\begin{array}{c}\text { CI } \\
\text { M }\end{array}$ & Mdn & $\begin{array}{c}\text { All } \\
\text { SD }\end{array}$ \\
\hline
\end{tabular}




\begin{tabular}{|c|c|c|c|c|c|c|c|c|c|c|c|c|c|c|}
\hline $\begin{array}{l}\text { Performing } \\
\text { administrative or } \\
\text { management } \\
\text { duties } \\
\end{array}$ & 51 & 11 & 50 & 10 & 35 & 97 & 98 & 120 & 472 & (8) & 5.65 & 0.21 & 6.0 & 2.30 \\
\hline Mentoring others & 35 & 32 & 65 & 20 & 33 & 110 & 120 & 58 & 473 & (7) & 5.29 & 0.19 & 6.0 & 2.16 \\
\hline $\begin{array}{l}\text { Writing research } \\
\text { articles or other } \\
\text { scientific } \\
\text { documentation }\end{array}$ & 8 & 31 & 101 & 22 & 41 & 147 & 99 & 25 & 474 & (6) & 5.15 & 0.16 & 6.0 & 1.83 \\
\hline $\begin{array}{l}\text { Review of } \\
\text { documents for } \\
\text { other scientists }\end{array}$ & 20 & 50 & 143 & 46 & 85 & 88 & 34 & 7 & 473 & (3) & 4.19 & 0.15 & 4.0 & 1.70 \\
\hline $\begin{array}{l}\text { Preparation to } \\
\text { teach a class }\end{array}$ & 210 & 46 & 28 & 7 & 1 & 32 & 115 & 35 & 474 & (1) & 3.58 & 0.25 & 2.0 & 2.81 \\
\hline $\begin{array}{l}\text { Education and } \\
\text { public outreach } \\
\text { (EPO) activities }\end{array}$ & 57 & 81 & 156 & 38 & 51 & 54 & 20 & 16 & 473 & (3) & 3.56 & 0.17 & 3.0 & 1.84 \\
\hline Teaching a class & 210 & 48 & 27 & 8 & 3 & 25 & 131 & 21 & 473 & (1) & 3.53 & 0.25 & 2.0 & 2.77 \\
\hline $\begin{array}{l}\text { Writing funding } \\
\text { proposals or } \\
\text { otherwise seeking } \\
\text { funding for future } \\
\text { projects }\end{array}$ & 76 & 93 & 199 & 35 & 36 & 26 & 6 & 3 & 474 & (3) & 2.96 & 0.13 & 3.0 & 1.44 \\
\hline
\end{tabular}

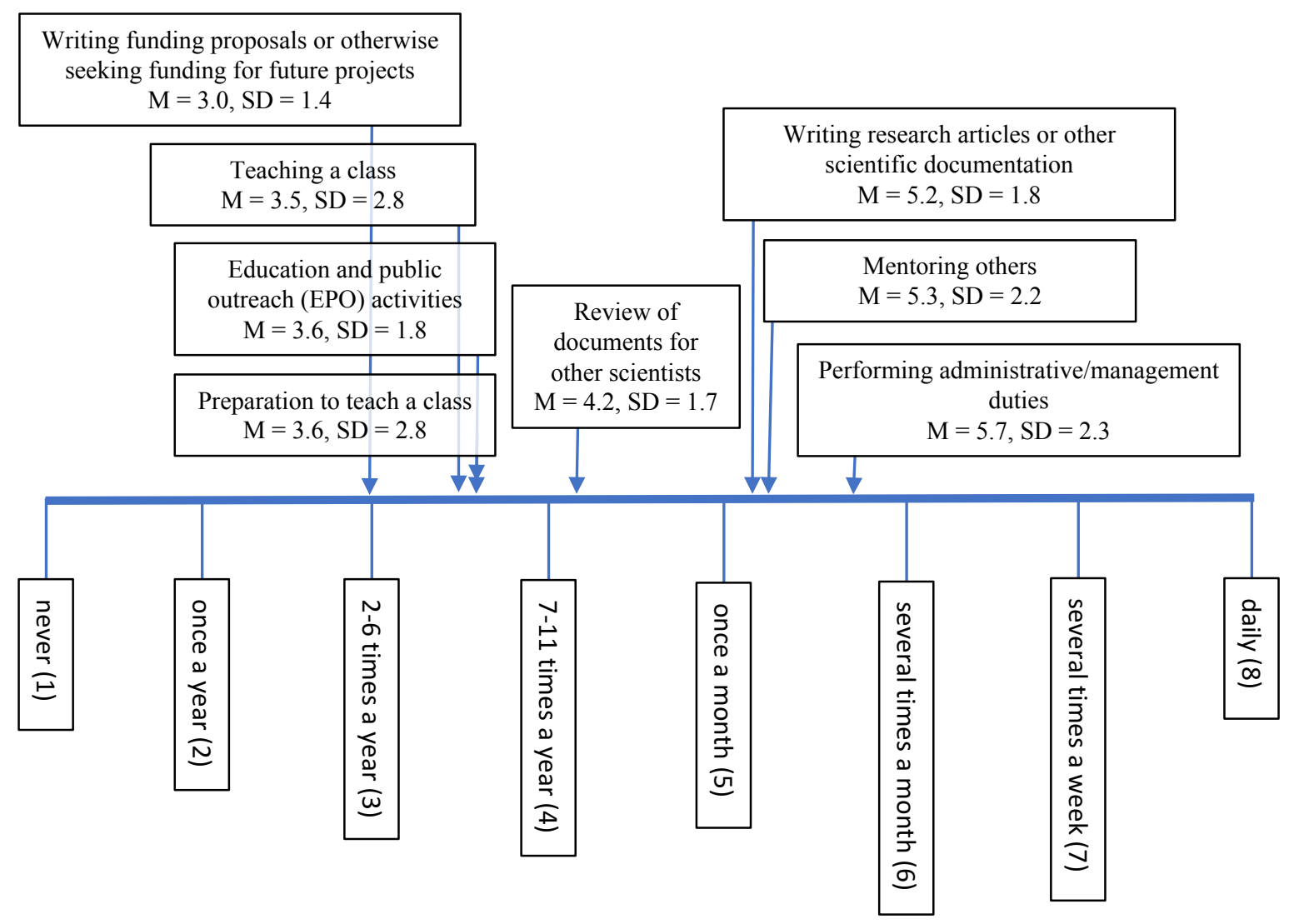


Figure 4.18. Social Interactions in Astronomy. The graphic above shows how often, on average, astronomers engage in various social interactions related to their practice of astronomy.

U.S. astronomers also share and argue their research via written publications, and a variety of oral presentations to local audiences or those at national and international meetings, and most often this work is part of a collaborative process. Most papers today in astronomy are written by collaborations; there are very few single author papers (Frogel, 2010). Based on the number of publications reported by U.S. astronomers, Frogel appears to be correct. This study indicates a Mdn of more than 50 publications with over $70 \%$ of U.S. astronomers reporting being author or co-author on more than 40 research publications (see Table 4.27), indicating that astronomers spend a fair bit of time writing, as well as collaborating with others through these publications. Women do report being author or co-author on approximately 10 fewer publications than men (see Table 4.27). However, this is likely due to the fact that more women have entered the field more recently.

When it comes to presentations made and conferences attended, U.S. astronomers are active as well. Nearly $43 \%$ of U.S. astronomers in this study report attending 1-2 professional meetings within the past year, and nearly $29 \%$ report attending 3-4 professional meetings in this same time period (see Table 4.27). In addition, astronomers report, on average, making slightly more than 3-4 formal presentations per year (see Table 4.28). There are no significant differences in the average number of professional meetings attended or formal presentations made between women and men astronomers, or those employed at academic or non-academic institutions.

Table 4.27

U.S. astronomer publications.

Q23 - On how many different scientific research publications are you considered an author or co-author, or editor? 


\begin{tabular}{|c|c|c|c|c|c|c|}
\hline $\begin{array}{c}\text { \# of Publications Authored or } \\
\text { Co-authored }\end{array}$ & $\begin{array}{l}\text { All } \\
\text { RC }\end{array}$ & $\begin{array}{c}\text { All } \\
\text { Response } \\
\%\end{array}$ & $\begin{array}{c}\mathbf{R w} \\
\%\end{array}$ & $\underset{\%}{\mathrm{Rm}}$ & $\begin{array}{l}\mathrm{Ra} \\
\%\end{array}$ & $\begin{array}{l}\mathbf{R n} \\
\%\end{array}$ \\
\hline (1) none & 0 & 0.0 & 0.0 & 0.0 & 0.0 & 0.0 \\
\hline (2) $1-5$ & 22 & 4.6 & 6.5 & 3.3 & 6.1 & 2.3 \\
\hline (3) $6-10$ & 28 & 5.9 & 11.3 & 4.2 & 6.5 & 6.3 \\
\hline (4) $11-15$ & 19 & 4.0 & 5.6 & 3.6 & 3.9 & 2.8 \\
\hline (5) $16-20$ & 16 & 3.4 & 6.5 & 1.8 & 3.9 & 4.0 \\
\hline (6) $21-30$ & 31 & 6.5 & 8.9 & 6.0 & 5.7 & 7.4 \\
\hline (7) $31-40$ & 25 & 5.3 & 7.3 & 4.5 & 5.2 & 6.3 \\
\hline (8) $41-50$ & 34 & 7.2 & 8.1 & 6.8 & 6.5 & 8.0 \\
\hline (9) More than 50 & 299 & $\begin{array}{r}63.1 \\
\end{array}$ & 46.0 & 69.9 & 62.2 & 63.1 \\
\hline Answered Question & & 474 & 124 & 336 & 230 & 176 \\
\hline Skipped Question & & 4 & 0 & 4 & 3 & 0 \\
\hline Mo & & (9) & $(9)$ & (9) & (9) & (9) \\
\hline $\mathbf{M}$ & & 7.61 & 6.84 & 7.93 & 7.49 & 7.74 \\
\hline CI of the $\mathrm{M}$ & & 0.20 & 0.44 & 0.21 & 0.30 & 0.30 \\
\hline Mdn & & 9.0 & 8.0 & 9.0 & 9.0 & 9.0 \\
\hline $\mathrm{SD}$ & & 2.21 & 2.48 & 1.98 & 2.33 & 2.03 \\
\hline
\end{tabular}

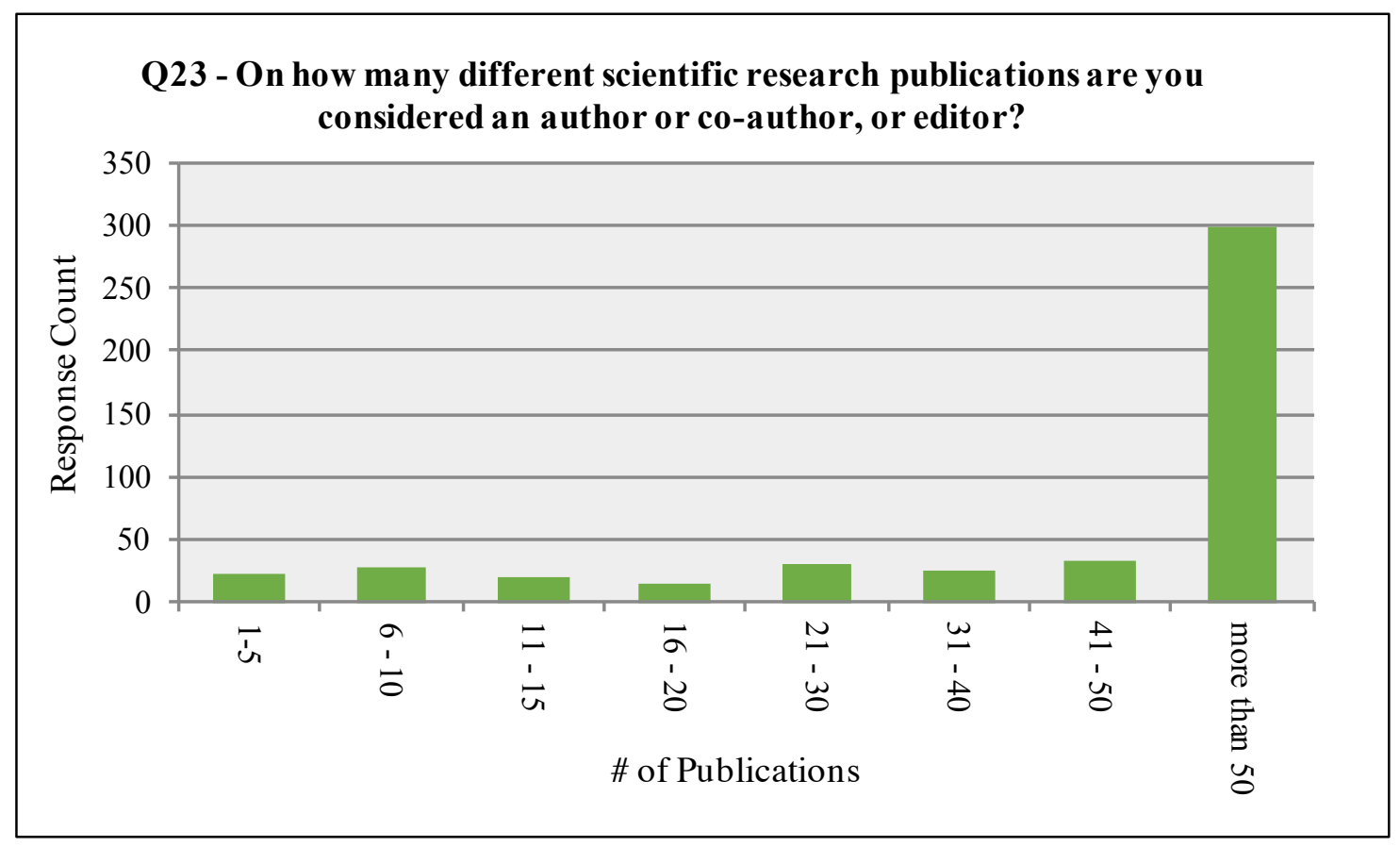

Figure 4.19. Astronomer Publications. The figure above shows the total number of publications on which U.S. astronomers report being either an author or co-author, or editor.

Table 4.28

Professional meetings/conferences attended. 


\begin{tabular}{|c|c|c|c|c|c|c|}
\hline $\begin{array}{l}\text { Q24 - In your work as an astr } \\
\text { professional meetings or conf } \\
\text { but are not limited to AAS, A }\end{array}$ & ome & $\begin{array}{l}\text { ver the } F \\
\text { d you att } \\
\text { U, etc.) }\end{array}$ & d? $(E$, & mples & lay in & \\
\hline $\begin{array}{c}\text { \# of Professional Meetings } \\
\text { Attended Per Year }\end{array}$ & $\begin{array}{l}\text { All } \\
\text { RC }\end{array}$ & $\begin{array}{c}\text { All } \\
\text { Response } \\
\text { \% }\end{array}$ & $\begin{array}{c}\text { Rw } \\
\%\end{array}$ & $\begin{array}{l}\mathrm{Rm} \\
\%\end{array}$ & $\begin{array}{l}\mathrm{Ra} \\
\%\end{array}$ & $\begin{array}{l}\text { Rn } \\
\%\end{array}$ \\
\hline (1) none & 52 & $10.9 \%$ & 4.8 & 12.7 & 10.8 & 3.4 \\
\hline (2) $1-2$ & 204 & $42.9 \%$ & 41.1 & 42.6 & 46.1 & 38.1 \\
\hline (3) $3-4$ & 137 & $28.8 \%$ & 37.1 & 26.3 & 26.3 & 36.9 \\
\hline (4) $5-6$ & 55 & $11.6 \%$ & 10.5 & 12.4 & 11.6 & 14.2 \\
\hline (5) $7-8$ & 18 & $3.8 \%$ & 4.8 & 3.6 & 3.0 & 5.1 \\
\hline (6) $9-10$ & 3 & $0.6 \%$ & 0.8 & 0.6 & 0.4 & 1.1 \\
\hline (7) more than 10 & 7 & $1.5 \%$ & 0.8 & 1.8 & 1.7 & 1.1 \\
\hline Answered Question & & 476 & 124 & 338 & 232 & 176 \\
\hline Skipped Question & & 2 & 0 & 2 & 1 & 0 \\
\hline Mo & & (2) & (2) & (2) & (2) & (2) \\
\hline $\mathbf{M}$ & & 2.62 & 2.75 & 2.60 & 2.58 & 2.88 \\
\hline CI of the M & & 0.10 & 0.18 & 0.13 & 0.15 & 0.16 \\
\hline Mdn & & 2.0 & 3.0 & 2.0 & 2.0 & 3.0 \\
\hline SD & & 1.13 & 1.02 & 1.18 & 1.13 & 1.06 \\
\hline
\end{tabular}

Table 4.29

Formal presentations made.

\begin{tabular}{|c|c|c|c|c|c|c|}
\hline \multicolumn{7}{|c|}{$\begin{array}{l}\text { Q25 -In your work as an astronomer, over the past year, how many } \\
\text { formal presentations did you make about your research at conferences, } \\
\text { meetings, workshops, lunch talks, etc.? }\end{array}$} \\
\hline $\begin{array}{c}\text { Formal } \\
\text { Presentations Made }\end{array}$ & $\begin{array}{c}\text { All } \\
\text { Response } \\
\text { Count } \\
\end{array}$ & $\begin{array}{c}\text { All } \\
\text { Response } \\
\% \\
\end{array}$ & $\begin{array}{c}\text { Rw } \\
\%\end{array}$ & $\underset{\%}{\mathrm{Rm}}$ & $\begin{array}{l}\mathrm{Ra} \\
\%\end{array}$ & $\begin{array}{l}\text { Rn } \\
\%\end{array}$ \\
\hline (1) none & 65 & 13.8 & 8.1 & 14.9 & 9.5 & 8.1 \\
\hline (2) $1-2$ & 121 & 25.6 & 26.0 & 25.1 & 25.1 & 24.9 \\
\hline (3) $3-4$ & 122 & 25.8 & 23.6 & 26.6 & 28.1 & 26.6 \\
\hline (4) $5-6$ & 87 & 18.4 & 20.3 & 18.5 & 17.3 & 26.0 \\
\hline (5) $7-8$ & 30 & 6.4 & 10.6 & 5.1 & 8.7 & 4.6 \\
\hline (6) $9-10$ & 18 & 3.8 & 3.3 & 4.2 & 3.5 & 4.6 \\
\hline (7) $11-15$ & 17 & 3.6 & 4.9 & 3.3 & 4.8 & 2.3 \\
\hline (8) $16-20$ & 4 & 0.8 & 1.6 & 0.6 & 0.9 & 0.6 \\
\hline (9) more than 20 & 8 & 1.7 & 1.6 & 1.8 & 2.2 & 1.7 \\
\hline Answered Question & \multicolumn{2}{|c|}{472} & 123 & 335 & 231 & 173 \\
\hline Skipped Question & \multicolumn{2}{|c|}{6} & 1 & 5 & 2 & 3 \\
\hline Mo & \multicolumn{2}{|c|}{ (3) } & $(2)$ & (3) & (3) & (3) \\
\hline $\mathbf{M}$ & \multicolumn{2}{|c|}{3.18} & 3.46 & 3.13 & 3.37 & 3.33 \\
\hline CI of the $\mathrm{M}$ & \multicolumn{2}{|c|}{0.16} & 0.31 & 0.18 & 0.23 & 0.24 \\
\hline $\mathrm{Mdn}$ & \multicolumn{2}{|c|}{3.0} & 3.0 & 3.0 & 3.0 & 3.0 \\
\hline $\mathrm{SD}$ & \multicolumn{2}{|c|}{1.72} & 1.75 & 1.71 & 1.76 & 1.60 \\
\hline
\end{tabular}


When it comes to social interactions: With how many people are astronomers

collaborating, and who are they? On average, astronomers in this study collaborate in significant ways with between 6 and 10 colleagues per week (see Table 4.30). While there is no significant difference between men and women astronomers, those at non-academic institutions report a greater number of collaborators than those at academic institutions.

Table 4.30

Number of collaborators.

Q26 - In doing your work as an astronomer, over the past year, what is the average number of colleagues with whom you collaborated with in significant ways during a typical work-week? (The collaborations may have taken place via face-to-face communication, Skype, telephone, email, etc.)

\begin{tabular}{|c|c|c|c|c|c|c|}
\hline Colleagues Collaborated With & $\begin{array}{c}\text { All } \\
\text { Response } \\
\text { Count }\end{array}$ & $\begin{array}{c}\text { All } \\
\text { Response } \\
\%\end{array}$ & $\begin{array}{c}\text { Rw } \\
\%\end{array}$ & $\begin{array}{l}\mathrm{Rm} \\
\%\end{array}$ & $\begin{array}{l}\mathrm{Ra} \\
\%\end{array}$ & $\begin{array}{c}\mathrm{Rn} \\
\%\end{array}$ \\
\hline (1) none & 12 & 2.5 & 3.3 & 1.8 & 1.7 & 1.1 \\
\hline (2) 1 - 5 colleagues & 229 & 48.3 & 48.0 & 48.7 & 50.4 & 35.2 \\
\hline (3) 6 - 10 colleagues & 144 & 30.4 & 29.3 & 30.3 & 31.3 & 37.5 \\
\hline (4) $11-15$ colleagues & 33 & 7.0 & 7.3 & 7.1 & 7.0 & 8.5 \\
\hline (5) 16 - 20 colleagues & 23 & 4.9 & 5.7 & 4.7 & 5.2 & 6.3 \\
\hline (6) $21-25$ colleagues & 12 & 2.5 & 1.6 & 3.0 & 1.3 & 4.0 \\
\hline (7) 26 - 30 colleagues & 5 & 1.1 & 1.6 & 0.9 & 0.4 & 2.3 \\
\hline (8) 35 - 40 colleagues & 1 & 0.2 & 0.0 & 0.3 & 0.4 & 0.0 \\
\hline (9) $31-35$ colleagues & 2 & 0.4 & 0.0 & 0.6 & 0.4 & 0.6 \\
\hline (10) more than 40 colleagues & 13 & 2.7 & 3.3 & 2.7 & 1.7 & 4.6 \\
\hline Answered Question & \multicolumn{2}{|c|}{474} & 123 & 337 & 230 & 176 \\
\hline Skipped Question & \multicolumn{2}{|c|}{4} & 1 & 3 & 3 & 0 \\
\hline Mo & \multicolumn{2}{|c|}{ (2) } & (2) & (2) & (2) & (3) \\
\hline $\mathbf{M}$ & \multicolumn{2}{|c|}{2.98} & 2.98 & 3.01 & 2.86 & 3.40 \\
\hline CI of the $\mathrm{M}$ & \multicolumn{2}{|c|}{0.15} & 0.31 & 0.18 & 0.19 & 0.29 \\
\hline $\mathrm{Mdn}$ & \multicolumn{2}{|c|}{2.0} & 2.0 & 2.0 & 2.0 & 3.0 \\
\hline SD & \multicolumn{2}{|c|}{1.67} & 1.71 & 1.68 & 1.46 & 1.93 \\
\hline
\end{tabular}

According to the National Science Board (2012), nearly 24\% of physical scientists engage with others internationally through their work. Of the collaborations U.S. astronomers have, it appears a limited number are international; nearly $85 \%$ of U.S. astronomers report 
having six (6) or fewer, or no international collaborators over the course of a year (see Table 4.31). Further, there is no significant difference between men and women astronomers, or those at non-academic or academic institutions when it comes to how many international collaborators U.S. astronomers work with annually.

Table 4.31

Number of international collaborators.

\begin{tabular}{|c|c|c|c|c|c|c|}
\hline $\begin{array}{c}\text { Colleagues Collaborated with in } \\
\text { Another Country }\end{array}$ & $\begin{array}{c}\text { All } \\
\text { Response } \\
\text { Count } \\
\end{array}$ & $\begin{array}{c}\text { All } \\
\text { Response } \\
\% \\
\end{array}$ & $\begin{array}{c}\text { Rw } \\
\%\end{array}$ & $\underset{\%}{\mathbf{R m}}$ & $\begin{array}{c}\mathrm{Ra} \\
\%\end{array}$ & $\begin{array}{l}\mathbf{R n} \\
\%\end{array}$ \\
\hline (1) none & 88 & 18.6 & 20.2 & 17.4 & 20.4 & 11.4 \\
\hline (2) $1-3$ colleagues & 213 & 45.1 & 47.6 & 44.6 & 45.0 & 43.4 \\
\hline (3) $4-6$ colleagues & 98 & 20.8 & 21.0 & 20.7 & 19.9 & 25.1 \\
\hline (4) 7 - 9 colleagues & 25 & 5.3 & 1.6 & 6.6 & 5.6 & 6.3 \\
\hline (5) $10-12$ colleagues & 22 & 4.7 & 4.0 & 5.1 & 5.2 & 5.1 \\
\hline (6) $13-15$ colleagues & 6 & 1.3 & 1.6 & 1.2 & 0.9 & 2.3 \\
\hline (7) $16-18$ colleagues & 1 & 0.2 & 0.8 & 0.0 & 0.0 & 0.6 \\
\hline (8) 19 - 21 colleagues & 1 & 0.2 & 0.0 & 0.3 & 0.4 & 0.0 \\
\hline (9) more than 21 colleagues & 18 & 3.8 & 3.2 & 4.2 & 2.6 & 5.7 \\
\hline Answered Question & \multicolumn{2}{|c|}{472} & 124 & 334 & 231 & 175 \\
\hline Skipped Question & \multicolumn{2}{|c|}{6} & 0 & 6 & 2 & 1 \\
\hline Mo & \multicolumn{2}{|c|}{ (2) } & $(2)$ & $(2)$ & $(2)$ & $(2)$ \\
\hline $\mathbf{M}$ & \multicolumn{2}{|c|}{2.61} & 2.49 & 2.68 & 2.51 & 2.94 \\
\hline CI of the M & \multicolumn{2}{|c|}{0.15} & 0.29 & 0.19 & 0.20 & 0.28 \\
\hline Mdn & \multicolumn{2}{|c|}{2.0} & 2.0 & 2.0 & 2.0 & 2.0 \\
\hline SD & \multicolumn{2}{|c|}{1.69} & 1.62 & 1.73 & 1.55 & 1.87 \\
\hline
\end{tabular}

There are also a limited number of collaborations with others who work primarily in a science/engineering discipline other than astronomy. Tables 4.32 and 4.33 (below) show the number of collaborations between U.S. astronomers from this study and scientists/engineers from other disciplines, and which disciplines outside astronomy these collaborators represent most frequently. Nearly $57 \%$ of U.S. astronomers report having no collaborations in the past year with individuals outside of astronomy, and 27.1\% report working with just 1-3 colleagues 
outside astronomy in this same time period (see Table 4.32). The disciplines outside astronomy that U.S. astronomers most frequently collaborate with include computer/information sciences, physics, electrical/computer engineering, mathematics/statistics, aerospace/aeronautical/astronautical engineering, Earth/atmospheric/ocean sciences, and mechanical engineering (see Table 4.33). While there is no significant difference between men and women astronomers, those at non-academic institutions report a greater number of collaborators outside of astronomy than those at academic institutions (see Table 4.32). This may be somewhat surprising considering astronomers at universities often have potential collaborators from other disciplines in the building next door.

Table 4.32

Number of collaborators outside astronomy.

Q28 - How many of the colleagues with whom you have collaborated with, in significant ways, over the past year work primarily in a science/engineering discipline other than astronomy?

\begin{tabular}{|c|c|c|c|c|c|c|}
\hline $\begin{array}{l}\text { Colleagues Collaborated with } \\
\text { Outside Astronomy }\end{array}$ & $\begin{array}{l}\text { All } \\
\text { RC }\end{array}$ & $\begin{array}{c}\text { All } \\
\text { Response } \\
\%\end{array}$ & $\begin{array}{c}\text { Rw } \\
\%\end{array}$ & $\underset{\%}{\mathrm{Rm}}$ & $\begin{array}{l}\mathrm{Ra} \\
\%\end{array}$ & $\begin{array}{l}\text { Rn } \\
\%\end{array}$ \\
\hline (1) none & 268 & 56.7 & 62.1 & 54.0 & 60.2 & 50.9 \\
\hline (2) 1 - 3 colleagues & 128 & 27.1 & 25.8 & 28.1 & 28.1 & 25.1 \\
\hline (3) $4-6$ colleagues & 45 & 9.5 & 9.7 & 9.3 & 7.4 & 12.0 \\
\hline (4) 7 - 9 colleagues & 13 & 2.7 & 0.8 & 3.6 & 1.7 & 4.6 \\
\hline (5) $10-12$ colleagues & 9 & 1.9 & 0.8 & 2.4 & 1.3 & 3.4 \\
\hline (6) $13-15$ colleagues & 2 & 0.4 & 0.0 & 0.6 & 0.4 & 0.6 \\
\hline (7) $16-18$ colleagues & 2 & 0.4 & 0.0 & 0.6 & 0.4 & 0.6 \\
\hline (8) 19 - 21 colleagues & 1 & 0.2 & 0.8 & 0.0 & 0.0 & 0.6 \\
\hline (9) more than 21 colleagues & 5 & 1.1 & 0.0 & 1.5 & 0.4 & 2.3 \\
\hline Answered Question & \multicolumn{2}{|c|}{473} & 124 & 335 & 231 & 175 \\
\hline Skipped Question & \multicolumn{2}{|c|}{5} & 0 & 5 & 2 & 1 \\
\hline Mo & \multicolumn{2}{|c|}{$(1)$} & $(1)$ & $(1)$ & $(1)$ & $(1)$ \\
\hline $\mathbf{M}$ & \multicolumn{2}{|c|}{1.77} & 1.56 & 1.85 & 1.61 & 2.05 \\
\hline $\mathrm{CI}$ of the $\mathrm{M}$ & \multicolumn{2}{|c|}{0.12} & 0.17 & 0.15 & 0.14 & 0.24 \\
\hline $\mathrm{Mdn}$ & \multicolumn{2}{|c|}{1.0} & 1.0 & 1.0 & 1.0 & 1.0 \\
\hline $\mathrm{SD}$ & \multicolumn{2}{|c|}{1.29} & 0.96 & 1.39 & 1.05 & 1.64 \\
\hline
\end{tabular}

Table 4.33 
Collaborations in disciplines outside astronomy.

\begin{tabular}{|c|c|c|}
\hline $\begin{array}{l}\text { Q29 - If you responded "none" to the previous question, } \\
\text { question. Into which science and engineering disciplines d } \\
\text { (from disciplines other than astronomy) with whom you co } \\
\text { Please check all that apply. }\end{array}$ & $\begin{array}{l}\text { Ise skip thi } \\
\text { our collea } \\
\text { borate bes }\end{array}$ & \\
\hline Non-Astronomy Collaborator Discipline & $\begin{array}{c}\text { Response } \\
\text { Percent }\end{array}$ & $\mathbf{R C}$ \\
\hline Computer/information sciences & 45.7 & 90 \\
\hline Physical sciences - physics & 36.5 & 72 \\
\hline Engineering - electrical/computer engineering & 31.0 & 61 \\
\hline Mathematics/statistics & 24.4 & 48 \\
\hline Engineering - aerospace/aeronautical/astronautical engineering & 23.4 & 46 \\
\hline Physical Sciences - Earth/atmospheric/ocean sciences & 22.3 & 44 \\
\hline Engineering - mechanical engineering & 21.8 & 43 \\
\hline Engineering - other engineering & 11.2 & 22 \\
\hline $\begin{array}{l}\text { Biological sciences (food science, biochemistry, cell biology, } \\
\text { environmental life science, etc.) }\end{array}$ & 8.6 & 17 \\
\hline Physical sciences - chemistry & 7.6 & 15 \\
\hline Social sciences (e.g. economics, education, political sciences, etc.) & 6.1 & 12 \\
\hline Engineering - materials/metallurgical engineering & 5.6 & 11 \\
\hline Engineering - civil engineering & 2.5 & 5 \\
\hline Engineering - chemical engineering & 1.5 & 3 \\
\hline Health & 1.0 & 2 \\
\hline Psychology & 1.0 & 2 \\
\hline I don't know & 1.0 & 2 \\
\hline Other (please specify) & & 19 \\
\hline Answ & d Question & 197 \\
\hline Skip & d Question & 281 \\
\hline
\end{tabular}

Question 29 provided an opportunity for survey respondents to identify other categories for collaborators outside astronomy. Nineteen (19) respondents selected "Other" and provided additional comments. Based on these comments additional categories have been identified and are presented in Table 4.34 below. 
Table 4.34

Collaborators: other discipline categories.

\begin{tabular}{|l|c|}
\hline \multicolumn{2}{|l|}{ Q29 - Other Response Summary } \\
\hline Additional Non-Astronomy Collaborator Categories & $\begin{array}{c}\text { Response } \\
\text { Count }\end{array}$ \\
\hline Optics or optical engineering & 4 \\
\hline Philosophy of science/ethics & 2 \\
\hline Software engineering & 2 \\
\hline \multicolumn{2}{|c|}{ \# Respondents Who Replied “Other" } \\
\hline
\end{tabular}

\section{Perceptions of U.S. Astronomers}

- Research Questions 4: What are astronomers' perceptions about career influences, work related activities, personal motivations for doing astronomy, and how to make astronomy education more reflective of the practice of astronomy?

Perceptions of U.S. astronomers were assessed via four survey questions (Q1, Q33, Q34, and Q35). The survey began intentionally with a question about what influenced the survey respondent in choosing a career as an astronomer. It was felt that beginning the survey with this type of question could increase interest by the respondents and lead to a higher survey completion rate. Data from 477 respondents are used in the analysis of Question 1.

Later in the survey, Question 31 asked participants whether or not they would like to end the survey, or continue on to answer three optional open-ended questions (Q33, Q34, and Q35) to help enrich the study. The three questions were provided, and participants were given the option of answering the three question via the online survey, requesting a telephone interview to answer the questions, or to exit the survey without answering the questions. A total of 365 respondents declined to answer the three open-ended questions. One-hundred-six (106) selected 
yes, and seven (7) stated they would prefer to respond via a telephone interview. Of the seven respondents who requested a phone interview, only six provided contact information in question 32. One person, Respondent \# 362, did not return email or phone calls so an interview could not be arranged.

\section{Astronomer Career Influences}

- Sub-question 4a: What are astronomers' perceptions about factors that influenced them to pursue a career in astronomy?

As we consider ways to encourage more young learners to pursue STEM related careers, including astronomy, it is important to identify what factors have influenced others to enter into the field of astronomy. While astronomers point to a variety of factors, the top influencing factors seem to fall into three major areas: pop culture (A TV program, movie, book, and the Space Program), a personal experience (at a museum, planetarium, science center, observing the sky, or doing research), and a mentor of some sort (teacher or family member). Data from both the online survey and the telephone interviews support these findings. Throughout the phone interviews (see Appendix E) respondents talked about the importance of experiencing and doing things in astronomy, as well as the importance of teachers who inspire their students. Respondent 351 stated, "I think the best learning experience I think you can give kids at any level up to and including college in terms of astronomy, is to actually have them go out and do their own project."

The areas where we see the greatest difference include women where $8.2 \%$ more women reported being inspired by a family member to pursue a career in astronomy than men, and $4.2 \%$ more men reported being inspired by a TV program, movie, or book than women. In addition, 
$6.6 \%$ more astronomers at non-academic institutions were inspired by a teacher or science class in a K-12 school than those who are practicing astronomers at academic institutions.

Table 4.35

Career influences.

Q1 - What do you believe influenced you and led you to a career in astronomy? Please select all that apply.

\begin{tabular}{|c|c|c|c|c|c|c|}
\hline Influence Description & $\begin{array}{l}\text { All } \\
\text { RC }\end{array}$ & $\begin{array}{c}\text { All } \\
\text { Response } \\
\% \\
\end{array}$ & $\begin{array}{c}\text { Rw } \\
\%\end{array}$ & $\underset{\%}{\mathrm{Rm}}$ & $\begin{array}{l}\text { Ra } \\
\%\end{array}$ & $\begin{array}{l}\text { Rn } \\
\%\end{array}$ \\
\hline A TV program, movie, or book & 206 & 43.2 & 40.3 & 44.5 & 47.6 & 45.5 \\
\hline $\begin{array}{l}\text { An informal science experience at a } \\
\text { museum, planetarium, science center, etc. }\end{array}$ & 171 & 35.9 & 33.9 & 36.6 & 36.1 & 39.2 \\
\hline An instructor or science class in college & 133 & 27.9 & 28.2 & 28.0 & 27.5 & 29.5 \\
\hline A teacher or science class in a K-12 school & 132 & 27.7 & 28.2 & 27.7 & 25.8 & 32.4 \\
\hline A family member & 123 & 25.8 & 31.5 & 23.3 & 25.8 & 25.6 \\
\hline $\begin{array}{l}\text { Doing a research project in science as a } \\
\text { child }\end{array}$ & 62 & 13.0 & 14.5 & 13.0 & 13.7 & 12.5 \\
\hline $\begin{array}{l}\text { Participating in a science fair or other } \\
\text { science competition }\end{array}$ & 47 & 9.9 & 9.7 & 9.7 & 8.6 & 11.4 \\
\hline A friend & 28 & 5.9 & 8.1 & 4.7 & 4.7 & 6.7 \\
\hline Prestige associated with astronomy & 22 & 4.6 & 7.3 & 4.1 & 5.6 & 4.6 \\
\hline I'm unsure & 19 & 4.0 & 4.0 & 3.5 & 4.3 & 4.0 \\
\hline A video or computer game & 9 & 1.9 & 0.0 & 2.4 & 1.7 & 2.8 \\
\hline Money to be made as an astronomer & 3 & 0.6 & 0.0 & 0.9 & 0.4 & 1.1 \\
\hline Other & 192 & 40.2 & & & & \\
\hline Answered Question & \multicolumn{2}{|c|}{477} & 124 & 339 & 233 & 176 \\
\hline Skipped Question & \multicolumn{2}{|c|}{1} & 0 & 1 & 0 & 0 \\
\hline
\end{tabular}

One hundred ninety-two (192) respondents selected "Other" in Question 1 and provided additional comments. Based on these comments additional categories are identified in Table 4.36 .

Table 4.36

Other career influences. 


\begin{tabular}{|c|c|}
\hline \multicolumn{2}{|l|}{ Q1 - “Other" Response Summary } \\
\hline Other Career Influence Categories & RC \\
\hline Observing the night/day sky & 42 \\
\hline NASA, Space Program, Space Race & 34 \\
\hline A natural/unexplained interest or curiosity as a child & 14 \\
\hline Building a telescope & 10 \\
\hline \# Respondents Who Replied "Other" & 192 \\
\hline
\end{tabular}

\section{Perceptions About Work-related Activities}

- Sub-Question $4 \mathrm{~b}$. What are astronomers' perceptions about their work-related activities?

Previously in Chapter 4, data were presented outlining what astronomers do. Sub-

Question $4 \mathrm{~b}$ presents an opportunity to explore astronomers' perceptions related to what they do.

Data from closed survey questions, open-ended survey questions, and telephone interviews was employed to draw and support conclusions. Ninety-seven (97) respondents (92 written through the online survey and five via phone interview) chose to answer question 33. Table 4.37 below identifies how astronomers would like to change the activities they currently engage in. Please note that while data for women and men astronomers is presented in these tables, there are too few respondents to questions 33,34 , and 35 to make significant claims of differences between men and women astronomers.

It is apparent that astronomers want to have more time for research; and less time engaged in administrative and bureaucratic activities and writing funding proposals or otherwise seeking funding to support their activities. Data presented previously in Chapter IV (see Table 4.26) indicates astronomers spend significant time performing administrative and/or management duties as well as writing funding proposals. It is important to note that while astronomers, on average, are writing funding proposals just 2-6 times per year, each funding proposal can require an investment of many hours. A recent study found that it takes 116 Principal Investigator hours 
and 55 Co-Investigator hours to prepare the average research grant (von Hippel \& von Hippel, 2015). Further adding to the frustration many astronomers feel, the typical success rate on these funding requests is between 10-30\% (O'Connell, 2016). In addition to more time for research, it is apparent that many astronomers also value the education and public outreach activities they engage in and would like to do more, and this is equally true of both men and women. Telephone interview data from Respondents \#30 and \#351 (as well as others) support these findings as well (see Appendix E). In response to the question, "In a perfect world, how would you change what you as an astronomer do," Respondent \#30 stated, "I would definitely say go to fewer meetings, have more time to actually do science or bring science to other people, to schools or even through you know, undergraduate or graduate student research, through my own research or sharing my own experiences I do." Respondent \#351 stated, "I think the most important thing I would change, the biggest thing I would change would be the amount of time we spend basically trying to get money to do the other things we do."

It is further interesting to note, based on perceptions of U.S. astronomers, the majority of change desired falls into the area of the social interactions typically engaged in, rather than tools and techniques used.

Table 4.37

Astronomers proposed changes to activities they engage in.

Q33 -In a "perfect world" how would you change what you as an astronomer do?

\begin{tabular}{|l|l|c|c|c|}
\hline $\begin{array}{l}\text { A }- \text { Attitudes } \\
\mathbf{T}-\text { Tools and } \\
\begin{array}{l}\text { Techniques } \\
\text { S- Social }\end{array}\end{array}$ & Theme Description & $\begin{array}{c}\text { All } \\
\text { Response } \\
\#\end{array}$ & $\begin{array}{c}\text { Rw } \\
\mathbf{\%}\end{array}$ & $\begin{array}{c}\mathbf{R m} \\
\mathbf{\%}\end{array}$ \\
\hline \multicolumn{1}{|c|}{$\mathbf{S}$} & $\begin{array}{l}\text { Less time/effort writing funding proposals or } \\
\text { otherwise seeking funding }\end{array}$ & 45 & 24.4 & 75.6 \\
\hline
\end{tabular}




\begin{tabular}{|c|l|c|c|c|}
\hline S & $\begin{array}{l}\text { Less time performing administrative or } \\
\text { bureaucratic tasks (e.g. staff meetings, writing } \\
\text { reports, hourly time sheets, office trainings, office } \\
\text { forms, etc.) }\end{array}$ & 27 & 40.7 & 59.3 \\
\hline T, S & More time for research & 20 & 20.0 & 80.0 \\
\hline \multicolumn{2}{|l|}{ Additional Categories Identified by at least 5\% of Respondents } \\
\hline S & $\begin{array}{l}\text { More time and/or recognition for education and } \\
\text { outreach activities, and mentoring }\end{array}$ & 17 & 29.4 & 64.7 \\
\hline S & Less time spent teaching & 5 & 40.0 & 60.0 \\
\hline S & More opportunities to collaborate & 5 & 0.0 & 100.0 \\
\hline & \# or \% Respondents Who Answered Question 33 & $\mathbf{9 7}$ & $\mathbf{3 5 . 1 \%}$ & $\mathbf{6 4 . 9 \%}$ \\
\hline
\end{tabular}

\section{What Makes Astronomy Meaningful?}

- Sub-question 4c: What are astronomers' perceptions about what makes doing astronomy personally meaningful?

Ninety-six (96) respondents (91 written through the online survey and five via phone interview) chose to answer Question 34 related to what makes astronomy meaningful. Several themes emerged via the online survey and telephone interviews. It seems clear U.S. astronomers are motivated by the fact that they are exploring and uncovering that which is unknown; the thrill of discovery (see Table 4.38). The main purpose of research is to discover (Antonakis, 2017) and astronomers today are highly motivated by the fact that they spend time engaged in the search for the unknown. This finding is further supported by the fact that astronomers desire to do more of it (see Table 4.37) and the interview transcripts (Appendix E). In addition to finding meaning in the discoveries they make and the new knowledge they uncover, astronomers also find meaning in sharing what they do with others via mentoring, teaching, education/outreach activities, etc. (see Table 4.38). Again, this finding is supported by the fact that astronomers desire to have more time and recognition for education and outreach activities, and mentoring others (see Table 4.37). Closely linked to the thrill of discovery is the motivation provided by the exploratory 
nature of astronomy and the idea that astronomy is intellectually challenging, and captures the imagination. Numerous astronomers go on to identify the connection between astronomy and the human spirit, the "awe-inspiring" nature of the universe, and the problem-solving nature of the work as factors that motivate them in the practice of their science. Clearly the factors U.S. astronomers from this study find most meaningful, appear to be deeply personal and less tangible.

Table 4.38.

What makes astronomy meaningful to U.S. astronomers.

Q34 - What makes astronomy meaningful to you?

\begin{tabular}{|c|c|c|c|c|}
\hline $\begin{array}{l}\mathbf{A}-\text { Attitudes } \\
\mathbf{T}-\text { Tools and } \\
\text { Techniques } \\
\mathbf{S}-\text { Social } \\
\text { Interactions }\end{array}$ & Theme Description & $\begin{array}{c}\text { All } \\
\text { Response } \\
\quad \#\end{array}$ & $\begin{array}{l}\mathbf{R w} \\
\%\end{array}$ & $\mathbf{R m} \%$ \\
\hline $\mathbf{T}, \mathbf{S}$ & $\begin{array}{l}\text { Making discoveries and/or gaining a deeper } \\
\text { understanding or new knowledge about the universe }\end{array}$ & 26 & 26.9 & 73.1 \\
\hline $\mathbf{S}$ & Mentoring, teaching, or sharing with others & 20 & 30.0 & 80.0 \\
\hline $\mathbf{A}$ & $\begin{array}{l}\text { Exploratory nature of the work; astronomy is } \\
\text { intellectually challenging, captures the imagination } \\
\text { and/or satisfies curiosity }\end{array}$ & 19 & 36.8 & 63.2 \\
\hline \multicolumn{5}{|c|}{ Additional Categories Identified by at least $5 \%$ of Respondents } \\
\hline $\mathbf{A}$ & $\begin{array}{l}\text { The connection between astronomy and humanity, the } \\
\text { human spirit, and/or the human perspective }\end{array}$ & 18 & 16.7 & 83.3 \\
\hline A & $\begin{array}{l}\text { The beauty or "awe-inspiring" nature of the universe; } \\
\text { astronomy provides greater perspective }\end{array}$ & 16 & 25.0 & 75.0 \\
\hline $\mathbf{T}$ & $\begin{array}{l}\text { Problem solving nature of the work - solving } \\
\text { problems/asking and answering questions }\end{array}$ & 14 & 28.6 & 71.4 \\
\hline $\mathbf{T}, \mathbf{A}$ & In astronomy you are investigating "big questions" & 13 & 15.4 & 76.9 \\
\hline $\mathbf{S}$ & Feeling or knowing my work is valued by others & 7 & 28.6 & 71.4 \\
\hline $\mathbf{A}, \mathbf{T}$ & $\begin{array}{l}\text { Astronomy connects other disciplines (e.g. math, } \\
\text { physics, chemistry, climate science, etc.) }\end{array}$ & 7 & 28.6 & 71.4 \\
\hline \multicolumn{2}{|r|}{ \# or \% Respondents Who Answered Question 34} & 96 & $31.3 \%$ & $67.7 \%$ \\
\hline
\end{tabular}

\section{Changes Needed Pre-K through College}


- Sub-Question 4d: What are astronomers' perceptions about how pre-K through college astronomy education should be changed to be more reflective of astronomy as it is practiced today?

Ninety-six (96) respondents (91 written through the online survey and five (5) via phone interview) chose to answer Question 35 related to changes needed to make astronomy education more reflective of real-world practice today. The primary emerging theme in U.S. astronomers is the belief that astronomy should be taught as an evolving process of science, and less like an established set of facts (see Table 4.40). This is largely in agreement with virtually every major science reform initiative in the U.S. over the past four decades (see Table 4.39). The following major reform documents describe this phenomenon as follows:

- Science for All Americans (Rutherford \& Ahlgren, 1990 states, "Scientific ideas are subject to change. Change in knowledge is inevitable because new observations may challenge prevailing theories. In science, the testing and improving and occasional discarding of theories, whether new or old, go on all the time."

- Project 2061: Benchmarks for Science Literacy (American Association for the Advancement of Science, 1994, pg. 5) states, "Scientists themselves accept the notion that scientific knowledge is always open to improvement and can never be declared absolutely certain." The document goes on to state, "The picture of change in science is not simple. As new questions arise, new theories are proposed, new instruments are invented, and new techniques are developed." This leads to new experiments, new observations, new discoveries, and refinement of what we (scientist and non-scientists) believed to be true. 
- National Science Education Standards (National Academies Press, 1996, pg. 21) states, "Science is a way of knowing that is characterized by empirical criteria, logical argument, and skeptical review."

- A Framework for K-12 Science Education: Practices, Crosscutting Concepts, and Core Ideas (National Research Council, 2012, pg. 2-3), precursor to the NGSS states, "Science is not just a body of knowledge that reflects current understanding of the world; it is also a set of practices used to establish, extend, and refine that knowledge." Further the evolutionary practice of science is stressed throughout the NGSS (NGSS Lead States, 2013).

In addition to the belief that astronomy should be taught as an evolving process of science, a second theme also emerged. Astronomers believe learners should have more experience with computing and programming. This is not surprising considering the fact that astronomers today, on average, spend more than $70 \%$ of their time working at their computer (see Table 4.14). As we look at the majority of recommendations made by astronomers as to how education could be improved to be more reflective of their practice, there is close correlation between recommendations being made by astronomers and major science reform initiatives. Table 4.39 below identifies how the top seven (7) recommended changes by U.S. astronomers compares to recommendations made in recent science education reform documents.

Table 4.39

U.S. astronomers' recommendations and science education reform.

\section{Astronomers' Recommended Change and Science Education Reform}


1 - Science for All Americans (Rutherford \& Ahlgren, 1990)

2 - Project 2061: Benchmarks for Science Literacy (American Association for the Advancement of

Science, 1994)

3 - National Science Education Standards (National Academies Press, 1996, pg. 21)

4 - A Framework for K-12 Science Education: Practices, Crosscutting Concepts, and Core Ideas

(National Research Council, 2012)

5 - Next Generation Science Standards (NGSS Lead States, 2013)

\begin{tabular}{|c|c|c|c|c|c|}
\hline Recommended Change by U.S. Astronomers & 1 & 2 & 3 & 4 & 5 \\
\hline $\begin{array}{l}\text { Teach astronomy as an evolving process of science, not an established set of } \\
\text { facts }\end{array}$ & $\mathrm{x}$ & $\mathrm{x}$ & $\mathrm{x}$ & $\mathrm{X}$ & $\mathrm{X}$ \\
\hline More experience with computing/computer programming & $\mathrm{x}$ & $\mathrm{X}$ & $\mathrm{x}$ & $\mathrm{X}$ & $\mathrm{X}$ \\
\hline More opportunities to work with/analyze data & $\mathrm{x}$ & $\mathrm{x}$ & $\mathrm{x}$ & $\mathrm{X}$ & $\mathrm{X}$ \\
\hline More opportunities to do astronomy research & $\mathrm{x}$ & $\mathrm{X}$ & $\mathrm{x}$ & $\mathrm{X}$ & $\mathrm{X}$ \\
\hline More experiences with using and/or building telescopes or other equipment & $\mathrm{X}$ & $\mathrm{X}$ & $\mathrm{X}$ & $\mathrm{X}$ & $\mathrm{x}$ \\
\hline More hands-on/inquiry-based learning & $\mathrm{X}$ & $\mathrm{x}$ & $\mathrm{X}$ & $\mathrm{X}$ & $\mathrm{x}$ \\
\hline More experience with statistics/math & $\mathrm{x}$ & $\mathrm{x}$ & $\mathrm{x}$ & $\mathrm{x}$ & $\mathrm{x}$ \\
\hline
\end{tabular}

NOTE: While language varies within each document, the "spirit" of the language was the focus in this comparison. For example, documents may not explicitly reference engaging students in astronomy research, but may call for students to engage in more research practices.

Table 4.40

Perceived changes needed in astronomy education.

\begin{tabular}{|c|c|c|c|c|}
\hline \multicolumn{5}{|c|}{$\begin{array}{l}\text { Q35 -As you think about your own Pre-Kindergarten through college learning, how do } \\
\text { you think astronomy-related learning experiences could be changed to be more reflective } \\
\text { of what astronomers do? }\end{array}$} \\
\hline $\begin{array}{l}\mathbf{A}-\text { Attitudes } \\
\mathbf{T}-\text { Tools and } \\
\text { Techniques } \\
\mathbf{S}-\text { Social } \\
\text { Interactions }\end{array}$ & Theme Description & $\begin{array}{c}\text { All } \\
\text { Response } \\
\#\end{array}$ & $\begin{array}{l}\text { Rw } \\
\%\end{array}$ & $\underset{\%}{\mathbf{R m}}$ \\
\hline $\mathbf{A}, \mathbf{T}$ & $\begin{array}{l}\text { Teach astronomy as an evolving process of science, } \\
\text { not an established set of facts }\end{array}$ & 26 & 19.2 & 80.8 \\
\hline $\mathbf{T}$ & $\begin{array}{l}\text { More experience with computing/computer } \\
\text { programming }\end{array}$ & 19 & 31.6 & 63.2 \\
\hline \multicolumn{5}{|c|}{ Additional Categories Identified by at least $5 \%$ of Respondents } \\
\hline $\mathbf{T}$ & More opportunities to work with/analyze data & 15 & 20.0 & 80.0 \\
\hline $\mathrm{A}, \mathrm{T}, \mathrm{S}$ & More opportunities to do astronomy research & 12 & 33.3 & 66.7 \\
\hline $\mathbf{T}$ & $\begin{array}{l}\text { More experiences with using and/or building } \\
\text { telescopes or other equipment }\end{array}$ & 10 & 10.0 & 90.0 \\
\hline$A, T, S$ & More hands-on/inquiry-based learning & 10 & 30.0 & 70.0 \\
\hline $\mathbf{T}$ & More experience with statistics/math & 9 & 22.2 & 77.8 \\
\hline
\end{tabular}




\begin{tabular}{|c|l|c|c|c|}
\hline $\mathbf{S}$ & $\begin{array}{l}\text { More experience with astronomers, see what they } \\
\text { do, see them as normal people }\end{array}$ & 8 & 25.0 & 75.0 \\
\hline $\mathbf{T}, \mathbf{S}$ & More experience in written/oral communication & 8 & 25.0 & 75.0 \\
\hline $\mathbf{A}, \mathbf{T}, \mathbf{S}$ & More astronomy in the curriculum & 8 & 37.5 & 62.5 \\
\hline $\mathbf{A}, \mathbf{S}$ & $\begin{array}{l}\text { Improve quality of teachers/teaching (e.g. better } \\
\text { knowledge, less bias, more passion about the } \\
\text { subject) }\end{array}$ & 6 & 0.0 & 100.0 \\
\hline $\mathbf{A}, \mathbf{T}, \mathbf{S}$ & Use astronomy to teach other subjects & 6 & 0.0 & 100.0 \\
\hline & \# or \% Respondents Who Answered Question 35 & $\mathbf{9 6}$ & $\mathbf{3 9 . 6 \%}$ & $\mathbf{5 9 . 4 \%}$ \\
\hline
\end{tabular}

\section{Summary}

U.S. astronomers today are predominantly white and male, and the majority have been practicing astronomy for more than 20 years. Approximately half are employed at non-academic institutions (e.g. NASA, Green Bank Observatory, Kitt Peak National Observatory), and the remainder are employed at universities across the U.S. At these facilities, the research astronomers engage in falls across a broad spectrum of astronomy sub disciplines. There does however appear to be a change taking place in one key demographic; women entering the field. Women with more than 15 years of experience make up just $19.3 \%$ of the total respondents in this study, while women with less than 15 years of experience make up $49.6 \%$ of the total respondents with less than 15 years of experience, indicating women may be entering the field today in significantly greater numbers. If this pattern persists, and efforts could be made to address the "leaky pipeline", it could lead to gender balance within the astronomy community, thus contributing to the national movement to increase representation of women across STEM disciplines.

In their practice of astronomy, U.S. astronomers engage in a variety of attitudes or habits of mind, the use of various tools and techniques, and engage with others through a variety of social interactions. There was significant variance (larger SD) for much of the data in this study. 
This variance indicates many of the day-to-day activities astronomers engage in may be largely influenced by the nature of their research and other job-related responsibilities specific to an institution. However, while there was variation across the total population, there were fewer differences based on gender and institution type (academic verses non-academic) where an astronomer is employed. Key differences in years of experience, time at the computer, and use of intuition were found to exist based on gender, while differences in collaborators, time spent mentoring others, and designing new scientific equipment were found to exist between U.S. astronomers at academic and non-academic institutions. However, astronomers, regardless of gender or institution type, for the most part, experience and prioritize the practices in astronomy in similar ways.

Finally, while recent science education reform efforts do capture much of the current practice of astronomy, this research points to key findings that have the potential to improve science education. These findings will be discussed further as part implications for practice and policy, and recommendations for future research in Chapter 5. 


\section{CHAPTER 5}

\section{SUMMARY AND CONCLUSIONS}

\section{Summary}

This study identified and quantified the activities in which professional astronomers engage, and the findings provide valuable knowledge, that can be used to design formal and informal learning experiences $\mathrm{K}$ through adult to more closely reflect the science of astronomy and the people who engage in the practice. The results serve as a tool for astronomy educators, curriculum developers, and others as they work to create learning experiences that more authentically reflect the practice of astronomy. Further, this study provides an inward look at the astronomical community itself, and provides an opportunity to address desired changes and improvements. Beyond astronomy, the study provides a "roadmap" for similar research to be conducted in other STEM disciplines, providing an opportunity to investigate similarities and differences in the practice of science across disciplines.

In its endeavor to push the bounds of science and technology and explore the universe, the U.S. spends billions of dollars each year. The people who lead this important area of research are called astronomers. In order to protect the investment made and the future of astronomy, a human resource pipeline including a skilled and knowledgeable workforce must be maintained, and a quality education is key. The purpose of this study was to better quantify and qualify what it is that U. S. astronomers today do, providing a tool for those wanting to better understand the practice of astronomy today, and those wanting to create more authentic learning experiences in astronomy that better reflect what astronomers do.

The research questions outlined in Chapter 1 and discussed in Chapter 4 were grounded in three important areas of scientific practice, a) Research Question 1 - attitudes, b) Research 
Question 2 - tools and techniques, and c) Research Question 3 - social interactions. These research questions provided the framework to explore frequency of engagement and/or perceived importance by U.S. astronomers of various scientific practices. In addition, the study took advantage of access to the astronomy community to further explore a fourth research question. Research Question 4 focused on the perceptions astronomers have about career choice influences, work-related activities they engage in, motivations for doing astronomy, and changes needed in education.

The research questions themselves evolved out of an extensive literature review and selfreflection process. Through the literature it was clear that the practice of science in general requires the practice of certain attitudes, such as critical thinking, commitment, respect for evidence, and honesty (Edelson, 2003; Anderson, Bencze, 2000; Anderson, 2002; Kozlow \& Nay, 1976). Further, it was confirmed that astronomers across disciplines were spending significantly less time at the telescope and much more time at their computers (American Astronomical Society, 2005). Also, the literature search indicated scientists use models and mathematics for purposes beyond explaining their data, including predicting outcomes and asking new questions (Van Der Valk, Van Driel, \& De Vos, 2007). As an astronomy educator for more than 20 years, and having worked with numerous astronomers on various research projects throughout that time, the researcher for this study was in a unique position. He was able to combine significant personal knowledge as well as knowledge from the literature review in the development of the research questions and the subsequent survey instrument.

In an effort to secure astronomers' for the study email addresses were collected from various online sources and invitations were sent by the researcher to known U.S. astronomers. In addition, an article with an open invitation to U.S. astronomers was posted on the American 
Astronomical Society website. A total of 503 individuals responded to the survey instrument, however 25 individuals were removed because they did not meet participant requirements, leaving 478 U.S. astronomer participants.

Data provided by survey participants provides a solid foundation from which findings and conclusions are drawn. Today's population of astronomers is largely white, male, and older, however moving toward gender balance. The population as a whole places great importance on the practice of attitudes such as thinking critically, respecting the evidence, honesty, and objectivity. Unlike many might think, astronomers spend little time at the telescope collecting data, but rather the vast majority of their time is spent working at a computer. Further, engaging in administrative duties, writing, use of mathematics, searching for funding, mentoring others, and collaborating with colleagues are all critical tools/techniques and social skills in the practice of astronomy today. Finally, pop culture and personal experience plays a significant role in attracting individuals to a career in astronomy, and exploration and uncovering that which is unknown, the thrill of discovery, is what keeps them motivated.

\section{Conclusions}

The conclusions of the study are organized into implications for policy and practice and recommendations for future research. Astronomy and/or STEM educators, curriculum resource developers, those responsible for astronomy-related or STEM-related education, and the professional astronomy community itself will find this study of particular interest. Implications and areas for future research are outlined in the text that follows.

\section{Implications for Policy and Practice}

This study has a number of implications of importance for education practitioners as well as curriculum developers and those involved in STEM education policy making. Individual 
career choices should be an informed decision, and this study provides a level of information not previously available to those considering or advising about careers in astronomy. In addition, those who are developing curricular resources, teacher professional development or student research experiences, with a focus or claim of authentic astronomy practices, now have a robust resource they can point to in guiding their activities. Further, this research indicates that while the vast majority of the Next Generation Science Standards (NGSS Lead States, 2013) is on target, additional uses of models and the incorporation of intuition practices in science learning could improve the NGSS effort. These implications are further discussed in the text that follows.

Career Advising and Choice. According to survey findings, published in College Student Journal, from more than 800 students, potential job characteristics was one of the major influencing factors in career choice (Beggs, Bantham, \& Taylor, 2008). At the same time, a recent Lemelson-MIT survey shows that more than $50 \%$ of high school students say they may be discouraged from pursuing a STEM career because of a "lack of understanding of the subjects or what people in these fields do" (Lemelson-MIT Program, 2010, p. 1). We also know that once in college, fewer than $40 \%$ of students who enter college majoring in a STEM field complete a STEM degree (Drew, 2011; Presidents Council of Advisors on Science and Technology, 2012). For teachers and guidance counselors, and other adults who often find themselves providing career advice to youth, this study helps paint a detailed picture of what they can expect from a career in astronomy. For example, while many students and other non-astronomers believe astronomers spend a lot of their time at the telescope, the reality is they do not. In addition, many high school astronomy students that this researcher has taught over the years failed to understand the important role math and written communication play in astronomy. This information can be vitally important as individuals consider careers and make decisions about college and their 
professional careers. The sample text that follows, which has been composed by the researcher and informed largely by the findings of this study, could easily be incorporated into career resources to inform high school students' choices:

So, you think you want to be an astronomer? Knowing the "story" of today's astronomers will benefit both those providing career advice, and those who seek it. Who are these individuals we call astronomers, what motivates them, and how do you know if you might be "one of them?"

Astronomers today are inspired by the exploratory and problem-solving nature of their work, the discoveries they make and gaining a deeper understanding about the universe. They point to the beauty or "awe-inspiring" nature of the universe and the connection between astronomy and humanity as motivators. Additionally, they find meaning in sharing their work with others through mentoring, teaching, and various education outreach activities.

For the most part, astronomy is a math and computation intensive science. In preparation for a career in astronomy, students should gain as strong a background as possible in physics, mathematics, and computer science. In addition, nearly all astronomers have earned a $\mathrm{PhD}$, and serve multiple post-docs prior to securing fulltime employment. Approximately 50\% of astronomers work at a university or college, and half are employed at observatory-related facilities or science centers supported by the government or private sector. Astronomers also appear to change jobs at the same rate as the average U.S. worker.

Actual duties performed at the place of employment can vary significantly. At the university level, some astronomers might spend the vast majority of their time teaching classes, while others focus on research and teach no classes. However, most astronomers engage in a combination of research and course instruction. Similarly, some astronomers at the observatory-related facilities spend significant time at the telescope in support of other astronomers or observing equipment, or designing new equipment (e.g. cameras or other detectors, etc.), while others spend the majority of their time engaged in data collection and management at a facility thousands of miles away from the observatory itself.

While astronomers point to their time at the observatory as a motivating factor, with few exceptions, astronomers today spend very little time at the telescope or other instruments collecting data. More than half of U.S. astronomers report spending no time at the telescope within the past year, and overall the average astronomer spends just 1020 hours per year at the telescope collecting data. Modern observatories are located in remote areas of the planet or off the planet all together. Instead, astronomers spend the vast majority of their time at the computer. On average, astronomers today spend more than $70 \%$ of their time at a computer engaged in a variety of activities including:

- searching and/or reading literature related to research or science interests,

- analyzing and interpreting scientific data,

- writing or modifying computer programs/scripts or app development,

- retrieving and using data from pre-existing data archives for various research projects, 
- developing computer simulations,

- performing administrative/management duties,

- writing/reviewing scientific papers/presentations,

- writing grant proposals to secure funding for research/projects, and

- communicating/collaborating with others.

Astronomers today also practice habits of mind or science attitudes. It is important to think critically, maintain a respect for evidence, and remain honest and objective in data analysis and reporting. Further, in the practice of astronomy it is important to be open to uncertainty. The conclusions that the astronomer draws are limited by the data and the tools and techniques that are used. An attitude of commitment is also important. On average, it takes approximately two years to complete a single research project, and many can take three years or longer. In addition, being open to uncertainty and the use of imagination and intuition are important attitudes in the practice of astronomy. It is important to note that while imagination and intuition are important and can lead to new ways of thinking about a problem or a new discovery, astronomers, like other scientists, are bound to the data. New ideas must be subjected to a rigorous, honest and objective data analysis process.

A career in astronomy also means collaboration. In a typical work-week, on average, U.S. astronomers collaborate with six to 10 colleagues. The majority of these colleagues are within the U.S. and are also astronomers themselves. However, some international collaboration as well as collaboration with scientists from other science and engineering disciplines, does take place.

These collaborations often take place as part of research projects and publications. As an astronomer today, one can expect to engage in, on average, five different investigations/research projects at any one time, and author numerous research publications. Seventy percent of astronomers today have either authored or co-authored more than 40 research publications. Obviously, those who choose a career as an astronomer do a great deal of writing.

In addition to sharing their work through written publications, astronomers attend meetings where they share their research through presentations. Astronomers typically attend two to three professional meetings or conferences each year, and make three to four formal presentations per year about their research.

In considering a career in astronomy, it is also important to think about what inspires you. Are you motivated by the "quest" for the unknown? Do you like to problem solve, and for that matter, work on multiple problems at the same time? Does uncertainty make you uncomfortable? In addition, what are your strengths in aptitude? Do you like math and working with computers? How are your written and oral communication skills? Socially, do you like working with others? Answers to such questions can help an individual answer the question, "Is a career as an astronomer a good fit for me?"

Curricular Resources. Whether it is an astronomy course in a school, or an astronomer experience within a virtual gaming environment, findings from this study can help frame the experience for the learner. There are calls nationally for a " 50 percent increase in the number of 
U.S. youth who have an effective, authentic STEM experience each year prior to completing high school" (Committee on STEM Education, 2013, p. 9). The findings in this study capture the authentic practice of astronomy and can be used by astronomy education curriculum/resource developers as well as those developing virtual experiences, such as Second Life and other avatarbased environments, to create experiences that are better grounded in real-world practices.

Research Experiences for Teachers and Students. There are numerous programs in existence today that work to provide teachers and students with authentic research experiences. Research Experiences for Teachers (Silverstein et al, 2009), the NASA-IPAC Teacher Archive Research Project (Rebull et al, 2015), and Pulsar Search Collaboratory (Rosen et al, 2013) are all examples of such programs. As discussed in Chapter 1, such experiences can significantly benefit young learners. Findings from this study provide an opportunity for those developing these kinds of programs to evaluate their current design and make targeted improvements, providing teachers and students with experiences that more authentically reflect astronomy as a whole.

Informing NGSS and Other Science Reform Initiatives. While findings from this study largely support more recent science reform initiatives, there are potential areas for improvement. The NGSS (NGSS Lead States, 2013) calls for the use of models to help organize and explain astronomy-related phenomena (see Table 4.22), however, that is not where it should end. Astronomers in this study also report using models to come up with new questions and develop new hypothesis. Further, A Framework for K-12 Science Education: Practices, Crosscutting Concepts, and Core Ideas (National Research Council, 2012) and the NGSS that followed fail to address the role of intuition in science. The findings from this study show that astronomers use their intuition to come up with new questions to study and identify new 
knowledge resulting from their research. These findings could be used to significantly improve the NGSS by adding performance expectations that call for the use of models to come up with new questions and develop new hypothesis, and to encourage learning experiences that help students explore the role of intuition in science.

Globally, as we attempt to address the issues of "fake news" and individuals choosing news sources that closely align to their personal beliefs, understanding the role of intuition may have broader implications beyond science. Based on a recent Pew Research Center study, 51\% of conservative Republicans, and 34\% of liberal Democrats, who said they see mostly one-sided news say this is okay (Mitchell, Gottfried, Barthel, \& Shearer, 2016). Considering the impact news might have on our "gut reaction" or "first impression" when it comes to formulating beliefs and decision making, perhaps it is time for educators to address the role of intuition in the formulation of new knowledge. If we can help learners to understand effective use of intuition, its limitations, and that it must be supported by evidence, we may be able to positively impact the current information crisis facing the nation.

Gender Balance in Astronomy. Based on data from this study, it does appear that the community of U.S. astronomers may be moving toward gender balance. However, the data are likely impacted at some level by the "leaky pipeline" in astronomy today (Clancy et al, 2017; Cheryan et al, 2016; Ivie, White, \& Chu, 2016). It will be important to further explore these results in an effort to determine how much can be attributed to actual change in gender balance in the discipline of astronomy, and what portion may be attributed to the loss of women early in their astronomy careers.

\section{Recommendations for Future Research}


From the inception of this project, the researcher believed that such a wide survey of U.S. astronomers could not only lead to a deeper understanding of what astronomers do, but it could also help to identify potential future research opportunities. While the implications of this study are numerous and significant, as predicted the study also uncovered rich opportunities for future research. These areas are discussed in the text that follows.

Pop Culture and Astronomy. Based on findings in this study, the factor most frequently identified in leading to an individual selecting a career in astronomy is a TV program, movie, or book (see Table 4.35). While many believe we already graduate too many $\mathrm{PhD}$ astronomers (Benderly, 2010), we may be “missing the boat." In the 50's, 60's, 70's, and 80's we had Sputnik, the Space Race, Moon landings, Star Trek, Star Wars, E.T., and so on. These events and blockbuster movies and TV series had a significant impact. Many young people grew up wanting to be an astronaut or doing something space-related. Today, while astronomy is popular, it does not appear to be the pop culture sensation it once was. What does this mean for long-term public support for astronomy? Further research into the status of astronomy in pop culture, and the role of pop culture in public support for science endeavors could help us better predict the expected level of support for astronomy in the future, and potential budget implications. In addition, we must keep in mind that when the majority of participants in this study chose a career in astronomy, the Internet was not nearly as prominent as it is today. It will be important to assess the role internet-based social media and websites have on interest in careers as an astronomer.

Impact of Years of Experience. In this study, an examination of gender verses years of experience revealed astronomy as a discipline that may be moving toward gender balance (see Table 4.6). Further disaggregating the data based on years of experience for other survey questions may be fruitful as well. Comparing responses to survey questions by astronomers with 
15 years or less of experience with those who have more than 15 years of experience might bring to light changes that are occurring in the practice of astronomy, or point to how astronomers develop professionally over time.

Collaboration in Astronomy. Collaboration among astronomers happens frequently. On average astronomers collaborate in a significant way with six to 10 colleagues per week (see Table 4.30). However, based on this study these same astronomers, on average, collaborate with fewer than four international colleagues per year. This is surprising considering the international nature of astronomy. The result may be accurate, but it could also be attributed, at least in part, to a change in wording and possible survey fatigue. Late in the online survey, Question 26 asked how many colleagues “during a typical work-week" astronomers collaborated with. The very next question (Question 27) asked for the number of international colleagues astronomers collaborated with "over the past year." A respondent may have missed the more subtle change in timeframe, and therefore may have responded with a lesser value than intended.

Beyond the U.S. verses international collaborator question, it would be interesting to know who these collaborators are in more detail. How do collaborations change over time? Also, there seem to be few collaborations across disciplines (see Table 4.32). In an era where interdisciplinary STEM is becoming more critical, it would be valuable to look more closely at these interdisciplinary collaborations in astronomy and explore how they can be promoted among other astronomers.

Gender and Astronomer Perceptions. In questions 33-35 (see Tables 4.37, 4.38, and 4.40) that address astronomer perceptions on work-related activities, motivations, and education reform, there are many instances where the percent response rate for women or men astronomer for a particular item does not match to the percentage of women or men responding to the 
question as a whole. For example, Question 35 asks, “As you think about your own PreKindergarten through college learning, how do you think astronomy-related learning experiences could be changed to be more reflective of what astronomers do?" A total of 96 individuals responded to the question. Of this total $39.6 \%$ of the respondents were women and $59.4 \%$ where men. However, in their responses, just $19.2 \%$ of women astronomers who responded to Question 35 indicated a need for teaching astronomy as an "evolving process of science/not an established set of facts" compared to $80.8 \%$ of men who responded similarly. Again, in Question 35, 15 individuals identified "more opportunities to work with/analyze data" as a need to make learning more reflective of the practice of astronomy, $20 \%$ were women, and $80 \%$ were men. If men and women astronomers share similar perceptions about needs in astronomy education, we would expect to see values closer to $40 \%$ women and $60 \%$ men emerge for themes and categories. This is not the case. While in some cases there appears to be large differences between men and women astronomers, the data is inconclusive because an insufficient number of women and men astronomers chose to answer questions 33-35. In an effort to determine if these differences are real or an artifact of sampling error, a follow-up survey presenting the themes and categories identified in the analysis of questions 33-35 could be developed and administered to U.S. astronomers.

More Opportunities for Astronomers to do EPO. This study indicates astronomers may be interested in engaging in more education and public outreach (EPO) activities. An emerging category in Table 4.37 indicates astronomers want to do more EPO activities. Further, a theme identified in Table 4.38 shows many astronomers feel mentoring, teaching, or sharing with others makes astronomy meaningful to them. If the desire is there to engage in more EPO, 
educators and policy makers should explore ways to create greater opportunities for astronomers to engage in these types of activities.

The Role of Wealth in Selecting a Career in Astronomy. There is a persistent wealth gap in the U.S. The median white household in 2011 had nearly 16 times the wealth holding of blacks, and just over 13 times the wealth holding of Latinos. (Sullivan, Meschede, Dietrich, \& Shapiro, 2015). Further, working class whites, in particular those from Appalachia and rural America, are also disenfranchised. J.D. Vance (2016) in "Hillbilly Elegy" describes this poor white America often referred to as "white trash" and the consequences of centuries of poverty and lack of opportunity. The wealth gap in the U.S. has many implications when it comes to education. For example, poor schools simply cannot afford the same equipment, curricular resources, or skilled personnel that wealthier schools can. As an individual who has worked in astronomy education and outreach for many years, this researcher has made a number of observations:

- telescopes and other astronomical observing equipment, and education programs can be expensive, which can limit access;

- poorer schools have difficulty attracting teachers with sufficient background knowledge in astronomy;

- there are few minorities in astronomy today, and as a result young people of color have far fewer role models and mentors than wealthier whites;

- inner city environments, home to large numbers of minorities, are heavily light polluted, preventing children from seeing all but a few bright objects in the night sky; and

- even in rural communities, where children may have a spectacular and inspiring view of the night sky, schools are often unable to provide sufficient courses in astronomy, 
physics, computing science, and mathematics needed to prepare students for degree programs in astronomy,

- $\quad$ physics, computing science, and mathematics needed to prepare students for degree programs in astronomy.

These barriers alone may be sufficient to prevent children from ever considering a career in astronomy.

This study indicates little progress has been made to attract African Americans, Hispanics, or Native Americans to the field. What role does wealth play in choosing a career in astronomy? Exploring childhood family income levels for U.S. astronomers can help us to better understand the role financial status might play in choosing a career as an astronomer.

Planning for Different Types of Astronomy Research Projects. Findings from this study suggest that most astronomy research projects take one, two, or three or more years to complete (see Figure 4.11). Is this an artifact related to a tendency in the respondents to round "time to completion" to years or is this real? If it is real, such a finding leads to numerous other questions to explore. It would be helpful to better understand the qualities and needs of research projects requiring one year as opposed to two years verses three or more years. Further, it may be useful to explore potential relationships between these projects that last one year, two years, and three years and more. Are they sequential, does one lead to another, or do they happen concurrent where there are shorter term research projects that spin off from the longer $(3+)$ year projects? Finally, what relationship exists between years of experience of astronomers and length of research projects in which astronomers are engaged? A deeper understanding of the answers to these questions could provide some additional guidance to program managers, funders and 
policy makers in planning and the development of solicitations and resources to support various kinds of research projects, which would benefit the astronomy research enterprise as a whole.

Modification of Instrument for Other Disciplines. While there may be some common practices among scientists, there are also obvious differences. For example, consider the study of biology, geology, and astronomy. The majority of biologists study a subject that is tangible. The subject is present with them and variables can be manipulated and responses can be observed over time. However, for the geologist, while the subject being studied is often present, the subject is of such a massive scale that it may be impossible for conditions to be manipulated. They must wait for "mother nature" to bring about the conditions they wish to observe, and that can sometimes take years. The astronomers represent yet another difference. Their subject is not present, but rather light years away in many cases. There is nothing tangible for them to work with. They typically can not manipulate variables, and they do not interact with their subject outside the light that is emitted or reflected. Where biologists can take action, astronomers can not. How do these, and other basic differences, impact, for example, the length of time spent on a research project, or nature of collaborations, or time spent collecting data as opposed to analyzing it? Exploring the similarities and differences between astronomers and scientists in other disciplines could be beneficial to the science enterprise overall, and could lead to greater collaboration across disciplines. It would be interesting to administer a variation if the online survey used in this study to scientists from other disciplines, and compare findings.

Other Methods of Data Collection. This study was exploratory in nature and primarily used an online survey for data collection. Future research could take advantage of other data collection methods to support or further explore findings from this study. This should include 
case studies and additional more in-depth interviews with individual astronomers, and efforts that focus on how astronomers' activities change over time.

\section{Final Thoughts}

Astronomy is often referred to as a "gateway science." Stories of the stars, and discoveries of mysterious black holes and distant Earth-like planets can be powerful motivators for learners of all ages. The science enterprise responsible for advancements in astronomy that will one day lead to new and exciting discoveries requires a citizenry that understands the current practice of astronomy. This practice has changed significantly over the past 100 years, yet what and how young learners are taught is often more reflective of the distant past than astronomy today. If we are to attract the best people into the field, education and training must be more authentic; it must be more reflective of what today's astronomers do. Misconceptions can not only lead to poor career choices, but they can also result in a citizenry that fails to understand the fundamental nature of and needs in astronomy. As the economic climate becomes more and more competitive, an ill-informed citizenry places the entire enterprise at risk. This study brings to light important findings that can better inform practitioners, developers of curricular resources, and policy makers as they work in support of the astronomy enterprise, and more broadly, the STEM enterprise, to educate the next generation of explorers. 


\section{References}

AAAS. (2012). Research and development FY 2013. ( No. 37). Washington, DC: American Association for the Advancement of Science.

Adams, D. M., Mayer, R. E., MacNamara, A., Koenig, A., \& Wainess, R. (2012). Narrative games for learning: Testing the discovery and narrative hypotheses. Journal of Educational Psychology, 104(1), 235-249.

American Association for the Advancement of Science. (1994). Benchmarks for science literacy. New York, NY: Oxford University Press.

American Astronomical Society. (2005). A new universe to discover: A guide to careers in astronomy. Washington D.C.: American Astronomical Society.

American Astronomical Society. (2015). What is the AAS? Retrieved from http://aas.org/about/what-aas.

Anderson, G., \& Ivie, R. (2014). Demographics survey of 2013 US AAS members summary results. Washington, DC: Statistical Research Center of the American Institute of Physics.

Anderson, R. D. (2002). Reforming science teaching: What research says about inquiry. Journal of Science Teacher Education, 13(1), 1-12.

Antonakis, J. (2017). On doing better science: From thrill of discovery to policy implications. The Leadership Quarterly, 28(1), 5-21.

Asbell-Clarke, J. (2012). In Tim Spuck (Ed.), Personal Interview with Jodi Asbell-Clarke Director of the Educational Environments Group at TERC. Cambridge, MA

Banados, M. (Ed.). (2010). The universe of our elders. Santiago, Chile: ALMA.

Barab, S., Pettyjohn, P., Gresalfi, M., Volk, C., \& Solomou, M. (2012). Game-based curriculum and transformational play: Designing to meaningfully positioning person, content, and context. Computers \& Education, 58(1), 518-533.

Beggs, J., Bantham, J., \& Taylor, S. (2008). Distinguishing the factors influencing college students' choice of major. College Student Journal, 42(2), 381-394.

Bencze, J. L. (2000). Procedural apprenticeship in school science: Constructivist enabling of connoisseurship. Science Education, 84(6), 727-739.

Benderly, B. L. (2010). The real science gap. Miller-McCune Online.

Bereiter, C. (1994). Implications of postmodernism for science, or, science as progressive discourse. Educational Psychologist, 29(1), 3-12. 
Beveridge, W. I. B. (1950). The art of scientific investigation. Vintage Books-Random House Inc., New York.

Blumer, H. (1979). Critiques of research in the social sciences: an appraisal of Thomas and Znaniecki's The Polish peasant in Europe and America. New Brunswick, N.J., Transaction Books.

Bono, G., Stetson, P., Monelli, M., Fabrizio, M., Sanna, N., Nonino, M., . . Caputo, F. (2010). Dwarf galaxies in the local group: Cornerstones for stellar astrophysics and cosmology. Paper presented at the SF2A-2010: Proceedings of the Annual Meeting of the French Society of Astronomy and Astrophysics, (1), 327.

Bragaglia, A. (2010). Open clusters as tracers of the galactic disk. Paper presented at the $S F 2 A$ 2010: Proceedings of the Annual Meeting of the French Society of Astronomy and Astrophysics. S. Boissier, M. Heydari-Malayeri, R. Samadi and D. Valls (Eds.).

Bybee, R. (2002). Learning science and the science of learning: science educators' essay collection. NSTA Press, Arlington, VA.

Capra, F. (1991). The tao of physics: An exploration of the parallels between modern physics and eastern mysticism ( $3^{\text {rd }}$ ed.). Boston, MA: Shambhala.

Casey, R. (2012). STEM education: Preparing for the jobs of the future. Washington, DC: U.S. Congress Joint Economic Committee.

Charney, J., Hmelo-Silver, C. E., Sofer, W., Neigeborn, L., Coletta, S., \& Nemeroff, M. (2007). Cognitive apprenticeship in science through immersion in laboratory practices. International Journal of Science Education, 29(2), 195-213.

Chinn, C. A., \& Malhotra, B. A. (2002). Epistemologically authentic inquiry in schools: A theoretical framework for evaluating inquiry tasks. Science Education, 86(2), 175-218.

Cheryan, S., Ziegler, S. A., Montoya, A. K., \& Jiang, L. (2016). Why are some STEM fields more gender balanced than others?. Psychological Bulletin.

Clancy, K. B., Lee, K., Rodgers, E. M., \& Richey, C. (2017). Double jeopardy in astronomy and planetary science: Women of color face greater risks of gendered and racial harassment. Journal of Geophysical Research: Planets.

Committee on STEM Education. (2013). Federal science, technology, engineering, and mathematics (STEM) education 5-year strategic plan. Washington, DC: White House Office of Science and Technology Policy.

Cornell University. (2000, March 2). Astronomers meet at arecibo to discuss next-generation radio telescope. Retrieved from http://www.eurekalert.org/pub_releases/2000-03/CUNSAmaA-0203100.php. 
Creative Research Systems. (2014). Sample size calculator. Retrieved from http://www.surveysystem.com/sscalc.htm\#one.

Custom Insight (2016). Survey Random Sampler. Retrieved from http://www.custominsight.com/articles/random-sample-calculator.asp

DeCarlo, M. (2011). Americans spent over $\$ 15$ billion on video games in 2010. Retrieved from http:/www.techspot.com/news/41991-americans-spent-over-15-billion-on-video-games-in2010.html.

Drake, S. (1990). Galileo: Pioneer scientist (1st Edition ed.). Toronto, Ontario, Canada: University of Toronto Press, Scholarly Publishing Division.

Drew, C. (2011, November 4). Why science majors change their minds (it's just so darn hard). The New York Times

Eason, G. (2004). Bridging the gap from educator to scientist. Journal of College Science Teaching, 34(3), 26-29.

Edelson, D. C. (2003). Realizing authentic science learning through the adaptation of scientific practice. In B. J. Fraser, \& K. G. Tobin (Eds.), International handbook of science education (pp. 317-331). Dordrecht: Kluwer Academic Publishers.

Eisenstein, D., Miller, J., Agüeros, M., Bernstein, G., Blake, G., Feldmeier, J., \& Fischer, D. (2012). Advancing astronomy in the coming decade: Opportunities and challenges - report of the national science foundation division of astronomical sciences portfolio review committee. Washington, DC: National Science Foundation.

Esbjörn-Hargens, S. (2010). Integral theory in action: Applied, theoretical, and constructive perspectives on the AQAL model. New York, NY: SUNY Press.

European Association for Astronomy Education. (1994). Declaration on the teaching of astronomy in european schools. EU/ESO Workshop on Teaching of Astronomy in Europe's Secondary School, Garching, Germany.

Fabian, A. (2010). The impact of astronomy. Astronomy \& Geophysics, 51(3), 325-330.

Fernandes, A., Pessoa, A., \& Silva, M. R. (2014). Does astronomy generate economic benefits? Technological innovation seen through the lens of the european southern observatory's very large telescope'. International Journal of Technology, Policy and Management, 14(4), 327345.

Freedman, D. A., Collier, D., \& Sekhon, J. S. (2010). Statistical models and causal inference: a dialogue with the social sciences. New York, NY: Cambridge University Press. 
Freire, P. (2000). Pedagogy of the oppressed (30th anniversary ed.). New York, NY: Continuum.

Frogel, J. A. (2010). Astronomy's greatest hits: The 100 most cited papers in each year of the first decade of the 21st century (2000-2009). Publications of the Astronomical Society of the Pacific, 122(896), 1214.

GAISE College Report ASA Revision Committee. (2016). "Guidelines for Assessment and Instruction in Statistics Education College Report 2016." Online: http://www.amstat.org/education/gaise.

Gay, L., \& Airasian, P. (2000). Educational research ( $6^{\text {th }}$ ed.). Upper Saddle River, NJ: Merrill.

Gorjian, V., Meredith, K., Petach, H., Ramseyer, E., Spuck, T., Abajian, M., \& Team, NITARP Luminous Data Miners. (2011). Determination of the infrared luminosity of active galactic nuclei (AGN). Bulletin of the American Astronomical Society, (43) 142.

Guieu, S., Rebull, L., Stauffer, J., Vrba, F., Noriega-Crespo, A., Spuck, T., . . Maranto, A. (2010). Spitzer observations of IC 2118. The Astrophysical Journal, 720(1), 46-84.

Hakim, J. (2004). The story of science: Aristotle leads the way. L. J. Hopping (Ed.). Washington, DC: Smithsonian Books.

Hakim, J. (2005). The story of science: Newton at the center. L. J. Hopping (Ed.). Washington, DC: Smithsonian Books.

Hassan, I. H., \& Hassan, A. (1987). The postmodern turn: Essays in postmodern theory and culture. (pp. 12) Ohio State University Press Columbus, OH.

Hawking, S. (2009). Galileo and the birth of modern science. American Heritage's Invention \& Technology, 24(1), 36 .

Herzberg, M. (1952). Classical Myths. Boston, MA: Allyn and Bacon.

Huang, F., Lin, Y., Wu, P., Liu, Y., Jin, R., \& Su, J. (2014). Development of the astronomythemed interdisciplinary curriculum at taipei first girls high school. Paper presented at the International Journal of Modern Education Forum, 3(4), 129-134.

Impey, C. (2012). Astronomy in the United States: Workforce development and public engagement. Organizations, People and Strategies in Astronomy. A. Heck (Ed.). 77-91.

International Astronomical Union. (2015). About the IAU. Retrieved from http://www.iau.org/about/.

Ivie, R., White, S., \& Chu, R. Y. (2016). Women's and men's career choices in astronomy and astrophysics. Physical Review Physics Education Research, 12(2), 020109. 
Jackson, S. (Ed.). (2009). Research methods and statistics: A critical thinking approach (3rd ed.). Independence, KY: Cengage Learning.

Kirkpatrick, J. (2014). The 2013 CSWA Demographics Survey: Portrait of a Generation of Women in Astronomy. Women in Astronomy. Accessed on December 24, 2016 from http://womeninastronomy.blogspot.com/2014/03/the-2013-cswa-demographics-survey.html.

Kozlow, M. J., \& Nay, M. A. (1976). An approach to measuring scientific attitudes. Science Education, 60(2), 147-172.

Laerd Statistics. (2017). Measures of Central Tendency. Retrieved from https://statistics.laerd.com/statistical-guides/measures-central-tendency-mean-modemedian.php

Lemelson-MIT Program. (2010, January 29). Survey reveals ways to enhance teens' interest in science, technology, engineering and mathematics. Science Daily.

LSST: A new telescope concept. (2014). Retrieved from http://www.lsst.org/lsst/public/tour_software.

Markowitz, D. G. (2004). Evaluation of the long-term impact of a university high school summer science program on students' interest and perceived abilities in science. Journal of Science Education and Technology, 13(3), 395-407.

Mathews, M. R. (2003). The nature of science and science teaching. In B. J. Fraser, \& K. G. Tobin (Eds.), International handbook of science education (pp. 981-999). Dordrecht: Kluwer Academic Publishers.

Mayr, E. (2001). The philosophical foundations of darwinism. Proceedings of the American Philosophical Society, 488-495.

Mitchell, A., Gottfried, J., Barthel, M., \& Shearer, E. (2016). The Modern News Consumer: News attitudes and practices in the digital era. Pew Research Center's Journalism Project.

Morelli, B. N. (2006). Using astronomical databases in the search for minor planets. Unpublished manuscript.

Moreno, R., \& Mayer, R. (2007). Interactive multimodal learning environments. Educational Psychology Review, 19(September), 309-326.

Morrison, J. E. (2010). Astrolabe history. Retrieved from http://www.astrolabes.org/history.htm.

Moseman, A. (2009, January 23). The 5 most powerful telescopes, and 5 that will define the future of astronomy. Popular Mechanics. 
NASA. (2014). NASA Fiscal year 2015 - budget estimates. Washington, DC: National Aeronautics and Space Administration.

National Research Council. (2012). A framework for K-12 science education: Practices, crosscutting concepts, and core ideas. Washington D.C.: National Academies Press.

National Research Council. (2011). Introduction. Examining core elements of international research collaboration: Summary of a workshop. Washington, D.C.: The National Academies Press.

National Research Council. (1996). National science education standards. Washington D.C.: National Academies Press.

National Science Board. (2012). Science and engineering indicators 2012. ( No. NSB 12-01). Arlington, VA: National Science Foundation.

National Science Board. (2004). Science and engineering indicators 2004. Arlington,VA: National Science Foundation.

National Science Foundation. (2015). Doctorate-granting institutions, by state or location and major science and engineering fields of study: 2013. Retrieved from http://www.nsf.gov/statistics/sed/2013/data/tab7.pdf

National Science Foundation. (2010). Science \& engineering indicators 2010. Washington, DC: National Science Board.

National Science Foundation. (2007). Impact of proposal and award management mechanisms. Arlington, VA: National Science Foundation.

Nature. (2011). Those who can. Nature, 473(May 12), 123.

NGSS Lead States. (2013). Next generation science standards: For states, by states. Washington D.C.: National Academies Press.

Obama, B. (2009). Remarks by the President at the National Academy of Sciences Annual Meeting. Retrieved from https://www.whitehouse.gov/the-press-office/remarks-presidentnational-academy-sciences-annual-meeting

O'Connell, R. (2016). Tips on Writing Funding Proposals in Astronomy. Retrieved from http://www.faculty.virginia.edu/rwoclass/astr8500/s16-writing-proposals.html.

Ozmon, H., Craver, S. (2003). Philosophical foundations of education ( $7^{\text {th }}$ ed.). Merrill, Upper Saddle River, NJ. 
Pack, H. (2000). The hands-on universe web-based asteroid school project and discovery of trans-neptunian object 1998 FS144. Paper presented at the Amateur-Professional Partnerships in Astronomy, 220, 303-305.

Patton, M. Q. (2002). Qualitative evaluation and research methods (3rd ed.). Thousand Oaks, CA: Sage Publications.

Penn State (2017). Confidence Intervals for the Difference Between Two Population Proportions or Means. Retrieved from https://onlinecourses.science.psu.edu/stat100/node/57.

Pennypacker, C., Deustua, S., Perlmutter, S., Goldhaber, G., \& Arsem, E. (1994). Successful operation of remote telescopes for education and research. Bulletin of the American Astronomical Society, 26, 1423.

Pepe, A., Goodman, A., Muench, A., Crosas, M., \& Erdmann, C. (2014). How do astronomers share data? reliability and persistence of datasets linked in AAS publications and a qualitative study of data practices among US astronomers. PloS One, 9(8), e104798.

Percy, J. R. (2006). Teaching astronomy? why and how? Journal of the American Association of Variable Star Observers (JAAVSO), 35, 248-254.

Péroux, C., Bouché, N., Kulkarni, V. P., York, D. G., \& Vladilo, G. (2011). A SINFONI integral field spectroscopy survey for galaxy counterparts to damped lyman $\alpha$ systems-I. new detections and limits for intervening and associated absorbers. Monthly Notices of the Royal Astronomical Society, 410(4), 2237-2250.

Porquet, D., Dubau, J., \& Grosso, N. (2010). He-like ions as practical astrophysical plasma diagnostics: From stellar coronae to active galactic nuclei. Space Science Reviews, 157(1), 103-134.

Presidents Council of Advisors on Science and Technology. (2012). Report to the president engage to excel: Producing one million additional college graduates with degrees in science, technology, engineering, and mathematics. Washington, DC: Executive Office of the President.

Rahm, J., Miller, H. C., Hartley, L., \& Moore, J. C. (2003). The value of an emergent notion of authenticity: Examples from two student/teacher-scientist partnership programs. Journal of Research in Science Teaching, 40(8), 737-756.

Reader's Digest Association. (1995). Through indian eyes : The untold story of native american peoples. Pleasantville, NY: Reader's Digest Association.

Rebull, L. M., Burtnyk, K., Gorjian, V., Squires, G. K., \& Team, N. (2015, January). NITARP Summative Evaluation Report: 2013 Class. In American Astronomical Society Meeting Abstracts (Vol. 225). 
Rebull, L. (2009). In Tim Spuck (Ed.), Interview with Luisa Rebull - spitzer space telescope research program for teachers and students. Pasadena, CA.

Reiff, R. (2005). Scientists' Conceptions of Scientific Processes: Is the Scientific Method a OneSize-Fits-All Model?. Annual meeting of the Association for the Education of Science Teachers, January 2005.

Reisinger, D. (2011). 91 percent of kids are gamers, research says. Retrieved from http://news.cnet.com/8301-13506_3-20118481-17/91-percent-of-kids-are-gamers-researchsays/.

Richmond, M. W., Filippenko, A. V., Bustamante-Donas, J., Moeller, M., Pawellek, C., Tartara, H., \& Spence, M. (1996). UBV RI photometry of the type ic SN 1994I in M51. The Astronomical Journal, 111(January), 327-339.

Roberts, L. F., \& Wassersug, R. J. (2009). Does doing scientific research in high school correlate with students staying in science? A half-century retrospective study. Research in Science Education, 39(2), 251-256.

Robinson, G. (2004). Replicating a successful authentic science research program: An interview with dr. robert pavlica. Journal of Secondary Gifted Education, 15(4), 148-154.

Rosenberg, M., Russo, P., Bladon, G. \& Christensen, L. (2015). Astronomy in everyday life. Retrieved from https://www.iau.org/public/themes/why_is_astronomy_important/.

Rosen, R., Swiggum, J., McLaughlin, M. A., Lorimer, D. R., Yun, M., Heatherly, S. A., ... \& Ransom, S. M. (2013). The Pulsar Search Collaboratory: Discovery and Timing of Five New Pulsars. The Astrophysical Journal, 768(1), 85.

Rutherford, F. J., \& Ahlgren, A. (1990). Science for all Americans. New York, NY: Oxford University Press.

Ryan, G. W., \& Bernard, H. R. (2003). Techniques to identify themes. Field methods, 15(1), 85109.

Ryle, M., \& Hewish, A. (1950). The effects of the terrestrial ionosphere on the radio waves from discrete sources in the galaxy. Geophysical Journal International, 6(s2), 138.

Sandford, S. A., Aleon, J., Alexander, C. M., Araki, T., Bajt, S., Baratta, G. A., . . Zolensky, M. E. (2006). Organics captured from comet $81 \mathrm{P} /$ wild 2 by the stardust spacecraft. Science (New York, N.Y.), 314(5806), 1720-1724.

Seeds, M. A. (1992). Foundations of astronomy (3rd ed.). Belmont, CA: Wadsworth Inc.

Silverstein, S. C., Dubner, J., Miller, J., Glied, S., \& Loike, J. D. (2009). Teachers' participation in research programs improves their students' achievement in science. science, 326(5951), 440-442. 
Smith, C. (2015). In Tim Spuck (Ed.), Personal interview with chris smith - AURA head of mission in chile. CTIO, Chile.

Sokol, J. (2016). Why the Universe Needs More Black and Latino Astronomers. Retrieved from http://www.smithsonianmag.com/science-nature/how-can-we-give-black-and-latinoastronomers-foundation-reach-stars-180960213/

Spuck, T. S. (2004). A voyage through the radio universe. The Science Teacher, 71(8), 48-51.

Struve, O. (1950). The motions of the galactic cluster-type variables. Publications of the Astronomical Society of the Pacific, 62, 217.

Sullivan, L., Meschede, T., Dietrich, L., \& Shapiro, T. (2015). The Racial Wealth Gap. Institute for Assets and Social Policy, Brandeis University. DEMOS.

Temming, M. (2014, July 14). Astrology vs astronomy: what's the difference?. Sky \& Telescope. Retrieved from http://www.skyandtelescope.com/astronomy-resources/whats-differenceastrology-vs-astronomy/.

The Center for Informed Decision Making. (1998). Sound science. Retrieved from http://www.cygnus-group.com/CIDM/science.html

The Pew Research Center. (2009). Scientific achievements less prominent than a decade ago. Washington, DC: Pew Research Center for the People \& the Press.

Trumper, R. (2006). Factors affecting junior high school students' interest in physics. Journal of Science Education and Technology, 15(1), 47-58.

Turner, K. (2014). The Science Behind Intuition. Psychology Today, accessed online at https://www.psychologytoday.com/blog/radical-remission/201405/the-science-behindintuition.

U.S. Department of Labor. (2016). Employee Tenure in 2016. Retrieved from https://www.bls.gov/news.release/tenure.nr0.htm.

Vance, J. D., \& Vance, J. D. (2016). Hillbilly elegy. HarperCollins.

von Hippel, T., \& von Hippel, C. (2015). To apply or not to apply: a survey analysis of grant writing costs and benefits. PloS one, 10(3), e0118494.

Welser-Sherrill, L. (2007). StarTeach astronomy education: Arab and islamic astronomy. Retrieved from http://www.starteachastronomy.com/arab.html

Wilber, K. (2007). A brief history of everything. Boston, MA: Shambhala. 
Williger, G., Haberzettl, L., Lehnert, M., Nesvadba, N., \& Valls-Gabaud, D. (2010). GALEX NUV lyman break galaxies. Paper presented at the SF2A-2010: Proceedings of the Annual Meeting of the French Society of Astronomy and Astrophysics, 1, 395.

Wuchty, S., Jones, B. F., \& Uzzi, B. (2007). The increasing dominance of teams in production of knowledge. Science, 316(5827), 1036-1039.

Wyatt, S. P. (1950). The frequency function of true axial ratio for the spheroidal galaxies. Astronomical Journal, 55(October), 187.

Yore, L. D., Florence, M. K., Pearson, T. W., \& Weaver, A. J. (2006). Written discourse in scientific communities: A conversation with two scientists about their views of science, use of language, role of writing in doing science, and compatibility between their epistemic views and language. International Journal of Science Education, 28(2-3), 109-141.

Yurimoto, H., Abe, K., Abe, M., Ebihara, M., Fujimura, A., Hashiguchi, M., . . Zolensky, M. E. (2011). Oxygen isotopic compositions of asteroidal materials returned from itokawa by the hayabusa mission. Science (New York, N.Y.), 333(6046), 1116-1119.

Zion, M., Slezak, M., Shapira, D., Link, E., Bashan, N., Brumer, M., . . Valanides, N. (2004). Dynamic, open inquiry in biology learning. Science Education, 88(5), 728-753.

Van Der Valk, T., Van Driel, J. H., \& De Vos, W. (2007). Common characteristics of models in present-day scientific practice. Research in Science Education, 37(4), 469-488.

Wilder, R. L. (1967). The role of intuition. Science, 156(3775), 605-610.

Zwicky, F. (1950a). The cancer cluster of galaxies. Publications of the Astronomical Society of the Pacific, 62(368), 196-201.

Zwicky, F. (1950b). Physical characteristics of the cancer cluster of galaxies. Publications of the Astronomical Society of the Pacific, 62(369), 256-260. 
Appendix A

Invite to Participate Letter 
Dear Astronomers,

What is it that you do in the practice of your science?

This email is an invitation to participate in a research study that explores the activities in which astronomers currently engage. The goal of the study is to characterize what it is that you do as a practicing astronomer. The results will provide educators, curriculum developers, and others a valuable tool as they work to create more authentic (real-world) experiences, improving astronomy learning for all.

Participants in the survey must meet the following 4 requirements:

- have one or more science or science related degrees, with at least one at the Masters Degree level or higher,

- work primarily in one or more of the astronomy sub-disciplines (if you are unsure, please see definition of astronomy sub-disciplines at the end of this letter),

- currently engaged in, or have engaged in, at least one astronomy related research project within the past two years,

- and, be an astronomer primarily based in the United States, a U.S. territory, or a U.S. facility in another country.

This research study is being conducted by Tim Spuck, a doctoral candidate in Curriculum and Instruction under the supervision of Dr. James Rye, professor in the West Virginia University College of Education and Human Services. This research study is part of a dissertation that is being conducted in partial fulfillment of the requirements of the Curriculum and Instruction Doctoral Program at West Virginia University.

Your participation in this study is completely voluntary and consists of completing an online survey, which will take approximately 15 minutes. Your involvement in this research study will be kept as confidential as legally possible. It is not necessary for you to provide your name in order to participate in the study, and all data will appear as an aggregate in the final report without any association to participant names. However, at the end of the survey you will be given the option to answer several additional open-ended questions. If you chose to respond to these additional questions, you may choose to do so via the online survey, or you may request to respond via a telephone interview. If you chose the phone interview, you will be asked to provide your name and contact information, so that a phone interview can be arranged. Your name and contact information will remain confidential.

Although your response to all questions is encouraged, you may skip any question that you do not wish to answer, and you may discontinue the survey at any time. West Virginia University's Institutional Review Board acknowledgement of this project is on file.

LINK to the Online Survey: https://www.surveymonkey.com/r/Astro_Survey

Thank you for your willingness to participate. If you have any questions, please contact me at timspuck@gmail.com or 814-758-9527 (Cell).

Sincerely,

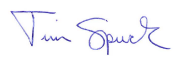

Tim Spuck 


\title{
Appendix B
}

\section{IRB Letter of Exemption - Initial Protocol Review}

\section{W WestVurginiaUniversity. \\ Office of Research Integrity and Compliance \\ 886 CHESNUT RIDGE ROAD MORGANTOWN, WV 25606 \\ Acknowledgement Letter Exempt Initial Protocol Review}

\author{
Action Date \\ $12 / 29 / 2015$ \\ To \\ James Rye \\ From \\ WVU Office of Research Integrity and Compliance \\ Approval Date \\ $12 / 29 / 2015$ \\ Expiration Date \\ $12 / 28 / 2018$ \\ Subject \\ Acknowledgement Letter Exempt Initial Protocol Review \\ Protocol Number \\ 1512954745 \\ Title \\ A Survey of U.S. Astronomers' Attitudes, Tools and Techniques, and Social \\ Interactions Engaged in through their Practice of Science
}

The above-referenced study was reviewed by the West Virginia University Institutional Review Board IRB and was granted exemption in accordance with 45 CFR 46.101.

- This is a well written exemption, category 2 protocol.

Documents reviewed and/or approved as part of this submission:

Brief Lit Review.pdf: 2015-12-29-05:00

Spuck_Cover Letter_b.pdf: 2015-12-29-05:00

Astronomer Survey_12_28.pdf: 2015-12-28-05:00

Spuck_Phone Interview Script.pdf: 2015-12-29-05:00

Documents for use in this study have been acknowledged and are available in the WVUkc system in the Notes and Attachments section of your protocol.

The Office of Research Integrity and Compliance is here to provide assistance to you from the initial submission of an IRB protocol and all subsequent activity. Please feel free to contact us by phone at 304.293.7073 with any question you may have. Thank you. 
Appendix C

Participant Online Survey 


\section{Survey of Practicing Astronomers}

\section{Survey of Practicing Astronomers in the U.S.}

\section{Information About You}

1. What do you believe influenced you and led you to a career in astronomy? Please select all that apply.

An informal science experience at a museum, planetarium, science center, etc.

A video or computer game

A family member

Doing a research project in science as a child

A teacher or science class in a $\mathrm{K}-12$ school

A TV program, movie, or book

Participating in a science fair or other science competition

An instructor or science class in college

A friend

Money to be made as an astronomer

Prestige associated with astronomy

I'm unsure

OTHER: An optional text box has also been included below for you to add additional details, or additional factors that may have influenced you and led you to a career in astronomy. Feel free to respond with either a bulleted list or narrative text.

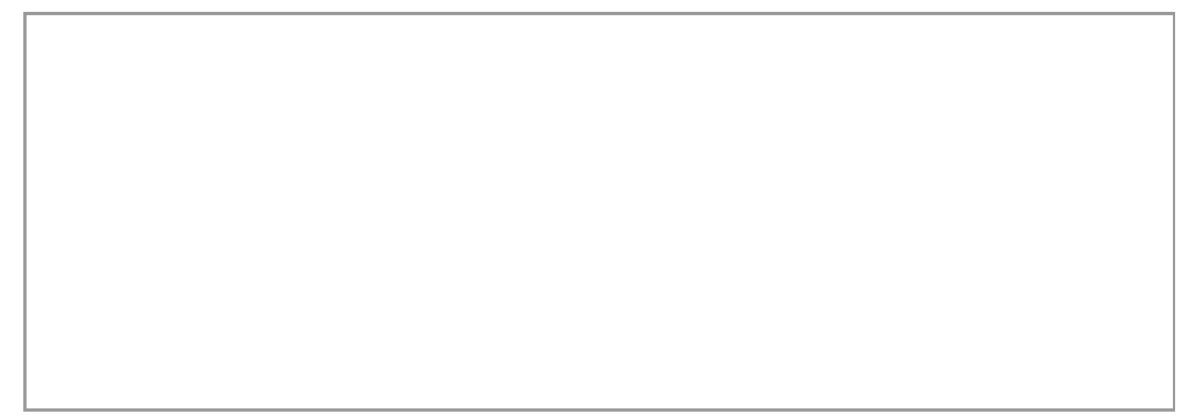


2. Which best describes your current employment situation?

I am primarily employed ... (click on drop-down menu)

Other (please specify)

(n)

3. Please select all degrees completed.

$\square$ PhD

$\square \mathrm{MD}$

$\square$ MA

$\square$ MS

$\square$ MBA

$\square \mathrm{MPH}$

$\square$ BS

$\square \mathrm{BA}$

$\square \mathrm{JD}$

$\square$ Other professional/health degrees (e.g. EDM, EDD, DDS, DVM)

Other (please specify)

(n)

4. Gender (Please feel free to skip this question if you would like.) 


\section{Ethnicity (Please feel free to skip this question if you would like.)}

Select all that apply.

Asian / Pacific Islander

Black or African American

Hispanic or Latino

Native American or American Indian

White

Other (please specify)

6. Into which astronomy sub-discipline(s) is your current professional scientific work and/or research best categorized?

(Please check all that apply.)

Archaeoastronomy

Astrobiology

Astrochemistry

Astroengineering

Astrometry

Astronomy Education

Astrophysics

Celestial mechanics

Computational astronomy

Physical cosmology

Extragalactic astronomy

Other (please specify)

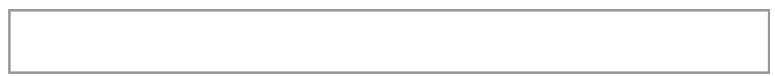

7. For how many years have you been a practicing astronomer?
Galactic astronomy

Gamma-ray astronomy

Gravitational-wave astronomy

Neutrino astronomy

Observational astronomy

Planetary science

Radio astronomy

Solar Astronomy

Stellar astronomy

X-ray astronomy

\section{$\checkmark$}


8. How long have you been at your current place of employment?

\section{$\rightarrow$}

9. Throughout your professional career as a scientist, at how many different institutions have you been employed?

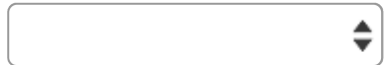

The Practice of Astronomy: Attitudes

10. In doing your work as an astronomer, how important are the following attitudes?

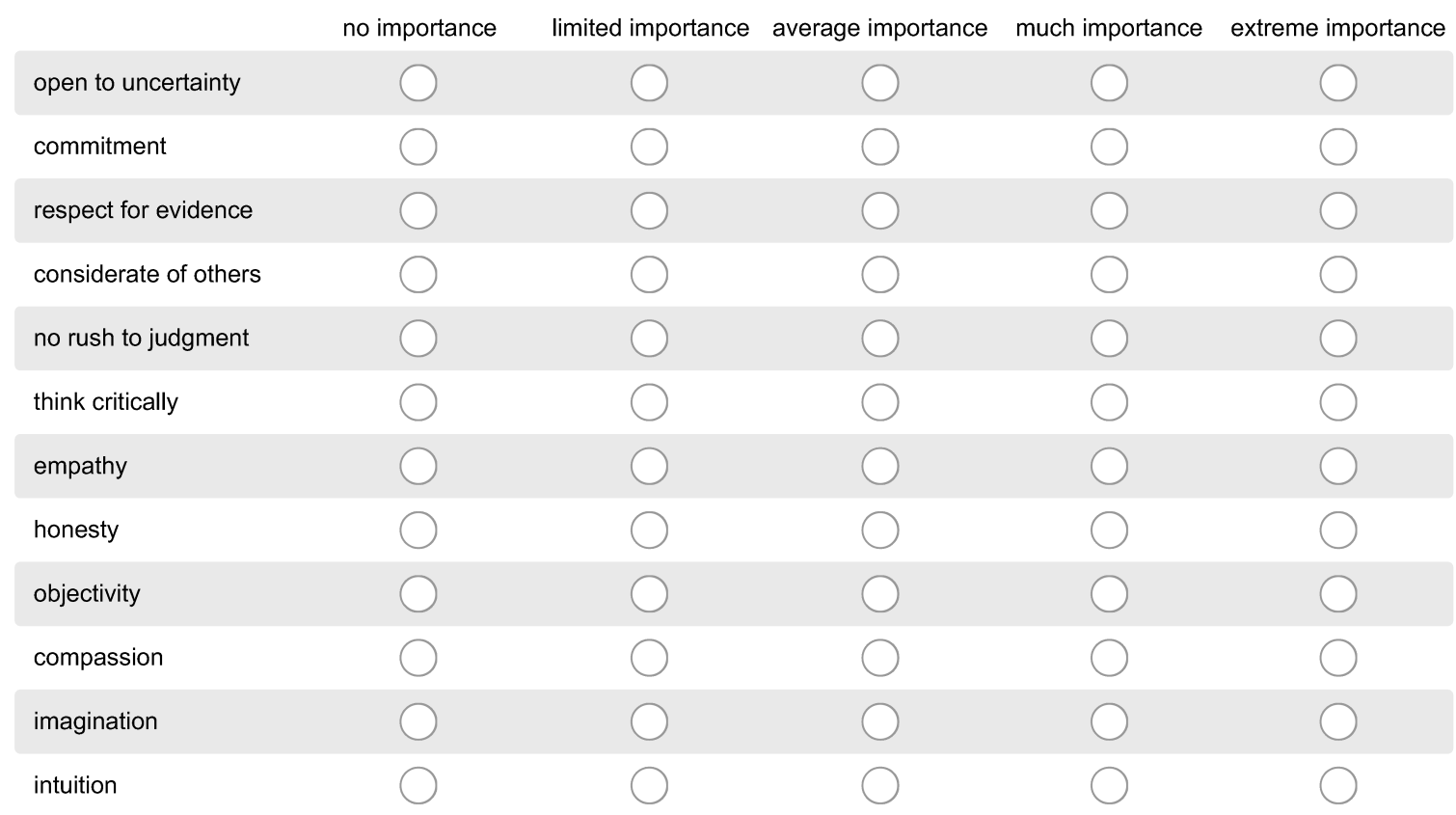

11. When engaging in your activities as as astronomer, how important is it to consider

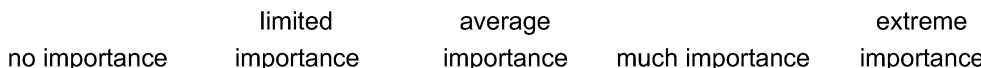

the impact your research might have
on society?
the impact your own personal
opinions might have on your
research?
the impact your own personal biases
might have on your research?


The Practice of Astronomy: Tools and Techniques

12. In your work as an astronomer today, how many different investigations/research projects are you engaged in?

NOTE: For the purpose of this study, a "research project" is defined as a science, technology, engineering, or mathematics investigation that could potentially lead to a journal article, book, or report, and that would have the potential of successfully going through a peer review process, and making it to publication.

\section{$\boldsymbol{\nabla}$}

13. In your work as an astronomer, on average over the past year, how often did you engage in

searching and/or reading literature related to your research or science interests?
thinking about and/or developing scientific questions?
designing procedures for scientific investigations?
designing new scientific equipment and/or instrumentation?
writing or modifying computer programs/scripts or app development?
the development of computer simulations?
the use of data from preexisting data archives for your own research project(s)?
the collection of new scientific data for your own research project(s)?
the analysis and interpretation of scientific data?

14. In your work as an astronomer, on average over the past year, how often did you engage in the use of models (e.g. computer, physical, mathematical, etc.) to

\footnotetext{
help organize or explain observations?

develop new hypothesis?

come up with new questions?
}

How Often

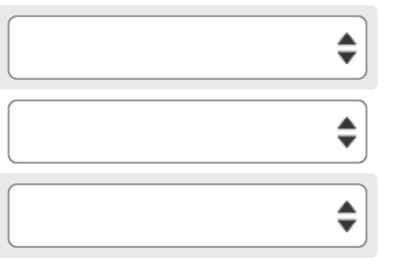


15. In your work as an astronomer, on average over the past year, how often did you

use your imagination?

16. In your work as an astronomer, over the past year, how many hours were you at the instrument/telescope, or in the instrument/telescope control room, when data was being collected for your research project(s)?

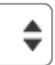

17. In your current work as an astronomer, which type ofdata are typically used by you for your research projects?

Select all that apply.

gamma-ray

x-ray

ultraviolet

visible

$\square$ infrared

microwave

$\square$ radio

gravitational wave

Other (please specify) 
18. In your current work as an astronomer, what kind of data do you typically work with for the research projects you are engaged in?

Select all that apply.

images

spectral data (line or continuum)

data from computer generated models

Other (please specify)

19. In doing your work as an astronomer, on average over the past year, how often did you use the following types of mathematics?

Several times Several times $\sim 7-11$ times a $2-6$ times a
Algebra
Geometry $(+,-, \mathrm{x}, l)$
Trigonometry
Statistics

Other (please specify and state how often)

20. In your work as an astronomer, on average over the past year, what percentage of your time was spent working at your computer and/or tablet (e.g. iPad, etc.)?

$\boldsymbol{\nabla}$

21. From start to conclusion, on average, how long have your astronomy-related research projects taken to complete?

(Please consider the start point to be the time when you begin seriously thinking about the question and begin preliminary research relevant to the question, and the end point to be the submission of the work for publication.)

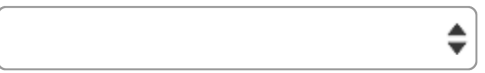


22. In your work as an astronomer, on average over the past year, how often did you

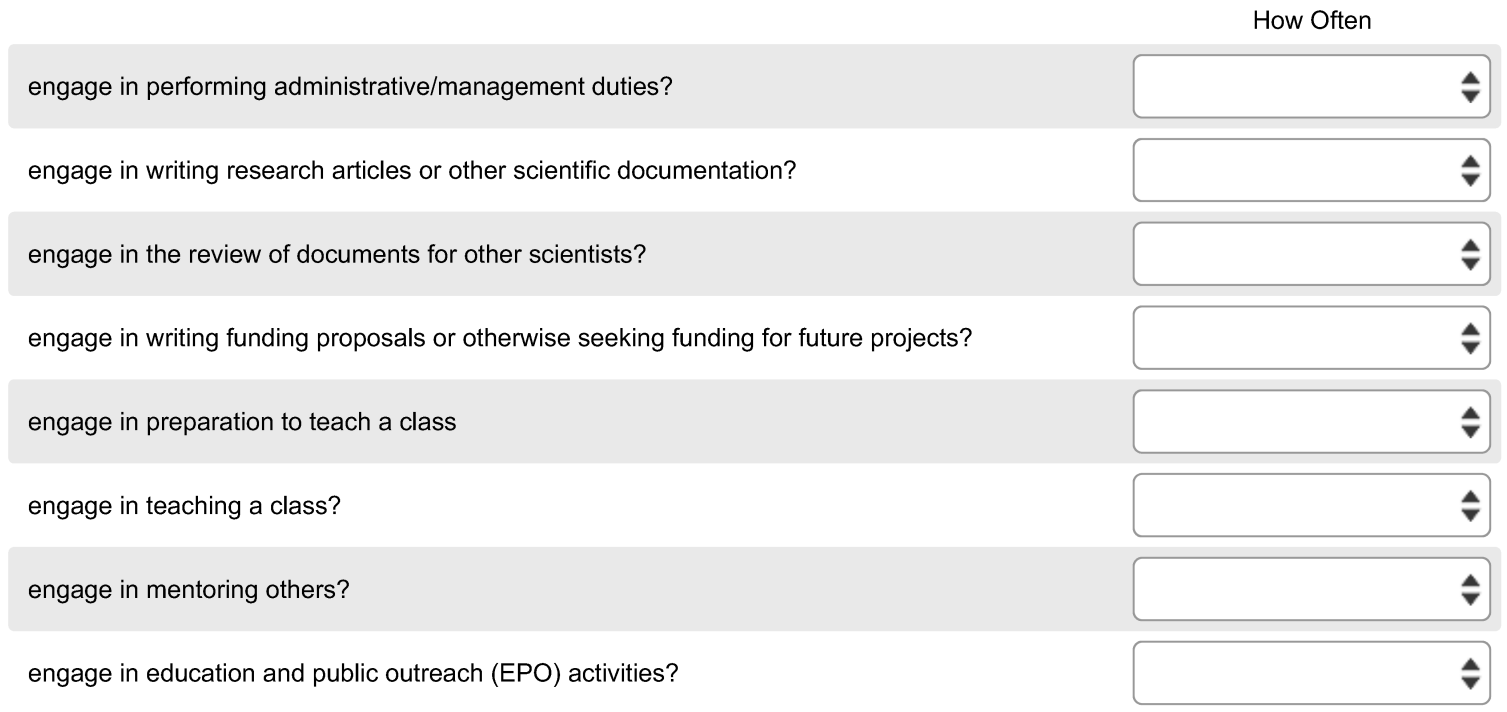

23. On how many different scientific research publications are you considered an author or coauthor, or editor?

(NOTE: For the purpose of this study a "scientific research publication" is defined as a science, technology, engineering, or mathematics (STEM) journal article, book, or report that has successfully gone through the peer review process, and made it to publication or is currently in the process of being published.)

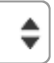

24. In your work as an astronomer, over the past year, how many professional meetings or conferences did you attend?

(Examples may include but are not limited to AAS, AAAS, AGU, etc.)

\section{$\rightarrow$}

25. In your work as an astronomer, over the past year, how many formal presentations did you make about your research at conferences, meetings, workshops, lunch talks, etc.?

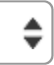


26. In doing your work as an astronomer, over the past year,what is the average number of colleagues with whom you collaborated with in significant ways during a typical work-week?

(The collaborations may have taken place via face-to-face communication, Skype, telephone, email, etc.) $\boldsymbol{\nabla}$

27. How many of the colleagues with whom you have collaborated with in significant ways over the past year are primarily located in a different country?

$\rightarrow$

28. How many of the colleagues with whom you have collaborated with, in significant ways, over the past year work primarily in a science/engineering discipline other than astronomy?

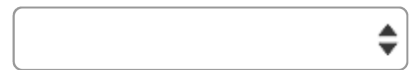


29. If you responded "none" to the previous question, please skip this question.

Into which science and engineering disciplines do your colleagues (from disciplines other than astronomy) with whom you collaborate best fit? Please check all that apply.

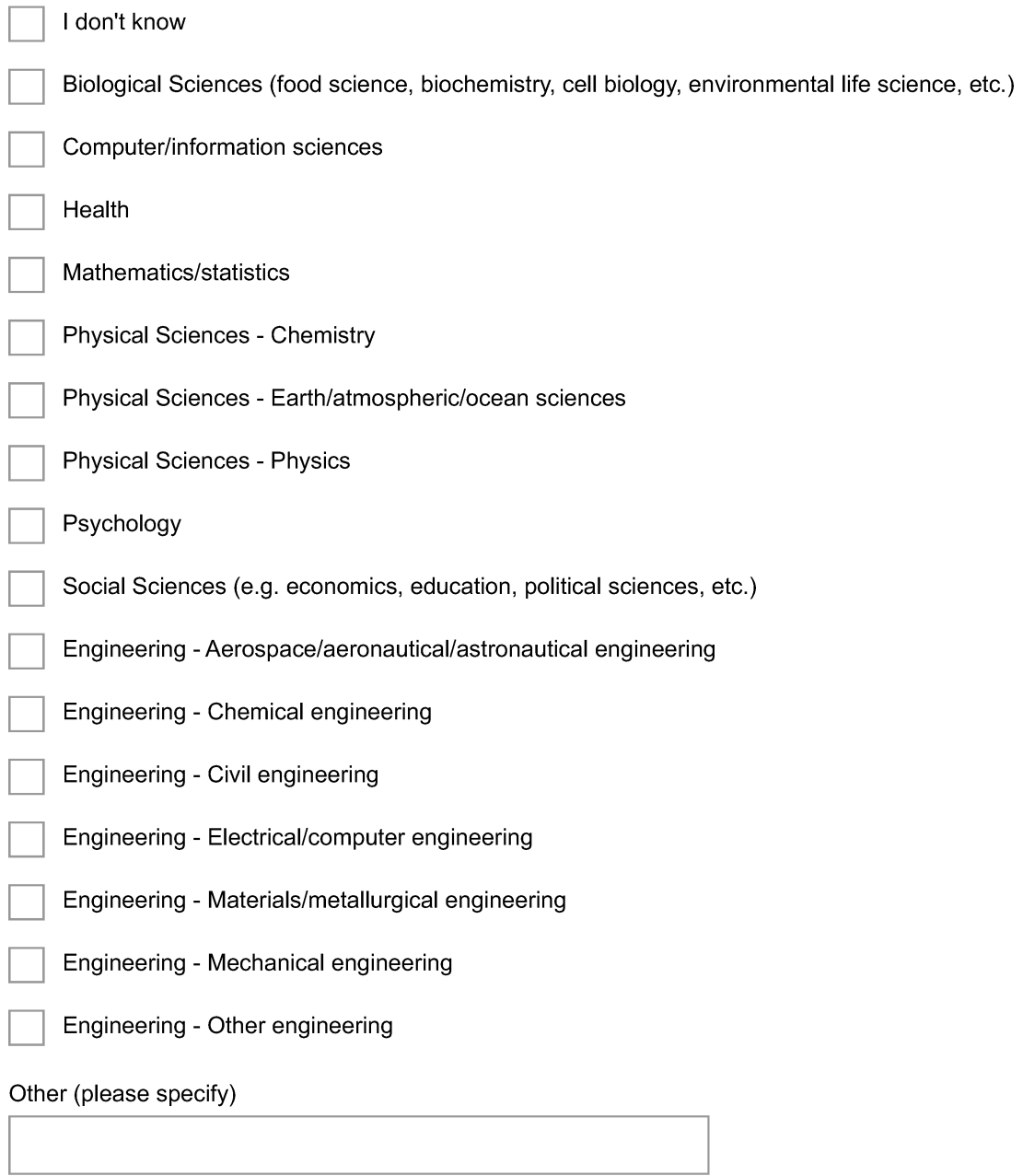

30. As an astronomer, over the past year, what is the average number of hours per week you spent engaged in all work related activities?

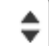


31. You may choose toend the survey at this time, or answer three optional open-ended questions that will help enrich this study. The three questions are as follows:

A. Through your responses in this survey you have identified what you as an astronomer do. In a "perfect world" how would you change what you as an astronomer do?

B. What makes astronomy meaningful to you?

C. As you think about your own Pre-Kindergarten through college learning, how do you think astronomyrelated learning experiences could be changed to be more reflective of what astronomers do?

You may choose to respond to these questions here, or request a telephone interview with the researcher to respond to the questions verbally.

Please select the appropriate response below, and click "Next".

Yes I would like to answer one or more of the optional open-ended questions now via this survey.

I would like to answer one or more of the optional open-ended questions via a telephone interview.

No thank you, I do not wish to respond to these questions. Please take me to the end of the survey now. 


\section{Survey of Practicing Astronomers}

2. Telephone Interview Request

1. Please provide your name and contact information so that a telephone interview can be arranged.

NOTE: due to the large number of people who may request a phone interview, not all those requesting phone interviews will be able to be accommodated. You may or may not be contacted.

Name:

Email Address:

Phone Number:

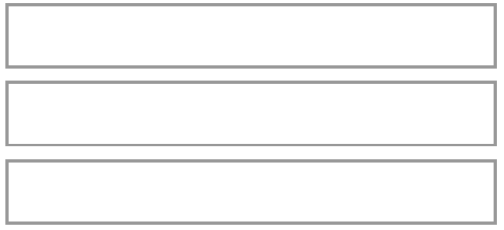




\section{Survey of Practicing Astronomers}

\section{Optional Open-Ended Questions}

Below are three optional open-ended questions. Please respond to any or all of the questions below, and click "Next" at the bottom of the page to end the survey.

1. Through your responses in this survey you have identified what you as an astronomer do. In a "perfect world" how would you change what you as an astronomer do? Feel free to respond with either a bulleted list or narrative text.

2. What makes astronomy meaningful to you? Feel free to respond with either a bulleted list or narrative text.

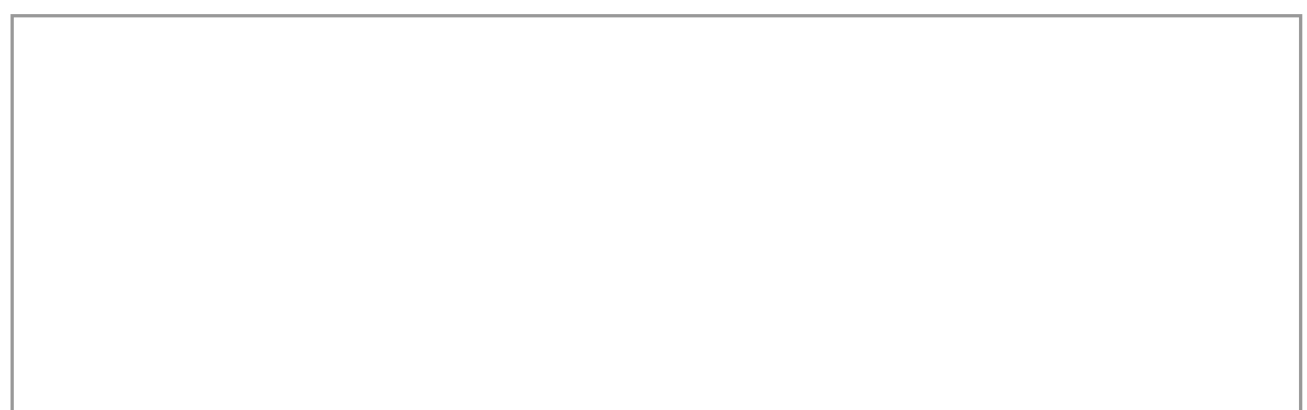


3. As you think about your own Pre-Kindergarten through college learning, how do you think astronomyrelated learning experiences could be changed to be more reflective of what astronomers do? Feel free to respond with either a bulleted list or narrative text.

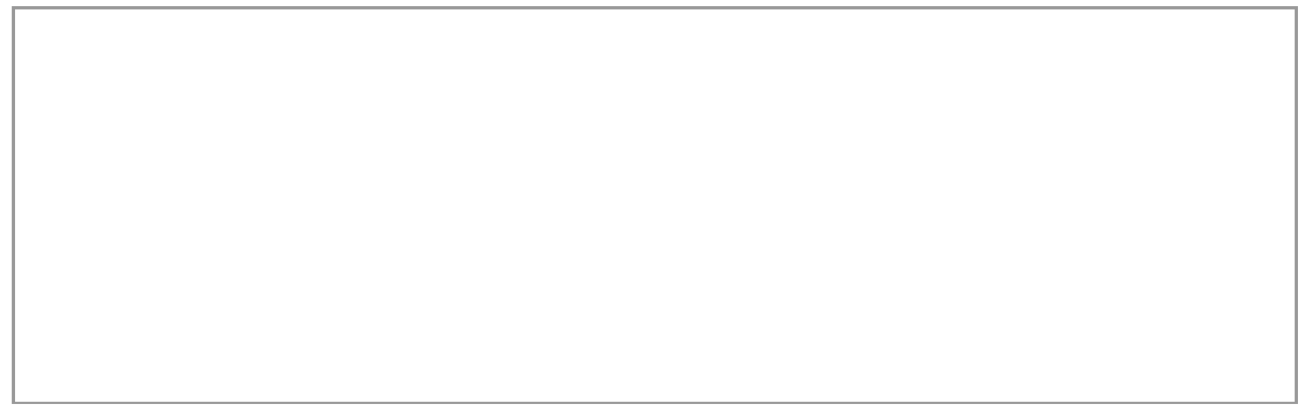




\section{Survey of Practicing Astronomers}

4. Survey Closing

Thank you again for taking the time to complete this survey. If you have any questions or comments, please feel free to contact Tim Spuck at timspuck@gmail.com. 


\section{Appendix D}

Additional Tables - Women/Men, and Academic/Non-academic Institutions

The tables below show the mean (M), confidence interval (CI), and standard deviation (SD) for data that has been disaggregated for men and women astronomers, and astronomers at academic and non-academic institutions who participated in this study.

Table A.1 below identifies how subcategories (men, women, from academic institutions, and non-academic institutions) of participating astronomers rank the importance of various attitudes in their practice of astronomy.

Table A.1

Disaggregated data for attitudes in the practice of astronomy.

Q10 - In doing your work as an astronomer, how important are the following attitudes?

(1) no importance, (2) limited importance, (3) average importance, (4) much importance, (5) extreme importance

\begin{tabular}{|c|c|c|c|c|c|c|c|c|c|c|c|c|}
\hline Attitude & Mw & $\begin{array}{c}\text { CI } \\
\text { Mw }\end{array}$ & SDw & Mm & $\begin{array}{c}\text { CI } \\
\mathrm{Mm}\end{array}$ & SDm & Ma & $\begin{array}{c}\text { CI } \\
\text { Ma }\end{array}$ & SDa & Mn & $\begin{array}{c}\text { CI } \\
\text { Mn }\end{array}$ & SDn \\
\hline Think Critically & 4.81 & 0.07 & 0.39 & 4.75 & 0.05 & 0.45 & 4.76 & 0.06 & 0.45 & 4.78 & 0.07 & 0.43 \\
\hline $\begin{array}{l}\text { Respect for } \\
\text { Evidence }\end{array}$ & 4.76 & 0.08 & 0.46 & 4.71 & 0.06 & 0.54 & 4.67 & 0.07 & 0.56 & 4.74 & 0.07 & 0.49 \\
\hline Honesty & 4.60 & 0.11 & 0.62 & 4.65 & 0.07 & 0.63 & 4.56 & 0.09 & 0.71 & 4.68 & 0.08 & 0.53 \\
\hline Objectivity & 4.58 & 0.10 & 0.57 & 4.57 & 0.07 & 0.62 & 4.49 & 0.09 & 0.64 & 4.61 & 0.09 & 0.58 \\
\hline Commitment & 4.35 & 0.13 & 0.74 & 4.44 & 0.07 & 0.67 & 4.37 & 0.10 & 0.73 & 4.42 & 0.10 & 0.65 \\
\hline $\begin{array}{l}\text { Open to } \\
\text { Uncertainty }\end{array}$ & 4.33 & 0.12 & 0.67 & 4.44 & 0.07 & 0.65 & 4.37 & 0.09 & 0.67 & 4.41 & 0.10 & 0.67 \\
\hline Imagination & 4.15 & 0.15 & 0.81 & 4.31 & 0.08 & 0.74 & 4.18 & 0.11 & 0.80 & 4.27 & 0.11 & 0.75 \\
\hline $\begin{array}{l}\text { No Rush to } \\
\text { Judgment }\end{array}$ & 3.89 & 0.16 & 0.91 & 4.01 & 0.09 & 0.79 & 3.90 & 0.11 & 0.81 & 4.03 & 0.12 & 0.81 \\
\hline Intuition & 3.77 & 0.17 & 0.94 & 4.04 & 0.08 & 0.75 & 3.90 & 0.11 & 0.80 & 4.00 & 0.12 & 0.80 \\
\hline $\begin{array}{l}\text { Considerate of } \\
\text { Others }\end{array}$ & 3.54 & 0.17 & 0.97 & 3.56 & 0.10 & 0.87 & 3.49 & 0.13 & 0.94 & 3.59 & 0.13 & 0.84 \\
\hline Empathy & 3.10 & 0.18 & 0.98 & 2.99 & 0.11 & 0.97 & 2.97 & 0.13 & 0.99 & 3.06 & 0.13 & 0.88 \\
\hline Compassion & 3.02 & 0.17 & 0.94 & 3.01 & 0.11 & 0.96 & 2.97 & 0.13 & 0.97 & 3.02 & 0.14 & 0.93 \\
\hline
\end{tabular}


Table A.2 below identifies how subcategories of participating astronomers rank the importance of considering personal bias and opinion, and impact on society in their practice of astronomy.

Table A.2

Disaggregated data for bias, opinion, and societal impact in astronomy.

Q11 - When engaging in your activities as astronomer, how important is it to consider

(1) no importance, (2) limited importance, (3) average importance, (4) much importance, (5) extreme importance

\begin{tabular}{|l|c|c|c|c|c|c|c|c|c|c|c|c|}
\hline \multicolumn{1}{|c|}{ Attitude } & Mw & $\begin{array}{c}\text { CI } \\
\text { Mw }\end{array}$ & SDw & Mm & $\begin{array}{c}\text { CI } \\
\text { Mm }\end{array}$ & SDm & Ma & $\begin{array}{c}\text { CI } \\
\text { Ma }\end{array}$ & SDa & Mn & $\begin{array}{c}\text { CI } \\
\text { Mn }\end{array}$ & SDn \\
\hline $\begin{array}{l}\text { The impact your } \\
\text { own personal } \\
\text { biases might have } \\
\text { on your research? }\end{array}$ & $\mathbf{3 . 8 2}$ & 0.17 & 0.95 & $\mathbf{3 . 8 2}$ & 0.11 & 0.96 & $\mathbf{3 . 8 2}$ & 0.12 & 0.93 & $\mathbf{3 . 9 1}$ & 0.14 & 0.94 \\
\hline $\begin{array}{l}\text { The impact your } \\
\text { own personal } \\
\text { opinions might } \\
\text { have on your } \\
\text { research? }\end{array}$ & $\mathbf{3 . 5 6}$ & 0.19 & 1.05 & $\mathbf{3 . 6 0}$ & 0.10 & 0.94 & $\mathbf{3 . 5 7}$ & 0.13 & 0.95 & $\mathbf{3 . 6 5}$ & 0.15 & 1.00 \\
\hline $\begin{array}{l}\text { The impact your } \\
\text { research might } \\
\text { have on society? }\end{array}$ & $\mathbf{2 . 9 0}$ & 0.19 & 1.07 & $\mathbf{2 . 8 1}$ & 0.10 & 0.95 & $\mathbf{2 . 7 2}$ & 0.12 & 0.92 & $\mathbf{3 . 0 5}$ & 0.15 & 0.99 \\
\hline
\end{tabular}

Table A.3 below identifies the frequency at which subcategories of participating astronomers engage in various research-related activities.

Table A.3

Disaggregated data for astronomer research related activities.

Q13 - In your work as an astronomer, on average over the past year, how often did you engage in

(1) never, (2) once a year, (3) 2 - 6 times a year, (4) 7 - 11 times a year, (5) once a month, (6) several times a month, (7) several times a week, (8) daily

\begin{tabular}{|l|c|c|c|c|c|c|c|c|c|c|c|c|}
\hline Tool/Technique & Mw & $\begin{array}{c}\text { CI } \\
\text { Mw }\end{array}$ & SDw & Mm & $\begin{array}{c}\text { CI } \\
\text { Mm }\end{array}$ & $\begin{array}{c}\text { SD } \\
\mathbf{m}\end{array}$ & Ma & $\begin{array}{c}\text { CI } \\
\text { Ma }\end{array}$ & SDa & Mn & $\begin{array}{c}\text { CI } \\
\text { Mn }\end{array}$ & SDn \\
\hline Searching and/or & $\mathbf{6 . 8 5}$ & 0.19 & 1.08 & $\mathbf{6 . 8 4}$ & 0.14 & 1.26 & $\mathbf{6 . 9 8}$ & 0.14 & 1.02 & $\mathbf{6 . 8 2}$ & 0.19 & 1.27 \\
\hline
\end{tabular}




\begin{tabular}{|c|c|c|c|c|c|c|c|c|c|c|c|c|}
\hline $\begin{array}{l}\text { reading literature } \\
\text { related to your } \\
\text { research or } \\
\text { science interests }\end{array}$ & & & & & & & & & & & & \\
\hline $\begin{array}{l}\text { The analysis and } \\
\text { interpretation of } \\
\text { scientific data }\end{array}$ & 6.73 & 0.26 & 1.44 & 6.42 & 0.19 & 1.74 & 6.73 & 0.19 & 1.44 & 6.51 & 0.24 & 1.61 \\
\hline $\begin{array}{l}\text { Thinking about } \\
\text { and/or developing } \\
\text { scientific } \\
\text { questions }\end{array}$ & 6.02 & 0.30 & 1.69 & 6.24 & 0.18 & 1.67 & 6.18 & 0.22 & 1.63 & 6.27 & 0.25 & 1.65 \\
\hline $\begin{array}{l}\text { Writing or } \\
\text { modifying } \\
\text { computer } \\
\text { programs/scripts } \\
\text { or app } \\
\text { development }\end{array}$ & 5.94 & 0.40 & 2.20 & 5.62 & 0.26 & 2.33 & 6.03 & 0.28 & 2.08 & 5.91 & 0.34 & 2.25 \\
\hline $\begin{array}{l}\text { Designing } \\
\text { procedures for } \\
\text { scientific } \\
\text { investigations } \\
\end{array}$ & 5.14 & 0.33 & 1.83 & 5.02 & 0.21 & 1.89 & 5.18 & 0.24 & 1.80 & 5.31 & 0.27 & 1.79 \\
\hline $\begin{array}{l}\text { The use of data } \\
\text { from preexisting } \\
\text { data archives for } \\
\text { your own research } \\
\text { project(s) }\end{array}$ & 4.79 & 0.36 & 1.99 & 4.78 & 0.22 & 2.03 & 4.96 & 0.27 & 1.99 & 4.70 & 0.30 & 1.99 \\
\hline $\begin{array}{l}\text { The collection of } \\
\text { new scientific } \\
\text { data for your own } \\
\text { research project(s) }\end{array}$ & 3.50 & 0.33 & 1.85 & 3.95 & 0.22 & 2.02 & 3.86 & 0.26 & 1.92 & 4.03 & 0.30 & 1.98 \\
\hline $\begin{array}{l}\text { The development } \\
\text { of computer } \\
\text { simulations }\end{array}$ & 2.76 & 0.39 & 2.16 & 3.49 & 0.26 & 2.36 & 3.43 & 0.32 & 2.36 & 3.43 & 0.36 & 2.34 \\
\hline $\begin{array}{l}\text { Constructing or } \\
\text { performing } \\
\text { maintenance on } \\
\text { scientific } \\
\text { equipment and/or } \\
\text { instrumentation }\end{array}$ & 1.96 & 0.32 & 1.79 & 2.42 & 0.22 & 2.05 & 2.12 & 0.24 & 1.79 & 2.63 & 0.35 & 2.30 \\
\hline $\begin{array}{l}\text { Designing new } \\
\text { scientific } \\
\text { equipment and/or } \\
\text { instrumentation }\end{array}$ & 1.79 & 0.27 & 1.49 & 2.23 & 0.21 & 1.93 & 1.90 & 0.23 & 1.71 & 2.53 & 0.30 & 2.00 \\
\hline
\end{tabular}

Table A.4 below identifies how often subcategories of participating astronomers engage in the use of models to develop hypothesis, come up with new questions, or help explain observations.

Table A.4 
Disaggregated data for use of models in astronomy.

Q14 - In your work as an astronomer, on average over the past year, how often did you engage in the use of models (e.g. computer, physical, mathematical, etc.) to

(1) never, (2) once a year, (3) 2 - 6 times a year, (4) 7 - 11 times a year, (5) once a month,

(6) several times a month, (7) several times a week, (8) daily

\begin{tabular}{|l|c|c|c|c|c|c|c|c|c|c|c|c|}
\hline Tool/Technique & $\mathbf{M w}$ & $\begin{array}{c}\text { CI } \\
\mathbf{M w}\end{array}$ & $\mathbf{S D w}$ & $\mathbf{M m}$ & $\begin{array}{c}\mathbf{C I} \\
\mathbf{M m}\end{array}$ & $\begin{array}{c}\text { SD } \\
\mathbf{m}\end{array}$ & $\mathbf{M a}$ & $\begin{array}{c}\mathbf{C I} \\
\mathbf{M a}\end{array}$ & $\mathbf{S D a}$ & $\mathbf{M n}$ & $\begin{array}{c}\mathbf{C I} \\
\mathbf{M n}\end{array}$ & SDn \\
\hline $\begin{array}{l}\text { Help organize or } \\
\text { explain } \\
\text { observations }\end{array}$ & $\mathbf{5 . 1 9}$ & 0.36 & 2.00 & $\mathbf{5 . 1 8}$ & 0.23 & 2.14 & $\mathbf{5 . 3 6}$ & 0.26 & 1.93 & $\mathbf{5 . 2 3}$ & 0.34 & 2.22 \\
\hline $\begin{array}{l}\text { Come up with } \\
\text { new questions }\end{array}$ & $\mathbf{3 . 8 8}$ & 0.35 & 1.93 & $\mathbf{3 . 9 4}$ & 0.22 & 1.99 & $\mathbf{3 . 9 0}$ & 0.27 & 1.99 & $\mathbf{4 . 0 8}$ & 0.30 & 1.97 \\
\hline $\begin{array}{l}\text { Develop new } \\
\text { hypothesis }\end{array}$ & $\mathbf{3 . 8 7}$ & 0.34 & 1.89 & $\mathbf{3 . 8 6}$ & 0.23 & 2.09 & $\mathbf{3 . 9 0}$ & 0.27 & 2.03 & $\mathbf{4 . 0 4}$ & 0.31 & 2.05 \\
\hline
\end{tabular}

Table A.5 below identifies how often subcategories of participating astronomers use their imagination and intuition in their practice of astronomy.

Table A.5

Disaggregated data for use of imagination and intuition in astronomy.

Q15 - In your work as an astronomer, on average over the past year, how often did you

(1) never, (2) once a year, (3) 2 - 6 times a year, (4) 7 - 11 times a year, (5) once a month,

(6) several times a month, (7) several times a week, (8) daily

\begin{tabular}{|l|c|c|c|c|c|c|c|c|c|c|c|c|}
\hline \multicolumn{1}{|c|}{ Tool/Technique } & Mw & $\begin{array}{c}\text { CI } \\
\text { Mw }\end{array}$ & SDw & $\mathbf{M m}$ & $\begin{array}{c}\text { CI } \\
\mathbf{M m}\end{array}$ & $\begin{array}{c}\text { SD } \\
\mathbf{m}\end{array}$ & $\mathbf{M a}$ & $\begin{array}{c}\mathbf{C I} \\
\mathbf{M a}\end{array}$ & $\mathbf{S D a}$ & $\mathbf{M n}$ & $\begin{array}{c}\text { CI } \\
\mathbf{M n}\end{array}$ & $\mathbf{S D n}$ \\
\hline $\begin{array}{l}\text { Use your } \\
\text { imagination? }\end{array}$ & $\mathbf{6 . 0 2}$ & 0.34 & 1.87 & $\mathbf{6 . 4 9}$ & 0.19 & 1.75 & $\mathbf{6 . 4 3}$ & 0.23 & 1.73 & $\mathbf{6 . 4 5}$ & 0.26 & 1.72 \\
\hline $\begin{array}{l}\text { Use your intuition } \\
\text { to come up with } \\
\text { new questions to } \\
\text { study? }\end{array}$ & $\mathbf{4 . 6 6}$ & 0.34 & 1.91 & $\mathbf{4 . 8 7}$ & 0.22 & 2.05 & $\mathbf{4 . 8 2}$ & 0.26 & 1.94 & $\mathbf{4 . 9 9}$ & 0.31 & 2.02 \\
\hline $\begin{array}{l}\text { Use your intuition } \\
\text { to identify new } \\
\text { knowledge } \\
\text { resulting from } \\
\text { your research? }\end{array}$ & $\mathbf{4 . 6 1}$ & 0.36 & 1.98 & $\mathbf{4 . 6 6}$ & 0.23 & 2.14 & $\mathbf{4 . 6 8}$ & 0.27 & 2.01 & $\mathbf{4 . 8 8}$ & 0.32 & 2.09 \\
\hline
\end{tabular}

Table A.6 below identifies how often subcategories of participating astronomers use various types of mathematics in their practice of astronomy.

Table A.6 
Disaggregated data for use of math in astronomy.

\begin{tabular}{|c|c|c|c|c|c|c|c|c|c|c|c|c|}
\hline \multicolumn{13}{|c|}{$\begin{array}{l}\text { Q19 - In doing your work as an astronomer, on average over the past year, how often did you use } \\
\text { the following types of mathematics? }\end{array}$} \\
\hline \multicolumn{13}{|c|}{$\begin{array}{l}\text { (1) - never, (2) once a year, (3) - } 2 \text { - } 6 \text { times a year, (4) - } 7 \text { - } 11 \text { times a year, (5) - several times a month, (6) - } \\
\text { several times a week, (7) - daily }\end{array}$} \\
\hline Tool/Technique & Mw & $\begin{array}{c}\text { CI } \\
\text { Mw }\end{array}$ & SDw & Mm & $\begin{array}{c}\text { CI } \\
\mathbf{M m}\end{array}$ & $\begin{array}{c}\text { SD } \\
\mathbf{m}\end{array}$ & Ma & $\begin{array}{c}\text { CI } \\
\text { Ma }\end{array}$ & SDa & Mn & $\begin{array}{c}\text { CI } \\
\text { Mn }\end{array}$ & SDn \\
\hline $\begin{array}{l}\text { Arithmetic }(+,-, \\
x, /)\end{array}$ & 6.72 & 0.12 & 0.68 & 6.70 & 0.08 & 0.72 & 6.75 & 0.09 & 0.66 & 6.71 & 0.10 & 0.64 \\
\hline Algebra & 6.05 & 0.21 & 1.17 & 5.97 & 0.15 & 1.33 & 6.23 & 0.14 & 1.04 & 5.82 & 0.22 & 1.47 \\
\hline Statistics & 5.36 & 0.26 & 1.44 & 5.39 & 0.16 & 1.49 & 5.56 & 0.18 & 1.38 & 5.42 & 0.21 & 1.37 \\
\hline Trigonometry & 4.70 & 0.30 & 1.64 & 5.22 & 0.17 & 1.54 & 5.23 & 0.21 & 1.54 & 4.98 & 0.23 & 1.53 \\
\hline Geometry & 4.72 & 0.29 & 1.61 & 5.09 & 0.17 & 1.51 & 5.13 & 0.20 & 1.48 & 4.90 & 0.23 & 1.51 \\
\hline Calculus & 4.27 & 0.29 & 1.60 & 4.62 & 0.20 & 1.86 & 4.78 & 0.24 & 1.81 & 4.30 & 0.25 & 1.67 \\
\hline
\end{tabular}

Table A.7 below identifies how often subcategories of participating astronomers engage in various social interactions related to their practice of astronomy.

Table A.7

Disaggregated data for social interactions in astronomy.

Q22 - In your work as an astronomer, on average over the past year, how often did you engage in

(1) never, (2) once a year, (3) 2 - 6 times a year, (4) 7 - 11 times a year, (5) once a month,

(6) several times a month, (7) several times a week, (8) daily

\begin{tabular}{|l|c|c|c|c|c|c|c|c|c|c|c|c|}
\hline \multicolumn{1}{|c|}{$\begin{array}{c}\text { Social } \\
\text { Interaction }\end{array}$} & $\mathbf{M w}$ & $\begin{array}{c}\mathbf{C I} \\
\mathbf{M w}\end{array}$ & $\mathbf{S D w}$ & $\mathbf{M m}$ & $\begin{array}{c}\mathbf{C I} \\
\mathbf{M m}\end{array}$ & $\begin{array}{c}\mathbf{S D} \\
\mathbf{m}\end{array}$ & $\mathbf{M a}$ & $\begin{array}{c}\mathbf{C I} \\
\mathbf{M a}\end{array}$ & $\mathbf{S D a}$ & $\mathbf{M n}$ & $\begin{array}{c}\text { CI } \\
\text { Mn }\end{array}$ & SDn \\
\hline $\begin{array}{l}\text { Performing } \\
\text { administrative/ma } \\
\text { nagement duties }\end{array}$ & $\mathbf{5 . 6 9}$ & 0.40 & 2.21 & $\mathbf{5 . 6 7}$ & 0.25 & 2.30 & $\mathbf{5 . 8 7}$ & 0.28 & 2.06 & $\mathbf{6 . 0 2}$ & 0.32 & 2.12 \\
\hline Mentoring others & $\mathbf{5 . 3 3}$ & 0.37 & 2.06 & $\mathbf{5 . 3 2}$ & 0.24 & 2.17 & $\mathbf{6 . 0 5}$ & 0.25 & 1.88 & $\mathbf{4 . 7 4}$ & 0.31 & 2.06 \\
\hline $\begin{array}{l}\text { Writing research } \\
\text { articles or other } \\
\text { scientific } \\
\text { documentation }\end{array}$ & $\mathbf{5 . 3 5}$ & 0.30 & 1.69 & $\mathbf{5 . 0 8}$ & 0.20 & 1.87 & $\mathbf{5 . 3 1}$ & 0.24 & 1.81 & $\mathbf{5 . 2 7}$ & 0.26 & 1.74 \\
\hline $\begin{array}{l}\text { Review of } \\
\text { documents for } \\
\text { other scientists }\end{array}$ & $\mathbf{4 . 2 8}$ & 0.30 & 1.68 & $\mathbf{4 . 1 8}$ & 0.18 & 1.68 & $\mathbf{4 . 2 7}$ & 0.23 & 1.70 & $\mathbf{4 . 3 5}$ & 0.25 & 1.66 \\
\hline $\begin{array}{l}\text { Preparation to } \\
\text { teach a class }\end{array}$ & $\mathbf{3 . 2 7}$ & 0.49 & 2.70 & $\mathbf{3 . 6 5}$ & 0.31 & 2.84 & $\mathbf{5 . 2}$ & 0.37 & 2.8 & $\mathbf{1 . 9 3}$ & 0.25 & 1.66 \\
\hline $\begin{array}{l}\text { Education and } \\
\text { public outreach }\end{array}$ & $\mathbf{3 . 7 8}$ & 0.33 & 1.82 & $\mathbf{3 . 4 9}$ & 0.20 & 1.85 & $\mathbf{3 . 8 5}$ & 0.24 & 1.76 & $\mathbf{3 . 2 8}$ & 0.28 & 1.84 \\
\hline
\end{tabular}




\begin{tabular}{|l|l|l|l|l|l|l|l|l|l|l|l|l|}
\hline (EPO) activities & & & & & & & & & & & & \\
\hline Teaching a class & $\mathbf{3 . 2 1}$ & 0.47 & 2.63 & $\mathbf{3 . 6 1}$ & 0.31 & 2.80 & $\mathbf{5 . 1 4}$ & 0.36 & 2.71 & $\mathbf{1 . 9 0}$ & 0.24 & 1.58 \\
\hline $\begin{array}{l}\text { Writing funding } \\
\text { proposals or } \\
\text { otherwise seeking } \\
\text { funding for future } \\
\text { projects }\end{array}$ & $\mathbf{3 . 1 0}$ & 0.25 & 1.38 & $\mathbf{2 . 9 3}$ & 0.16 & 1.47 & $\mathbf{3 . 2 0}$ & 0.17 & 1.30 & $\mathbf{3 . 0 1}$ & 0.23 & 1.50 \\
\hline
\end{tabular}




\section{Appendix E}

\section{Sample Astronomer Interview Transcripts}

Transcript from Telephone Interview with Respondent \#30

April 13, 2016 at 2:00 PM

Respondent 30: Hello.

Tim Spuck: $\quad$ Hey Jen [Respondent 30].

Respondent 30: Hey Tim, how are you doing?

Tim Spuck: $\quad$ I'm doing good.

Respondent 30: $\quad$ Good, good.

Tim Spuck: $\quad$ And are you doing well in Charlottesville?

Respondent 30: Yeah, everything's going fine. Everything's going fine. How is your study going?

Tim Spuck: $\quad$ It's actually going well. Need to wrap up data collection here and then we'll go ahead and get in to pulling it all together but so far, you know, it's been interesting. Some of the preliminary stuff out there. But I'll be happy to share the whole thing with you and give you your reading material [laughter].

Respondent 30: [laughter] My reading material, oh good, that's good.

Tim Spuck: $\quad$ All right. I know you probably have a million things going on. So, we can ... basically the interview is going to be 3 questions. Then just a last question about whether or not you have anything else to add.

Respondent 30: Okay. I will preface this with saying that I completely do not remember what was even on your survey. So, if there is anything that I'm supposed to refer to or keep in mind you could remind me of it, okay, I completely $\cdots$

Tim Spuck: $\quad$ Nope ... there is nothing that we need to refer to on the survey. It's going to be some open-ended questions that I'm sure from our previous discussions that you will be able to shoot straight from the hip and provide some very good responses.

Respondent 30: Okay, no pressure there, jeez. [laughter]

Tim Spuck: $\quad$ No, no pressure. This can be short, but I might ask a couple of follow-up probing questions. 
Respondent 30: $\quad$ Sure.

Tim Spuck: $\quad$ This should take about 10 minutes.

Respondent 30: Okay.

Tim Spuck: $\quad$ So, if it sounds like if I'm reading from a script it is because I am. So just wanted to get that out of the way so that I can keep consistency with the people that I'm talking to on phone and first of all I just want to ask if it is okay to record the call?

Respondent 30: $\quad$ Sure.

Tim Spuck: $\quad$ Okay. Excellent. Let me go ahead and just start off here. The research project is part of a dissertation that has being conducted in partial fulfillment of the requirements of the Curriculum and Instruction Doctoral Program at West Virginia University. Your involvement in this research project will be kept as confidential as legally possible. Your participation is completely voluntary and you may skip any question that you don't wish to answer or you may discontinue at any time. Do you have any questions or concerns at this time?

Respondent 30: $\quad$ No.

Tim Spuck: $\quad$ Okay. So, the interview consists of three open-ended questions. The first question is as follows. So, through your responses in the online survey you have identified what you as an astronomer do. In a perfect world, how would you change what you as an astronomer do?

Respondent 30: $\quad$ Okay so this is the part where I don't remember what I said, assuming that I ... sorry ...

Tim Spuck: It's okay. If you think about the activities that you currently engaged in on a day-to-day basis, what would you be interested about?

Respondent 30: $\quad$ I'm going to say that assuming that I, I honestly captured what I spend most of my time doing, I would definitely say go to a few meetings, have more time to actually do science or bring science to other people, to schools or even through you know, undergraduate or graduate student research, through my own research or sharing my own experiences I do, you know I spend a lot of my time in meetings. And I think if I could change what I was doing I like to support work that I do and I like the research that I do. But I feel like I go to more meetings now than I ever have where I'm not spending time doing either of these things.

Tim Spuck: $\quad$ So, what do you find yourself spending your time on in like most of the meeting, are they ... uh ... what do most of them I guess deal with? 
Respondent 30: I mean, it varies. Let's see, this morning I had one that was observatory wide. So, that was a little bit more of kind of NRAO [Observatory] business. I had one that was for a specific team that I'm on. I'm on the software support team. So, we had the team meeting this morning and the one after that was for the science staff. So, actually this morning was pretty varied. One was kind of an Observatory business, one was my specific, the team that I support business, and then, so it's more of a technical meeting, and then the third one was for all the science staff so it's a subset of the Observatory, but bigger than just ALMA [Observatory].

Tim Spuck: $\quad$ Okay all right. So, thank you for your response. So, moving on to question number two, what makes astronomy meaningful to you?

Respondent 30: $\quad$ So, I think the things ... the part that is meaningful for me is being able to, being fortunate, I do think I'm very fortunate, to get paid to do what I do and even if it's not necessarily me that's out there, you know, doing the observations or writing the papers or you know discovering these things, working for the observatory, I'm actually ... I'm in a position to support the people who are doing that. So, I think I've never, I was not one of those kids who grew up, you know, wanting to do astronomy, you know always knowing that I was going to be an astronomer when I grow up, I never knew that. I kind of decided it after graduate school even as I was finishing graduate school I really wasn't sure that I wanted to do this full time. And, you know, it was, it was actually fairly recently that I think I finally decided that not only could I make it a job but I did want to make it a job. So, I do think that I'm very lucky ... but, as I said in the first sentence, or in the first answer, it would be nice if I could spend a little bit more time doing the stuff that I find meaningful rather than all the stuff I have to do between those things.

Tim Spuck: $\quad$ Okay, all right, thank you. And so moving on to the third and the final question. As you think about your own pre-kindergarten through college learning and those experiences? How do you think astronomy related learning experiences could be changed to be more reflective of what astronomers do?

Respondent 30: $\quad$ So, I think it should involve more computers. I personally did not have any, at least as far as I know did not have any astronomy classes until College other than probably there was some solar system stuff at some point in middle school, because I knew my nine planets when there were still nine planets, so,

Tim Spuck: Hey, well, guess what? You might get that call to have nine planets again.

Respondent 30: Is that right? Are they bringing it back? 
Tim Spuck: $\quad$ Well no, not Pluto. But this other one that's out beyond Pluto, the Neptune-sized object.

Respondent 30: Okay, it's going to be a planet? I would have imagined it falls under all the same, well it should fall under all the same auspices as Pluto. But anyway, I'm fully support there being 8 . But when I learned them of course in the olden days there were nine. Anyway, other than that I really didn't have any astronomy until college and even there you know in some of the introductory classes there was still classes on constellation, you know and this is what people think astronomy is and I definitely think, you know if we are actually going to fairly represent what astronomers do, you know, you want to have more computers, we want to have building of models and comparison of models to data, and have it be more like a lab science. Every kid in high school take physics lab and biology lab and chemistry lab and you know we never had an astronomy lab. That was not just part of the curriculum and I think that should be portrayed as a laboratory science just as much as any of the others. In particular, comparing you know, what things should look like so what a simulation says, to what you actually measure, because that's really, I think in real life, what pretty much everyone is doing. You're either working on one side of that argument or the other, you know you're creating a prediction or you are testing the prediction and you know paving the way for more better predictions to be made. I think even in college you know a lot of the like even the homework assignments we got were lot of like pen and paper. You know, problem sets, just clean problem sets and I certainly don't solve problems that way now. Although we did of course have labs and introductory classes and things like that but, you know the more I guess, being an observational astronomer, I guess, I'm a little more biased in that direction. But I do think that if we really wanted people to see what astronomers do, I think it needs to be a little grittier, a little noisier, if that make sense, rather than kind of ...

Tim Spuck: $\quad$ Yeah, perfect sense. So, that concludes the interview questions. Do you have any other thoughts or comments that you like to add before we hang up?

Respondent 30: $\quad$ No, I don't think so.

Tim Spuck: $\quad$ Okay. Well, that's fantastic and thanks so much Jen [Respondent 30], I really appreciate you taking part of this.

Respondent 30: $\quad$ Absolutely. Good luck with everything.

Tim Spuck: $\quad$ Thank you. And I'll be happy to share the results with you and hopefully I'll run into you sometimes soon.

Respondent 30: $\quad$ I hope so too. 
Tim Spuck: $\quad$ All right you take care.

Respondent 30: $\quad$ You too Tim, thanks bye.

Tim Spuck: Bye. 


\section{Transcript from Telephone Interview with Respondent \#351 \\ April 11, 2016 at 5:30 PM}

Respondent 351: Hello this is John Weiss [Respondent 351].

Tim Spuck: Hey John [Respondent 351] this is Tim Spuck how are you doing?

Respondent 351: I am good how about yourself?

Tim Spuck: I am doing well, thank you very much for taking your time to do the interview. I really appreciate it. So, first of all I wanted to check with you and just make sure that it would be okay to record the call.

Respondent 351: Certainly.

Tim Spuck: $\quad$ Okay. Great, great and from my end I am pretty much just to follow a script here and so some things we are going to be ... uh ...it is going to be a little redundant, but I am just going to read off of my script just to stay with my format for the study, and so if you are okay to get started we can just get started.

Respondent 351: $\quad$ Sure thing.

Tim Spuck: $\quad$ Okay so this research project is part of a dissertation that is being conducted in partial fulfillment of the requirements for the Curriculum \& Instruction Doctoral Program at West Virginia University. Your involvement in this research project will be kept as confidential as legally possible, your participation is completely voluntary and you may skip any question that you do not wish to answer or you may discontinue at any time. Do you have any questions or concerns at this time?

Respondent 351: $\quad$ No.

Tim Spuck: $\quad$ Okay and we have already confirmed that I am going to audio tape this and I can do a written transcript from it, so you have already approved the recording of the conversation.

Respondent 351: $\quad$ Yes.

Tim Spuck: $\quad$ Okay so the interview consists of three open-ended questions. The first question is as follows, through your responses in the online survey you have identified what you as an astronomer do. In a perfect world, how would you change what you as an astronomer do?

Respondent 351: I think the most important thing I would change, the biggest thing I would change would be the amount of time we spend basically trying to get money to do the other things we do. I am sure you have seen statistics and things like that about how much time is spent by researchers, especially 
Tim Spuck: $\quad$ Sure and I think that's what it's about and I can certainly say that ... your colleagues certainly share in that opinion as far as what are the things that they might change as well.

Respondent 351: $\quad$ Yeah I kind of figured [laughter].

Tim Spuck: Okay let's move on to the next question here, thanks for the response...the next question is, what makes astronomy meaningful to you?

Respondent 351: Part of it is a connection to something bigger than, not just even humans, but just earth and seeing how earth kind of relates to everything in the universe. But I have to confess, this is the thing I think a lot of my colleagues would agree with if you cornered us and really got us to answer honestly. A lot of it is just the sheer joy of seeing things and learning things that there's just so many cool things that essentially the universe has laid out and done, the old thin ants from The Once and Future King, "anything not forbidden is mandatory." The universe manages to find ways of doing almost anything that we think it could do and that I think is meaningful. I mean it is not meaningful in that deep philosophical sense I suppose, but it is meaningful in that sense that I just really kind of get a thrill out of all these things. Trying to put science behind them and understanding behind them, but also just seeing them sometimes, and just going like wow the universe is still bigger and more creative than humanity has managed to get.

Tim Spuck: $\quad$ Yeah I think it is interesting that when you look at all the missions and whether it's the mission to Pluto or to Jupiter and still looking at the moons of Jupiter and just all of the things that you think you know what to expect but then there's all of these things that you never expected and they're there.

Respondent 351: Exactly. That was the quote from...there was one part of the Voyager mission somebody reportedly responded that had seen some of the images come down, "Who ordered that?" 
Tim Spuck: [Laughter] Yeah I have to agree with you I think the universe is just an amazing place and does some amazing things. Okay so moving on to the third question here; as you think about your own pre- kindergarten through college learning how do you think astronomy-related learning experiences could be changed to be more reflective of what astronomers do?

Respondent 351: I think one of the big things, and I do try to convey to my college students constantly, is the fact that we do do what we do in many ways more for the thrill of just knowing things and learning things and exploring things. And people always ask why do you do astronomy, especially when that there is funding in line, and there is always this well we are trying to understand the origins of life and we are trying to improve technologies or whatever ... but in the end, I think most of us do it because we are kind of like artists in the sense that if we weren't doing this we might go mad. And I think I try to convey that to kids especially you know kind of in their junior senior high school range. I think little kids understands really well about that kind of thing; they are still young enough they haven't been taught that it is not as cool to be curious, but at some point, they get this idea that that kind of curiosity is bad, and I think we need to teach them that no we are not just people sitting in lab coats doing things by some recipe book. It really is a creative fun process and messy.

I think that's the other thing they need to know is that it is messy and that you make a lot of mistakes along the way and it is okay for them to make mistakes too. At least certain mistakes are okay for the young kids to make [laughter]. Not like a blank check to go out shooting up heroin or something [laughter]. But I mean, I think that is one thing that we don't convince kids about, especially science classes are bad, math and sciences, is that I think we give them the impression that there are right answers and they should be able to get the right answers. If they can't get the right answers they are doing things wrong. And in fact, of course in the upper level science you learn pretty quickly that, no, actually we are just approximating guessing things, and there might be multiple ways to do this stuff that will get you valid returns on whatever you've done. And sometimes it is okay to guess and explore and see if things work or not. And I think if kids understood that better, they would also be more interested in not just science but a lot of things in their lives, and certainly become a little bit more open to them.

Tim Spuck: $\quad$ Excellent. Yeah, I taught Earth and space sciences for about 23 years and you said something here that I constantly tried to get my students to ... help them understand ... is that science is really messy. It's not this exact precision that sometimes people walk away thinking that it is. Okay ... thank you.

Respondent 351: Unfortunately, like I said, I think we just constantly give the wrong impression and the popular media especially does not help that either. 
Tim Spuck: Well that is true. Okay so are there any ... those are the three question that we had as part of the survey interview. And so before we end the call, do you have any additional thoughts that you might want to share along the lines of what astronomers do and the kinds of learning experiences that might be beneficial?

Respondent 351: That's a broad question.

Tim Spuck: $\quad$ It is yeah [laughter].

Respondent 351: I think the best learning experience I think you can give kids at any level up to and including college in terms of astronomy, is to actually have them go out and do their own project. Even if they want to go out and track where the moon rises every night or where the sun rises and sets in the evening, I think the best thing to have them do is actually go out and try to do some science on their own; it doesn't have to be a new science that no one has ever thought of and done before, but just that exploration, and learning that they can ask questions and answers questions with these tools. And also, it gets them more interested in what is going on because they see things. We could tell them that the sun does this, but when they go and see it themselves, now they are curious as to why it's doing that.

Tim Spuck: $\quad$ Yes, very good. All right, well, I certainly appreciate your time and both for taking the online survey and for spending a bit of time here just answering this questions through the interview. So, thanks very much John [Respondent 351].

Respondent 351: $\quad$ You are welcome.

Tim Spuck: Have a great afternoon.

Respondent 351: $\quad$ You too.

Tim Spuck: Thank you.

Respondent 351: $\quad$ Bye. 